\author{
Universidade de São Paulo \\ Instituto de Física
}

\title{
Síntese e caracterização de nanopartículas magnéticas: Aplicação como vetores de liberação de óxido nítrico
}

\author{
Miguel Angel Mosquera Molina
}

Orientadora: $\operatorname{Prof}^{\mathrm{a}} \operatorname{Dr}^{\mathrm{a}}$ Rosangela Itri

Dissertação de mestrado apresentada ao Instituto de Física para a obtenção do título de Mestre em Ciências

Banca examinadora:

Prof ${ }^{\mathrm{a}}$. Dr ${ }^{\mathrm{a}}$. Rosangela Itri (IF-USP)

Prof. Dr. Antonio Domingues dos Santos (IF-USP)

Prof. Dr. Pietro Ciancaglini (FFCLRP-USP)

São Paulo

2013 
FICHA CATALOGRÁFICA

Preparada pelo Serviço de Biblioteca e Informação do Instituto de Física da Universidade de São Paulo

Mosquera Molina, Miguel Angel

Síntese e caracterização de nanopartículas magnéticas: aplicação como vetores de liberação de óxido nítrico.

São Paulo, 2013.

Dissertação (Mestrado) - Universidade de São Paulo. Instituto de Física. Departamento de Física Aplicada.

Orientador: Prof $^{a}$ Dr $^{\mathrm{a}}$ Rosangela Itri

Área de Concentração: Física da Matéria Condensada

Unitermos: 1. Física da matéria condensada;

2. Nanopartículas; 3. Físico química; 4. Biofísica;

5. Luminescência (Química).

USP/IF/SBI-019/2013 


\section{Agradecimentos}

Gostaria de expressar meus sinceros agradecimentos:

Ao Instituto de Física da Universidade de São Paulo (IF-USP) pelo uso de suas instalações.

À Dra. Rosangela Itri, pela confiança, apoio contínuo e motivação nesse trabalho.

À Dra. Paula Haddad, pela dedicação e apoio na síntese química, medidas em espectroscopia FTIR e valiosas discussões.

Ao Dr. Maurício da Silva Baptista, pelo uso das facilidades do Laboratório de Processos Fotoinduzidos no Instituto de Química da Universidade de São Paulo.

À Dra. Amedea Seabra, pelo apoio e colaboração na medida da liberação de óxido nítrico.

Ao Dr. Antonio Domingues dos Santos do Departamento de Física de Materiais e Mecânica, pelo apoio nas medidas e discussões de VSM.

Ao Dr. Pedro Kyohara e à técnica Simone P. de Toledo do Departamento de Física Geral, pelo auxílio nas medidas de TEM.

Ao Dr. Alessandro Rodrigues do Departamento de Ciências Exatas e da Terra da UNIFESP campus Diadema, pelo auxílio nas medidas de Espectroscopia FTIR.

Ao Dr. Elia Tfouni e às técnicas Ivana A. Borin e Aline N. Chiba, pelo uso das facilidades do Laboratório de Fotoquímica-Inorgânica no Departamento de Química da Faculdade de Filosofia, Ciências e Letras de Riberão Preto - USP, assim como no auxílio nas medidas de liberação de NO e interpretação de resultados.

Aos técnicos do DFAP, Antônio Carlos, pela ajuda inicial nas medidas de DRX, e Serginho, na confecção dos recipientes para as medidas de VSM. 
iv

Aos meus amigos, Julio, Javier, Tiago, Fernando, Lindber, Carlos, Elisa, Leandro, Evandro, Lia, Ellen, Andreza, Omar, Thaís, Helena, ... pelo apoio e confianza; e pelas risadas ao longo do desenvolvimento deste trabalho.

À CAPES e CNPq pelo apoio financeiro. 


\section{ABREVIATURAS}

Principais abreviaturas utilizadas nesta dissertação

\begin{tabular}{|c|c|}
\hline NPs & : nanopartículas; \\
\hline NPMs & : nanopartículas magnéticas; \\
\hline $\mathrm{AO}$ & : ácido oleico; \\
\hline MSA & : ácido mercaptosuccínico; \\
\hline DMSA & : ácido dimercaptosuccínico; \\
\hline NPAO & : NPs recobertas com ácido oleico; \\
\hline NPMSA110 & : NPs funcionalizadas com MSA em razão molar de 1:10; \\
\hline NPMSA140 & : NPs funcionalizadas com MSA em razão molar de 1:40; \\
\hline NPMSA180 & : NPs funcionalizadas com MSA em razão molar de 1:80; \\
\hline NPDMSA110 & : NPs funcionalizadas com DMSA em razão molar de 1:10; \\
\hline NPDMSA140 & : NPs funcionalizadas com DMSA em razão molar de 1:40; \\
\hline NPDMSA180 & : NPs funcionalizadas com DMSA em razão molar de 1:80; \\
\hline $\mathrm{R}-\mathrm{SH}$ & : tiol; \\
\hline $\mathrm{R}-\mathrm{SNO}$ & : nitrosotiol; \\
\hline NP-SNO & :nanopartícula nitrosada; \\
\hline FTIR & : Espectroscopia Infravermelho; \\
\hline DRX & : Difração de Raios X; \\
\hline $\mathrm{D}_{R X}$ & : tamanho de cristalito; \\
\hline $\mathrm{L}_{(x)}$ & : função Lorentziana; \\
\hline MET & : Microscopia Eletrônica de Transmissão; \\
\hline $\mathrm{f}_{\mathrm{LN}}$ & : função logaritmo normal; \\
\hline VSM & : Magnetometria de Amostra Vibrante; \\
\hline$\mu$ & : momento magnético. \\
\hline
\end{tabular}




\section{Resumo}

Neste trabalho reporta-se uma nova estratégia para a liberação de óxido nítrico (NO), baseada em nanopartículas (NPs) de magnetita com potencial aplicação em biomedicina. As NPs de magnetita foram preparadas pelo método de coprecipitação utilizando cloretos ferroso e férrico, seguido de um recobrimento com ácido oleico (AO) com a finalidade de evitar a oxidação e reduzir a agregação das mesmas. Em seguida realizamos uma troca de ligantes por ácido mercaptosuccínico (MSA) e ácido dimercaptosuccínico (DMSA) em diferentes razões molares. Após a funcionalização, as nanopartículas são solúveis em água e apresentam grupos tióis ligados à superfície das NPs e expostos para a solução. As técnicas de caracterização utilizadas foram Espectroscopia Infravermelho (FTIR), Difração de RaiosX (DRX), Microscopia Eletrônica (MET) e Magnetometria de Amostra Vibrante (VSM).

Dos resultados de FTIR observa-se as bandas de estiramento e deformação de Fe-O características do óxido de ferro, assim como bandas de estiramento $\mathrm{S}-\mathrm{H}$ indicando a presença dos grupos tióis e, portanto, a funcionalização das NPs com MSA e DMSA. Os dados de RX mostram que as NPs tem estrutura da magnetita (tipo espinélio) e possuem tamanho de grão da ordem de 11nm. A funcionalização não altera as propriedades cristalinas do material. O tamanho de grão cristalino é compatível com os valores médios das distribuições de tamanho observados por TEM e VSM, que indicam uma polidispersão em torno de $20 \%$. Os resultados de VSM também demonstraram que as NPMs tem comportamento superparamagnético a temperatura ambiente, embora a magnetização de saturação se reduz a um valor de cerca de $30 \mathrm{emu} / \mathrm{g}$ para NPs funcionalizadas com DMSA (valor referência em «bulk» 92emu/g).

Os grupos tióis presentes na superfície das NPs funcionalizadas foram nitrosados através de uma solução acidificada de nitrito de sódio, obtendo-se assim NPs nitrosadas (NP-SNO). A quantidade de NO covalentemente ligado e liberado na superfície das NPs foi avaliado por quimioluminescência. Os resultados mostram que as NP-SNO liberam espontaneamente NO, em diferentes concentrações, em meio aquoso. Numa primeira etapa, avaliou-se, à temperatura ambiente, o perfil da liberação de NO a partir de NPs recobertas com MSA (razão molar 1:40). Os resultados indicam a possibilidade de uma liberação controlada de óxido nítrico, em quantidades $(\mu \mathrm{M})$ compatíveis para aplicação em biomedicina. Numa segunda etapa avaliou-se, de maneira comparativa, a capacidade de nitrosação e liberação de NO de NPs funcionalizadas com MSA e DMSA a diferentes razões molares. Os resultados não evidenciaram uma correlação com a razão molar NP:molécula ligante, mas NPs funcionalizadas 
com DMSA demonstraram ser mais eficientes tanto no processo de nitrosação, quanto na capacidade de liberar óxido nítrico. Estes resultados estão dentro dos níveis requeridos em aplicações biomédicas. Este novo veículo liberador de NO apresenta grande potencial para gerar quantidades desejadas de NO diretamente em alvos locais. 


\section{Abstract}

This work reports a new strategy for delivering nitric oxide (NO), based on magnetite nanoparticles (NPs) with potential application in biomedicine. Magnetite NPs were prepared through a co-precipitation method by using ferrous and ferric chlorides, followed by oleic acid (OA) coating to avoid oxidation and reduce their aggregation. Then, we realized a ligand exchange by mercaptosuccinic acid (MSA) and dimercaptosuccinic acid (DMSA) at different molar ratios. After functionalization, NPs were soluble in water, and have free thiol groups (SH) on their surface. We used Fourier Transform of Infrared Radiation (FTIR), X-Ray Diffraction (XRD), Transmission Electron Microscopy (TEM) and Vibrate Sample Magnetometry (VSM) to characterize the samples.

FTIR results evidenced stretching and bending absorption bands typical of Fe-O, as well as the $\mathrm{S}-\mathrm{H}$ stretching absorption bands indicating the presence of thiol groups on the iron oxide particles. In this way, NPs were functionalized with MSA and DMSA. X-Ray data showed that the NPs are, indeed magnetite with crystalline size of $11 \mathrm{~nm}$. Such a value agrees with those obtained by TEM and VSM data analysis, within a polydispersion of $20 \%$. Further, the functionalization did not alter the crystalline properties. VSM results demonstrated that the thiolated NPs had a superparamagnetic behavior at room temperature. However, DMSA-coating of the NP reduced significantly the value of saturation magnetization (from circa $70 \mathrm{emu} / \mathrm{g}$ for uncoated NP to $30 \mathrm{emu} / \mathrm{g}$ ).

Free thiol groups on NPs surface were nitrosated through an acidified nitrite solution, yielding nitrosated NPs (SNO-NP). The amount of NO covalently bounded and released on the NPs surface was evaluated by chemiluminescence. Results revealed that SNO-NP spontaneously released NO at different molar ratios, in aqueous solution. In a first stage of this work, at room temperature, NO release profile was evaluated from NPs covered by MSA (molar ratio 1:40). The results indicated a possibility of a controlled NO-releasing, at amounts $(\mu \mathrm{M})$ adequate to biomedical applications. In the second stage, we evaluated the capacity of nitrosation and NO-releasing from NPs functionalized by MSA e DMSA at different molar ratios. DMSA-coated NPs show to be efficient in nitrosation process as well as in the ability of releasing NO. These results were at required levels for biomedical applications. This new magnetic NO-delivery vehicle has a great potential to generate desired amounts of NO directly to target location. 


\section{Sumário}

$\begin{array}{lll}\mathbf{1} & \text { Introdução } & \mathbf{1}\end{array}$

$1.1 \quad$ Estrutura Cristalográfica da Magnetita . . . . . . . . . . . . . . . . . . . 4

1.2 Propriedades Magnéticas de NPMs . . . . . . . . . . . . . . . . . 7

$1.2 .1 \quad$ Energia de Anisotropia Magnética - NPs e Superparamagnetismo . . 10

1.3 Óxido Nítrico - NO . . . . . . . . . . . . . . . . . . . . 15

$1.3 .1 \quad$ Funções do NO . . . . . . . . . . . . . . . . . . . . 16

1.4 Objetivos da dissertação . . . . . . . . . . . . . . . . . . . 19

1.5 Estrutura da dissertação . . . . . . . . . . . . . . . . . . . 19

2 Procedimento de Síntese e Nitrosação das nanopartículas magnéticas 21

2.1 Materiais utilizados para a Síntese . . . . . . . . . . . . . . . . . . 21

2.2 Método de Síntese por coprecipitação . . . . . . . . . . . . . . . . . 21

2.3 Estabilidade e proteção das nanopartículas . . . . . . . . . . . . . . . . 22

2.4 Funcionalização das NPs - Troca de Ligantes . . . . . . . . . . . . . . . . . . 22

2.5 Nitrosação das NPs . . . . . . . . . . . . . . . . . 25

2.5 .1 Primeira Etapa . . . . . . . . . . . . . . . . . 25

2.5 .2 Segunda Etapa . . . . . . . . . . . . . . . . 25

$\begin{array}{llr}3 & \text { Técnicas Experimentais } & 29\end{array}$

$3.1 \quad$ Espectroscopia Infravermelho - FTIR . . . . . . . . . . . . . . . . . . . . . 29

3.2 Parte Experimental - FTIR . . . . . . . . . . . . . . . . . . 31

3.3 Difração de Raios X - DRX . . . . . . . . . . . . . . . . 32

3.4 Parte Experimental - DRX . . . . . . . . . . . . . . . . . . . 33

$3.5 \quad$ Microscopia Eletrônica de Transmissão - MET ～. . . . . . . . . . . . . . . . 36

3.6 Parte Experimental - MET . . . . . . . . . . . . . . . . . . . . 38 
3.7 Magnetometria de Amostra Vibrante - VSM . . . . . . . . . . . . . . . . . 39

3.8 Parte Experimental - VSM . . . . . . . . . . . . . . . . . . 41

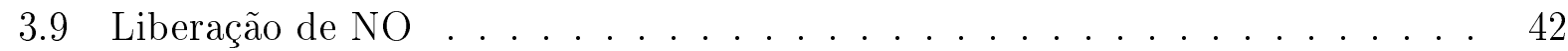

3.9 .1 Medida de Quimioluminescência . . . . . . . . . . . . . . . . . . . 42

3.10 Parte Experimental - Liberação de NO . . . . . . . . . . . . . . . . . . . . . . . . . . . . . . .

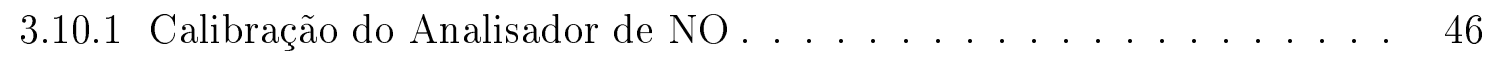

3.10 .2 Medida de liberação de NO . . . . . . . . . . . . . . . 48

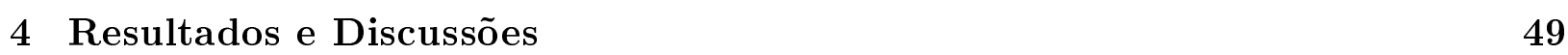

$4.1 \quad$ Espectroscopia Infravermelho - FTIR . . . . . . . . . . . . . . . . . 49

4.2 Difração de Raios X - DRX . . . . . . . . . . . . . . . . . 59

4.3 Microscopia Eletrônica de Transmissão - MET . . . . . . . . . . . . . . 68

4.4 Magnetometria de Amostra Vibrante - VSM . . . . . . . . . . . . . . . . . . . 74

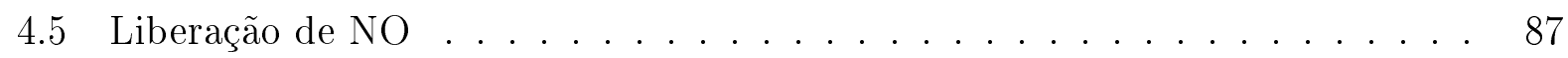

$4.5 .1 \quad$ Primeira Etapa $\ldots \ldots \ldots \ldots \ldots$. . . . . . . . . . . . 87

4.5 .2 Segunda Etapa . . . . . . . . . . . . . . . . . 89

$\begin{array}{lll}5 & \text { Conclusões } & 93\end{array}$

5.1 Caracterizações Químicas e Físicas das NPs . . . . . . . . . . . . . . . . 93

5.2 Liberação de $\mathrm{NO} \ldots \ldots \ldots \ldots \ldots \ldots \ldots$. . . . . . . . . . . . . . . . . . . . . . . . . . . . . . . . . .

5.3 Conclusão Final . . . . . . . . . . . . . . . . . . . . . . . . . . . . 94

\begin{tabular}{ll}
\hline Referências & 96
\end{tabular}

\begin{tabular}{|lr}
\hline A Propriedades Magnéticas & 109
\end{tabular}

A.1 Consideração Semiclássica ． . . . . . . . . . . . . . . . . . 109

A.2 Consideração Quântica . . . . . . . . . . . . . . . . . 113 


\section{Lista de Figuras}

1.1 a. Estrutura do ácido oleico. b. Estrutura do ácido mercaptosuccínico (MSA). c. Estrutura do ácido dimercaptosuccínico (DMSA). . . . . . . . . . 3

1.2 (a) Sítio tetraédrico (Sítio A) da estrutura espinélio; (b) Sítio octaédrico (Sítio B) da estrutura espinélio; (c) Cela unitária da estrutura espinélio e (d) Ampliação de 2/8 da cela unitária da estrutura espinélio. Figura extraída da referência [44]. . . . . . . . . . . . . . . . . . 5 5

1.3 Distribuição catiônica na estrutura espinélio normal (como exemplo: $\mathrm{ZnFe}_{2} \mathrm{O}_{4}$ ) e espinélio inverso (como exemplo: a magnetita, $\mathrm{Fe}_{3} \mathrm{O}_{4}$ ). No espinélio normal,

\begin{tabular}{|c|}
\hline e espinélio inverso (como exemplo: a magnetita, $\mathrm{Fe}_{3} \mathrm{O}_{4}$ ). No espinélio normal, \\
\hline \hline o cátion $\mathrm{Zn}^{2+}$ ocupa o sítio tetraédrico $(\mathrm{A})$ e o íon $\mathrm{Fe}^{3+}$ ocupa o sítio octaé- \\
\hline drico (B); no espinélio inverso, o cátion $\mathrm{Fe}^{3+}$ ocupa o sítio tetraédrico (A) e \\
\hline os íons $\mathrm{Fe}^{2+}$ e Fe ${ }^{3+}$ ocupam o sítio octaédrico (B). . . . . . . . . . . . . . 6 \\
\hline
\end{tabular}

1.4 Difratograma da magnetita, obtida da ficha catalográfica JCPDF 19-0629. 6

1.5 Modelo estrutural da magnetita indicando um eixo cristalino de fácil magne-

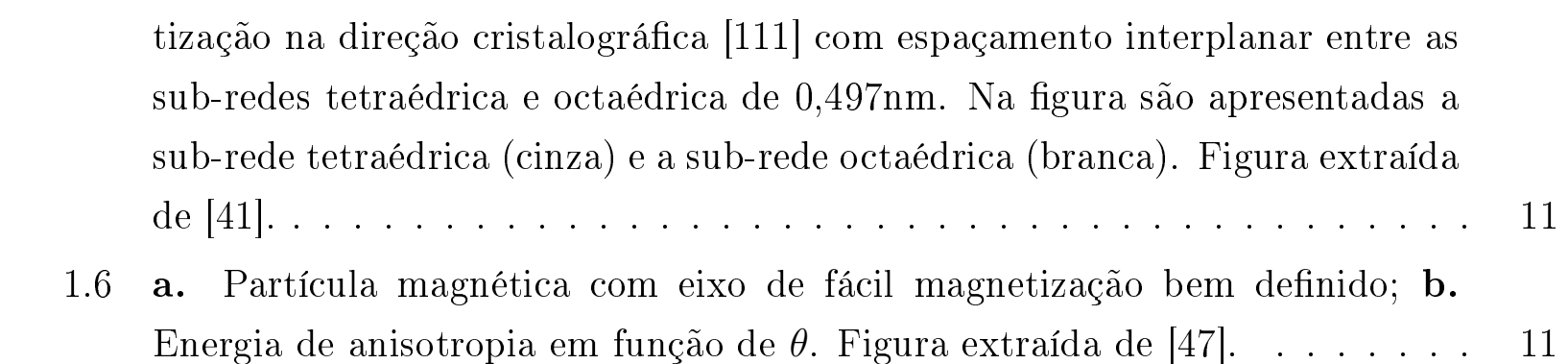

2.1 Esquema da obtenção das NPMs (NP), após serem recobertas com ácido oleico, antes da troca de ligantes(NPAO) e depois da troca de ligantes com MSA (NPMSA110, NPMSA140, NPMSA180) e com DMSA (NPDMSA110,

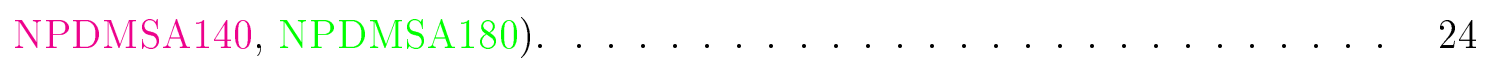


2.2 Esquema da nitrosação das NPs funcionalizadas com MSA ou DMSA (NP-SH)

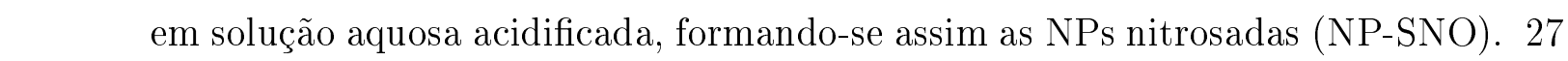

3.1 Interação dos Raios-X com os planos cristalográficos (com uma distância $d$ ) em um cristal, com frentes de onda $x x^{\prime}$ e $y y^{\prime}, \operatorname{com} \theta$ como ângulo de Bragg. Figura extraída da referência [43]. . . . . . . . . . . . . . . . 33

3.2 Efeito do tamanho de cristalito na curva de difração; a. Aumento da largura da curva de difração devido à diminuição da espessura do cristal. b. Pico de difração ideal no ângulo de Bragg que indica a distância entre os planos cristalinos. Extraído da referência [43]. . . . . . . . . . . . . . . 35

3.3 Distribuição Log-Normal da densidade de probabilidade de diâmetros repre-

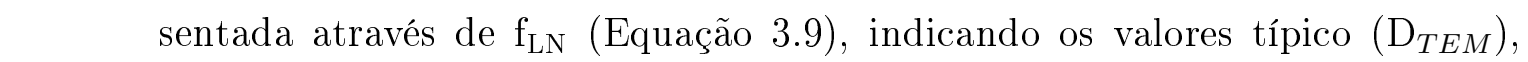
mediano $\left(\mathrm{d}_{0}\right)$ e médio $\left(<\mathrm{D}_{T E M}>\right) . \ldots \ldots \ldots \ldots . \ldots \ldots$

3.4 a. Curva de histerese de um ferrimagneto ou ferromagneto, indicando sua magnetização específica de saturação $\left(\sigma_{s}\right)$, e campo coercivo $\left(\mathrm{H}_{C}\right)$, assim como sua magnetização específica remanente $\left(\sigma_{r}\right)$, b. Curva de histerese para um

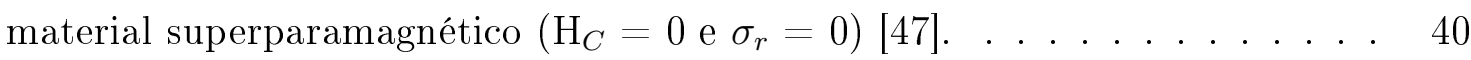

3.5 Esquema da liberação de NO no Analisador do Óxido Nítrico. a. Seringa utilizada para injetar soluções contendo nitrosotióis (R-SNO), b. Balão de vidro (célula do Analisador de NO) contendo ácido ascórbico (solução redutora dos R-SNO) na mesma pressão do $\mathrm{N}_{2}$, c. Cilindro de $\mathrm{N}_{2}$ a pressão de 5 - 6 Torr, d. Mangueira através da qual o NO liberado na célula vai para o Analisador de $\mathrm{NO}$, e. Cilindro contendo $\mathrm{O}_{2}$ a pressão 421 Torr, f. Analisador de NO. 43

3.6 Mecanismo de quimioluminescência no interior do Analisador do NO. A liberação de energia proveniente do decaimento do $\mathrm{NO}_{2}^{*}$ para $\mathrm{NO}_{2}$ correspondente a um estado de menor energia produz um fóton com energia $\mathrm{h} \nu$, detectado

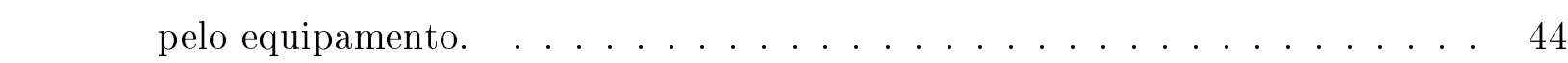

3.7 Esquema do potenciograma (V-t) obtido do Analisador de NO. Cada pico no \begin{tabular}{|l|}
\hline potenciograma está relacionado com a concentração do óxido nítrico ([NO]) \\
\hline \hline liberado a partir dos volumes $\left(\mathrm{V}_{R-S N O}\right)$ dos R-SNO injetados na célula do \\
\hline
\end{tabular} equipamento (Figura 3.5 . . . . . . . . . . . . . . . 45 
3.8 Delimitação manual da linha de início, linha final e linha de base para cada

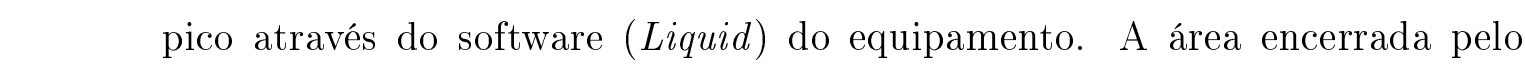
potenciograma, e entre as linhas de delimitação para a integração. O software

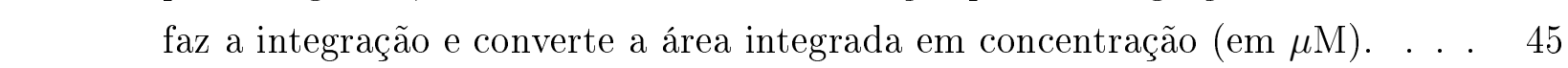

3.9 Curva de calibração do Analisador de NO, que relaciona a concentração molar de NO ([NO]) liberado em relação ao número de moles (n) de R-SNO contidos nolumes injetados da solução estoque. ..................4 4

4.1 Espectro FTIR das NPs após serem obtidas (NP) e modificadas na superfície com ácido oleico (NPAO). . . . . . . . . . . . . . . . . 50

4.2 Ampliação da região entre $400 \mathrm{~cm}^{-1}$ e $700 \mathrm{~cm}^{-1}$ do espectro FTIR das NPs

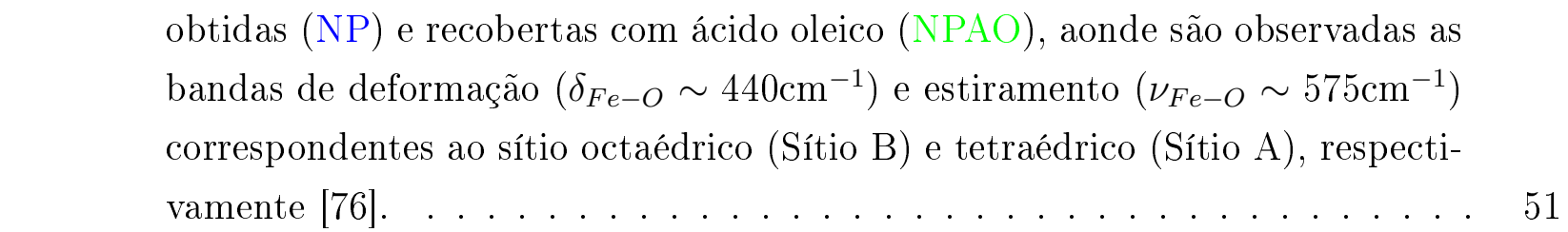

4.3 Interação quelante bidentada entre o grupo $\mathrm{COO}^{-}$do ácido oleico e o átomo de ferro. Figura extraída de $[20] . \ldots \ldots \ldots \ldots$. . . . . . . . . . 52

$4.4 \quad$ Esquema representativo do recobrimento das NPs com ácido oleico. . . . . . 52

$4.5 \quad$ Espectro FTIR do ácido mercaptosuccínico (MSA). . . . . . . . . . . . 53

4.6 Espectro FTIR do ácido dimercaptosuccínico (DMSA). . . . . . . . . . . . 53

4.7 Ampliação da região entre $2300 \mathrm{~cm}^{-1}$ e $2700 \mathrm{~cm}^{-1}$ do espectro de FTIR normalizado para as moléculas de MSA e de DMSA. As bandas de absorção em \begin{tabular}{|c|}
\hline torno de $2530 \mathrm{~cm}^{-1}$ e $2563 \mathrm{~cm}^{-1}$ (setas na figura) correspondem ao estiramento \\
\hline
\end{tabular}

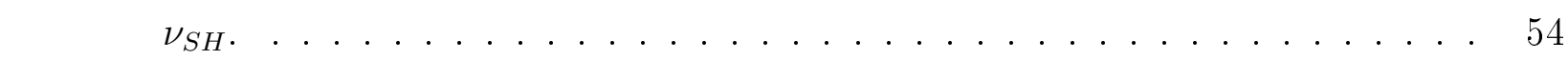

4.8 Espectro de FTIR das NPs funcionalizadas com MSA em razões de 1:10 (NPMSA110), 1:40 (NPMSA140) e 1:80 (NPMSA180). . . . . . . . . . 55

4.9 Espectro de FTIR das NPs funcionalizadas com DMSA em razões de 1:10 (NPDMSA110), 1:40 (NPDMSA140) e 1:80 (NPDMSA180). . . . . . . . . 56

4.10 Ampliação da região entre $950 \mathrm{~cm}^{-1}$ e $3000 \mathrm{~cm}^{-1}$ do espectro FTIR das NPs funcionalizadas com MSA. Observa-se a troca de ligantes da nanopartícula através da banda em $1050 \mathrm{~cm}^{-1}$ referente ao estiramento $\nu_{C-O}$, que indica a ligação da molécula de MSA com a NP, e as bandas entre $2853 \mathrm{~cm}^{-1}$ e $2923 \mathrm{~cm}^{-1}$ referente ao estiramento $\nu_{-S H} . \ldots \ldots \ldots \ldots . \ldots . \ldots . \ldots 57$ 
4.11 Ampliação da região entre $950 \mathrm{~cm}^{-1}$ e $3000 \mathrm{~cm}^{-1}$ do espectro FTIR das NPs funcionalizadas com DMSA. Observa-se a troca de ligantes da nanopartícula \begin{tabular}{|c|}
\hline através da banda em $1050 \mathrm{~cm}^{-1}$ referente ao estiramento $\nu_{C-O}$, que indica \\
\hline \hline a ligação da molécula de DMSA com a NP, e as bandas entre $2856 \mathrm{~cm}^{-1} \mathrm{e}$ \\
\hline $2920 \mathrm{~cm}^{-1}$ referente ao estiramento $\nu_{-S H} \ldots \ldots \ldots \ldots$. . . . . . . . . . 58
\end{tabular}

4.12 Recobrimento das NPs com MSA e DMSA, tendo como resultado final NPs funcionalizadas com grupos tióis na superfície. . . . . . . . . . . . 58

4.13 Curvas de difração de raios X das NPs após serem obtidas (NP) e após reco\begin{tabular}{|c|}
\hline brimento com ácido oleico (NPAO). Os traços em preto, indicados na Figura, \\
\hline representam as posições angulares e as intensidades de difração esperadas cor- \\
\hline respondentes aos planos cristalinos $(h k l)$ da estrutura espinélio da magnetita \\
\hline
\end{tabular} (JCPD 19-0629 - Figura 1.2$). \ldots \ldots \ldots$. . . . . . . . . . 6 60

4.14 Curvas de difração de raios X das NPs, após serem funcionalizadas com \begin{tabular}{|c|}
\hline ácido mercaptosuccínico (MSA) em razão de 1:10 (NPMSA110), de 1:40 \\
\hline
\end{tabular} (NPMSA140) e 1:80 (NPMSA180). Os traços em preto, indicados na Figura, representam as posições angulares e as intensidades de difração esperadas correspondentes aos planos cristalinos $(h k l)$ da estrutura espinélio da magnetita

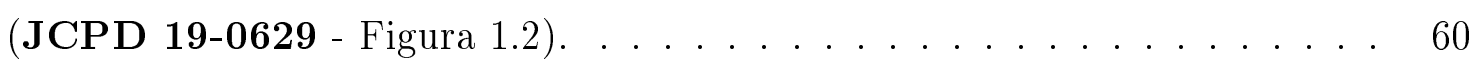

4.15 Curvas de difração de raios X das NPs, após serem funcionalizadas com \begin{tabular}{|c|}
\hline ácido dimercaptosuccínico (DMSA) em razão de 1:10 (NPDMSA110), de 1:40 \\
\hline (NPDMSA140) e 1:80 (NPDMSA180). Os traços em preto, indicados na \\
\hline
\end{tabular} Figura, representam as posições angulares e as intensidades de difração esperadas correspondentes aos planos cristalinos $(h k l)$ da estrutura espinélio da magnetita (JCPD 19-0629 - Figura 1.2$)$. . . . . . . . . . . . . 61

4.16 Ajuste do pico de difração no plano de reflexão (311) através de uma função \begin{tabular}{|r|l|l|l|l}
\hline Lorentziana (Equação & 3.8 para: a. NPs após serem sintetizadas (NP), b.
\end{tabular} NPs funcionalizadas com MSA na razão molar 1:40 (NPMSA140). . . . . . . 65

4.17 Micrografia das nanopartículas sintetizadas (NP) e sua distribuição de tama\begin{tabular}{|c|}
\hline nhos. O tamanho de grão cristalino $\mathrm{D}_{R X}$ é destacado com a linha vermelha \\
\hline .
\end{tabular} tracejada no histograma, $\mathrm{d}_{0},\left\langle\mathrm{D}_{T E M}>\right.$ e $\sigma_{T E M}$ correspondem à mediana, valor médio e desvio padrão da distribuição, respectivamente. . . . . . . . . . . . 69 
4.18 Micrografia das nanopartículas recobertas com ácido oleico (NPAO) e sua distribuição de tamanhos. O tamanho de grão cristalino $\mathrm{D}_{R X}$ é destacado com \begin{tabular}{|c|}
\hline a linha vermelha tracejada no histograma, $\mathrm{d}_{0},\left\langle\mathrm{D}_{T E M}\right\rangle \mathrm{e} \sigma_{T E M}$ correspondem \\
\hline
\end{tabular}

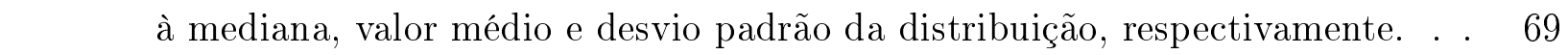

4.19 Micrografia das nanopartículas após serem funcionalizadas com ácido mercap-

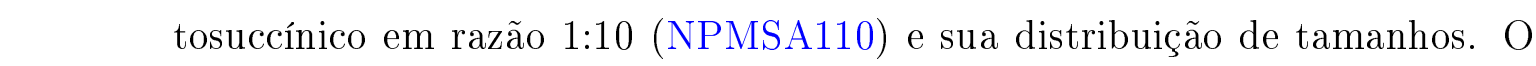
tamanho de grão cristalino $\mathrm{D}_{R X}$ é destacado com a linha vermelha tracejada \begin{tabular}{|c|}
\hline no histograma, $\mathrm{d}_{0},\left\langle\mathrm{D}_{T E M}\right\rangle$ e $\sigma_{T E M}$ correspondem à mediana, valor médio \\
\hline
\end{tabular}

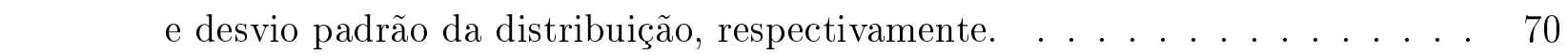

4.20 Micrografia das nanopartículas após serem funcionalizadas com ácido mercap-

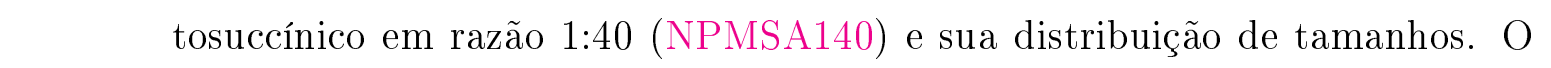
tamanho de grão cristalino $\mathrm{D}_{R X}$ é destacado com a linha vermelha tracejada \begin{tabular}{|c|}
\hline no histograma, $\mathrm{d}_{0},\left\langle\mathrm{D}_{T E M}\right\rangle$ e $\sigma_{T E M}$ correspondem à mediana, valor médio \\
\hline
\end{tabular}

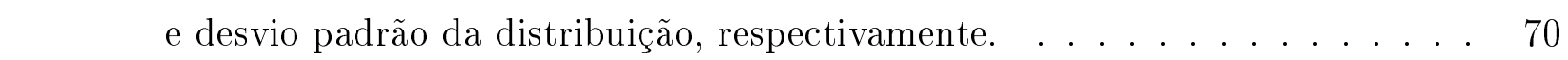

4.21 Micrografia das nanopartículas após serem funcionalizadas com ácido mercap\begin{tabular}{|l|}
\hline tosuccínico em razão 1:80 (NPMSA180) e sua distribuição de tamanhos. O \\
\hline tamanho de grão cristalino $\mathrm{D}_{R X}$ é destacado com a linha vermelha tracejada \\
\hline no histograma, $\mathrm{d}_{0},<\mathrm{D}_{T E M}>$ e $\sigma_{T E M}$ correspondem à mediana, valor médio \\
\hline e desvio padrão da distribuição, respectivamente. . . . . . . . . . . . . 71 \\
\hline
\end{tabular}

4.22 Micrografia das nanopartículas após serem funcionalizadas com ácido dimer\begin{tabular}{|c|}
\hline captosuccínico (DMSA) em razão 1:10 (NPDMSA110) e sua distribuição de \\
\hline tamanhos. O tamanho de grão cristalino $\mathrm{D}_{R X}$ é destacado com a linha verme- \\
\hline lha tracejada no histograma, $\mathrm{d}_{0},\left\langle\mathrm{D}_{T E M}>\right.$ e $\sigma_{T E M}$ correspondem à mediana, \\
\hline valor médio e desvio padrão da distribuição, respectivamente. . . . . . . . . . 71 \\
\hline
\end{tabular}

4.23 Micrografia das nanopartículas após serem funcionalizadas com ácido dimer\begin{tabular}{|l|}
\hline captosuccínico (DMSA) em razão 1:40 (NPDMSA140) e sua distribuição de \\
\hline tamanhos. O tamanho de grão cristalino $\mathrm{D}_{R X}$ é destacado com a linha verme- \\
\hline lha tracejada no histograma, $\mathrm{d}_{0},\left\langle\mathrm{D}_{T E M}>\right.$ e $\sigma_{T E M}$ correspondem à mediana, \\
\hline valor médio e desvio padrão da distribuição, respectivamente. . . . . . . . . . 72 \\
\hline
\end{tabular} 
4.24 Micrografia das nanopartículas após serem funcionalizadas com ácido dimercaptosuccínico (DMSA) em razão 1:80 (NPDMSA180) e sua distribuição de

\begin{tabular}{|c|}
\hline tamanhos. O tamanho de grão cristalino $\mathrm{D}_{R X}$ é destacado com a linha verme- \\
\hline lha tracejada no histograma, $\mathrm{d}_{0},\left\langle\mathrm{D}_{T E M}>\right.$ e $\sigma_{T E M}$ correspondem à mediana, \\
\hline
\end{tabular}
valor médio e desvio padrão da distribuição, respectivamente. . . . . . . . . . 72

4.25 a. Curva de histerese das nanopartículas após serem obtidas (NP) e após

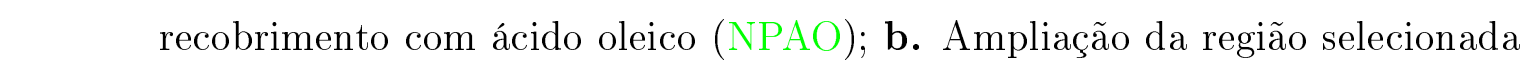

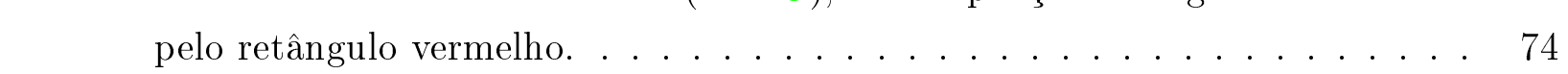

4.26 a. Curva de histerese das nanopartículas após serem funcionalizadas com MSA na razão de 1:10 (NPMSA110), 1:40 (NPMSA140) e 1:80 (NPMSA180);

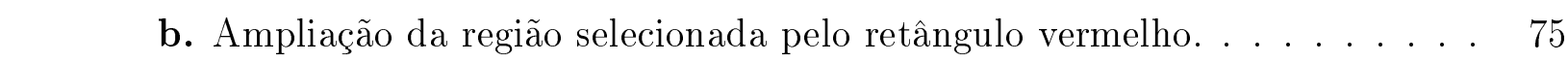

4.27 a. Curva de histerese das nanopartículas após serem funcionalizadas com

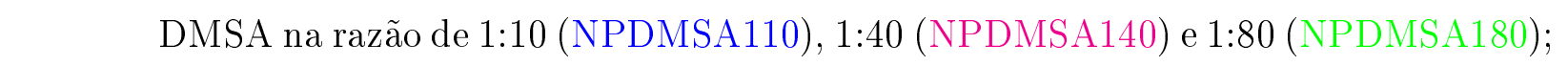

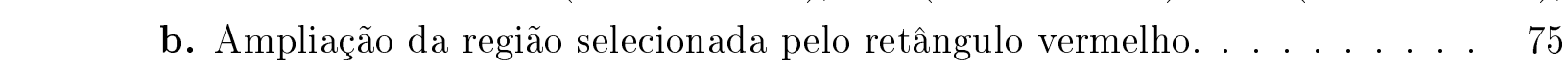

4.28 a. Ajuste do momento magnético (Equação 3.12 ) para as nanopartículas sintetizadas (NP). b. Distribuição de tamanhos, indicada pela função Log-

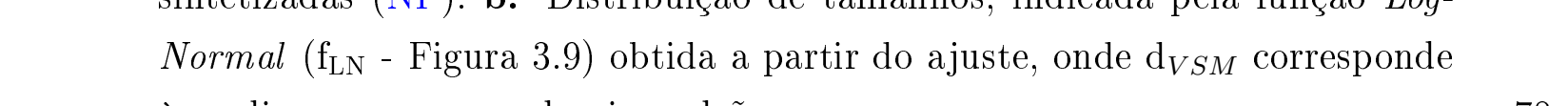

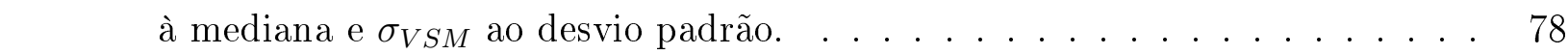

4.29 a. Ajuste do momento magnético (Equação 3.12 ) para as nanopartículas após recobrimento com ácido oleico (NPAO). b. Distribuição de tamanhos, indicada pela função Log-Normal $\left(\mathrm{f}_{\mathrm{LN}}\right.$ - Figura $\left.\mid 3.9\right)$ obtida a partir do ajuste, onde $\mathrm{d}_{V S M}$ corresponde à mediana e $\sigma_{V S M}$ ao desvio padrão. . . . . . . . . . . 79

4.30 a. Ajuste do momento magnético (Equação 3.12 ) para as nanopartículas \begin{tabular}{|l|}
\hline funcionalizadas com MSA em razão de 1:10 (NPMSA110). b. Distribuição \\
\hline de tamanhos, indicada pela função Log-Normal ( $\mathrm{f}_{\mathrm{LN}}$ - Figura 3.9) obtida a \\
\hline
\end{tabular}

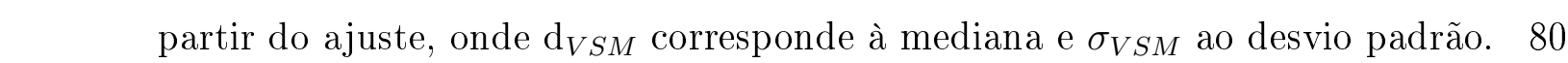

4.31 a. Ajuste do momento magnético (Equação 3.12 ) para as nanopartículas funcionalizadas com MSA em razão de 1:40 (NPMSA140). b. Distribuição de tamanhos, indicada pela função Log-Normal ( $\mathrm{f}_{\mathrm{LN}}$ - Figura 3.9 ) obtida a partir do ajuste, onde $\mathrm{d}_{V S M}$ corresponde à mediana e $\sigma_{V S M}$ ao desvio padrão. 81 
4.32 a. Ajuste do momento magnético (Equação 3.12 ) para as nanopartículas

\begin{tabular}{|c|}
\hline funcionalizadas com MSA em razão de 1:80 (NPMSA180). b. Distribuição \\
\hline \hline de tamanhos, indicada pela função Log-Normal (f $\mathrm{f}_{\mathrm{LN}}$ - Figura 3.9$)$ obtida a \\
\hline
\end{tabular}

partir do ajuste, onde $\mathrm{d}_{V S M}$ corresponde à mediana e $\sigma_{V S M}$ ao desvio padrão. 82

4.33 a. Ajuste do momento magnético (Equação 3.12 ) para as nanopartículas

funcionalizadas com DMSA em razão de 1:10 (NPDMSA110). b. Distribuição

\begin{tabular}{|c|}
\hline de tamanhos, indicada pela função Log-Normal ( $\mathrm{f}_{\mathrm{LN}}$ - Figura 3.9 ) obtida a \\
\hline
\end{tabular}

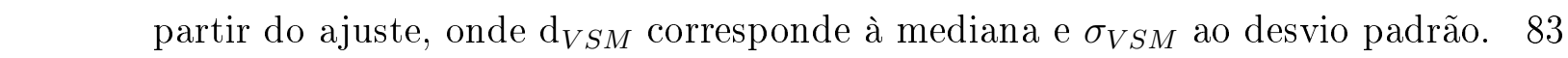

4.34 a. Ajuste do momento magnético (Equação 3.12 ) para as nanopartículas

\begin{tabular}{|c|}
\hline funcionalizadas com DMSA em razão de 1:40 (NPDMSA140). b. Distribuição \\
\hline
\end{tabular}

\begin{tabular}{|c|c|c|}
\hline de tamanhos, indicada pela função Log-Normal $\left(\mathrm{f}_{\mathrm{LN}}\right.$ - Figura 3.9 ) obtida a \\
\hline
\end{tabular}
partir do ajuste, onde $\mathrm{d}_{V S M}$ corresponde à mediana e $\sigma_{V S M}$ ao desvio padrão. 84

4.35 a. Ajuste do momento magnético (Equação 3.12 ) para as nanopartículas funcionalizadas com DMSA em razão de 1:80 (NPDMSA180). b. Distribuição \begin{tabular}{|c|c|c|c|}
\hline de tamanhos, indicada pela função Log-Normal (f $\mathrm{f}_{\mathrm{LN}}$ - Figura & 3.9 ) obtida a \\
\hline
\end{tabular} partir do ajuste, onde $\mathrm{d}_{V S M}$ corresponde à mediana e $\sigma_{V S M}$ ao desvio padrão. 85

4.36 Dados representativos da quimioluminescência para a liberação de NO a partir dos grupos S-NO presentes nas superfície das NPs. As flechas indicam as seguintes injeções: (i): $100 \mu$ l de NPs não nitrosadas (NPMSA140); (ii): $100 \mu$ l \begin{tabular}{|c|c|}
\hline de solução aquosa de $\mathrm{NaNO}_{2}$; (iii) e (iv): 100 e $10 \mu \mathrm{L}$ de da solução aquosa \\
\hline
\end{tabular}

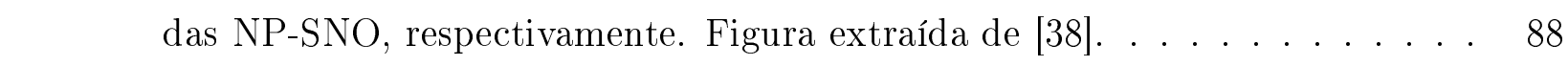

4.37 Perfil da Liberação de NO com respeito ao tempo. Figura extraída de [38]. . 88

4.38 Concentração de NO liberado ([NO]) em função da concentração das NPs \begin{tabular}{|c|}
\hline nitrosadas, obtidas a partir das NPs funcionalizadas com MSA em razões \\
\hline
\end{tabular}

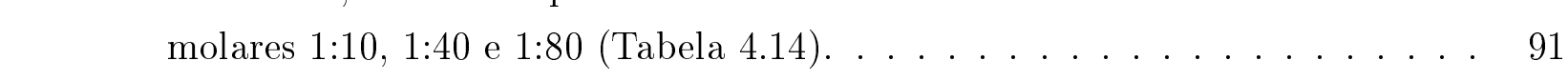

4.39 Concentração de NO liberado ([NO]) em função da concentração das nano\begin{tabular}{|c|}
\hline partículas nitrosadas, obtidas a partir das NPs funcionalizadas com DMSA \\
\hline
\end{tabular}

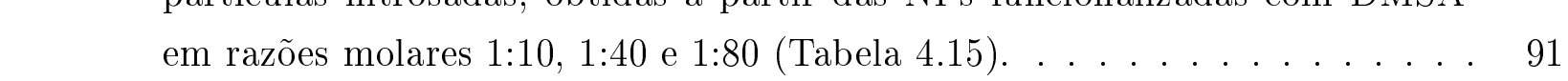

A.1 Momento magnético $\mu$ na direção do ângulo sólido. . . . . . . . . . . . . . 110 



\section{Capítulo 1}

\section{Introdução}

A Nanociência tem como objeto de estudo a obtenção, caracterização e muitas vezes funcionalização de materiais com dimensões nanométricas $\left(1 \mathrm{~nm}=10^{-9} \mathrm{~m}\right)$, para aplicações em áreas da ciência como a Física, Química, Biologia e Medicina. Materiais destas dimensões exibem propriedades físicas e químicas diferenciadas dos mesmos materiais em dimensões maiores, devido a alta razão superfície-volume. Nas últimas décadas, vem crescendo o número de aplicações de materiais nanoestruturados em Biomedicina [1, 2, 3]. Em especial, o estudo de nanopartículas magnéticas (NPMs) de dimensões menores que 100nm tem se destacado devido a alta reatividade química da superfície das mesmas, favorecendo a ligação de biomoléculas interessantes, e por apresentarem comportamento superparamagnético a temperatura ambiente [4, 5]. Dentro deste contexto, nanopartículas de óxido de ferro como magnetita $\left(\mathrm{Fe}_{3} \mathrm{O}_{4}\right)$ e a maghemita $\left(\gamma-\mathrm{Fe}_{2} \mathrm{O}_{3}\right)$ vem sendo muito estudadas pois, além das propriedades intrínsecas citadas acima, as mesmas apresentam difusão através de tecidos e baixa toxicidade [5, 6, 7]. Como exemplo de aplicação, a magnetita vem sendo utilizada com sucesso em ressonância magnética de imagem, resultando num aumento do contraste das imagens [8]. NPs de magnetita também vem sendo investigadas como sistemas transportadores e liberadores de fármacos adsorvidos em sua superfície, sendo chamadas, neste contexto, de nanofármacos [9].

A obtenção das nanopartículas de óxidos de ferro, pode ser realizada através de processos físicos ou químicos. No caso dos processos físicos, podemos citar, por exemplo, condensação por gás inerte [10], plasma [11], sputtering de íons [12], e ablação por laser a partir de ma- 
teriais macroscópicos [13]. Os processos químicos para obtenção de nanopartículas ocorrem a partir de átomos e moléculas que as formam via redução química [14], método sol-gel [15], sonoquímica [16], método solvotérmico [4], decomposição térmica [17] e coprecipitação [18].

Os métodos de síntese por termodecomposição e coprecipitação são também conhecidos por resultarem em partículas nanométricas de morfologia definida e baixa polidispersão [19], sendo, portanto, adequados para aplicações em sistemas biológicos. Entretanto, para garantir a estabilidade térmica e química das NPs após a síntese, evitando efeitos de agregação e oxidação [20, 21, 22], é necessário realizar modificações na superfície das mesmas.

O ácido oleico (AO) é um surfactante normalmente utilizado para estabilizar NPs [18, 23]. Alguns trabalhos mostraram que o ácido oleico é adsorvido na superfície das nanopartículas de óxido de ferro através da ligação química formada entre o grupo carboxila $\left(\mathrm{COO}^{-}\right)$do ácido oleico (Figura 1.1) e o átomo de Fe da nanopartícula [20, 24, 25]. Assim, após a adsorção do AO, as NPs ficam recobertas com o surfactante, sendo fácil dispersá-las em meio apolar.

Entretanto, para aplicações em Biomedicina, seja in vitro quanto in vivo, as NPMs devem ser dispersas em meios polares, como o meio biológico (soluções aquosas), para serem biocompatíveis. Neste contexto, vem sendo muito investigado o recobrimento das NPMs com moléculas que expõem grupos polares à solução e que contém grupos reacionais a moléculas de interesse biológico [26, 27, 28, 29]. Em particular, recobrimento das NPMs com ácido dimercaptosuccínico (DMSA) (Figura 1.1), que apresenta dois grupos tióis funcionais (-SH), vem sendo amplamente utilizado devido ao favorecimento da formação de pontes di-sulfeto com cisteínas de algumas proteínas e peptídeos [30, 31, 32, 33].

Nesta dissertação de mestrado, nos propomos, de maneira inédita, modificar a superfície de NPMs com ácido mercaptosuccínico (MSA) que apresenta apenas um grupo tiol por molécula (Figura 1.1), com posterior funcionalização com óxido nítrico (NO), como veículos de transporte e liberação de NO. Existem diferentes aplicações de NO em biomedicina, entre as quais podemos citar a de cicatrização de feridas [34, 35] e regulação de tono vasomotor [36, 37]. Os resultados geraram uma patente (INPI 018120023545), um trabalho recentemente publicado no Materials Science and Engineering $C$ (2013) [38] e dois trabalhos 
publicados no Journal of Physics (Conference Series) sobre citotoxicidade e genotoxicidade destas nanopartículas [39, 40]. Os trabalhos publicados estão anexados no final desta dissertação.

Em continuidade, estudamos de maneira comparativa a liberação de NO de NPMs recobertas com DMSA. Vale a pena mencionar que a utilização de MSA reduz o custo econômico da síntese das NPs (MSA: $\mathrm{R} \$ 2,24 / \mathrm{g}$ e DMSA: $\mathrm{R} \$ 55,48 / \mathrm{g}$, fonte Sigma-Aldrich).

Antes de descrevermos os métodos e resultados da síntese e caracterização das NPMs funcionalizadas com NO, descreveremos nesta Introdução alguns conceitos que utilizaremos ao longo da dissertação sobre as propriedades estruturais da magnetita e magnéticas de NPMs, seguido de uma breve introdução sobre propriedades e importância do óxido nítrico em sistemas biológicos.

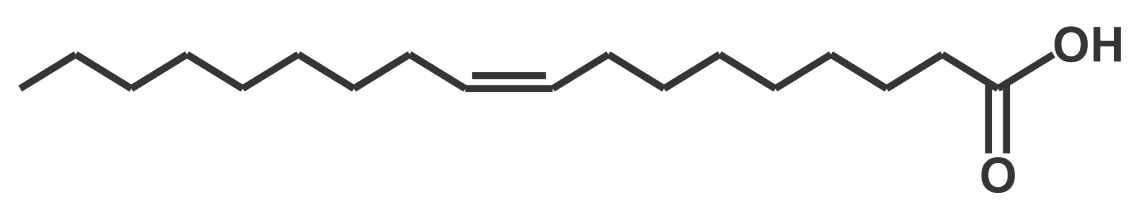<smiles>O=C(O)C[C@H](S)C(=O)O</smiles>

(b)<smiles>O=C(O)C(S)C(S)C(=O)O</smiles>

Figura 1.1: a. Estrutura do ácido oleico. b. Estrutura do ácido mercaptosuccínico (MSA). c. Estrutura do ácido dimercaptosuccínico (DMSA). 


\subsection{Estrutura Cristalográfica da Magnetita}

Existem 16 óxidos de ferro compostos por Fe e O e/ou OH. Na maioria dos compostos, o ferro apresenta estado de oxidação trivalente; apenas três compostos $\mathrm{FeO}, \mathrm{Fe}(\mathrm{OH})_{2}$ e $\mathrm{Fe}_{3} \mathrm{O}_{4}$ contém $\mathrm{Fe}^{+2}$ [41]. Na tabela 1.1, apresentamos os principais óxidos de ferro encontrados na natureza 42 .

Tabela 1.1: Principais óxidos de Ferro. Extraído da referência [42].

\begin{tabular}{cccc}
\hline \multicolumn{2}{c}{ Oxihidróxidos } & \multicolumn{2}{c}{ Óxidos } \\
Fórmula & Mineral & Fórmula & Mineral \\
\hline$\alpha$-FeOOH & Geotita & $\mathrm{Fe}_{5} \mathrm{HO}_{8} 4 \mathrm{H}_{2} \mathrm{O}$ & Ferrihidrita \\
$\beta$-FeOOH & Akaganeita & $\alpha-\mathrm{Fe}_{2} \mathrm{O}_{3}$ & Hematita \\
$\gamma$-FeOOH & Lepidocrocita & $\gamma-\mathrm{Fe}_{2} \mathrm{O}_{3}$ & Maghemita \\
$\delta$-FeOOH & Feroxyhyta & $\mathrm{Fe}_{3} \mathrm{O}_{4}$ & Magnetita \\
\hline
\end{tabular}

Neste trabalho estudaremos as propriedades da magnetita, um mineral preto, ferromagnético que contém $\mathrm{Fe}^{2+}$ e $\mathrm{Fe}^{3+}$. Alguns outros nomes são usados para identificar a magnetita, tais como óxido de ferro preto, mineral de ferro magnético, ímã natural (quando a polaridade natural está presente), tetraóxido de tri ferro, ferrita ferrosa, pedra de Hércules e Magneteisenerz (mineral de ferro magnético), devido a sua diversidade de utilização [41].

A estrutura cristalográfica da magnetita foi estabelecida em 1915, sendo uma das primeiras estruturas minerais estudada por Difração de Raios X [43] . Sua estrutura é do tipo espinélio, lembrando que os espinélios são minerais que têm a fórmula geral $\mathrm{A}^{2+} \mathrm{B}_{2}^{3+} \mathrm{O}_{4}^{2-}$, onde A e B são íons metálicos e O é oxigênio, com estrutura cúbica de face centrada (fcc), apresentada na Figura 1.2 [44].

As estruturas do tipo espinélio podem ser classificadas de acordo com a posição (chamada de sítio) que cátions semelhantes ocupam na estrutura, formando sub-redes tetraédricas (sítio A) e octaédricas (sítio B). No sítio tetraédrico, o íon metálico está localizado no centro de um tetraedro que tém íons oxigênio nos vértices (Figura 1.2); no sítio octaédrico (sítio B), o íon metálico está localizado no centro de um octaedro que tém íons oxigênio nos vértices (Figura 1.2). A formação de sub-redes é uma razão para a diversidade estrutural e magnética de óxidos metálicos [42]. 
(a)

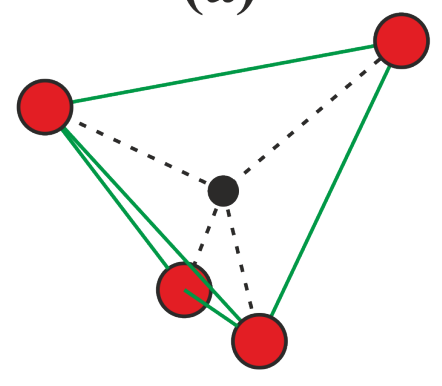

Sítio tetraédrico

(Sítio A)

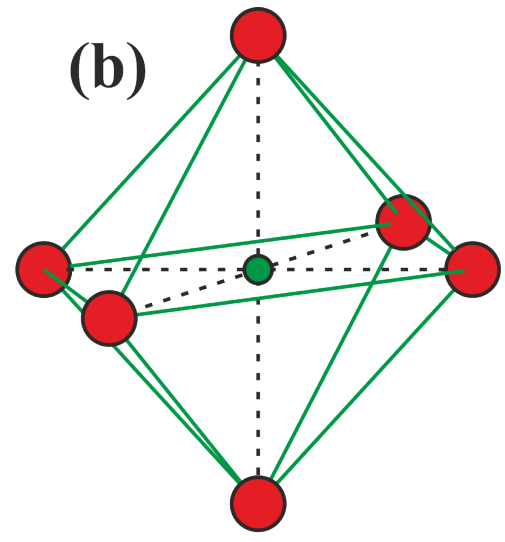

Sítio octaédrico

(Sítio B)

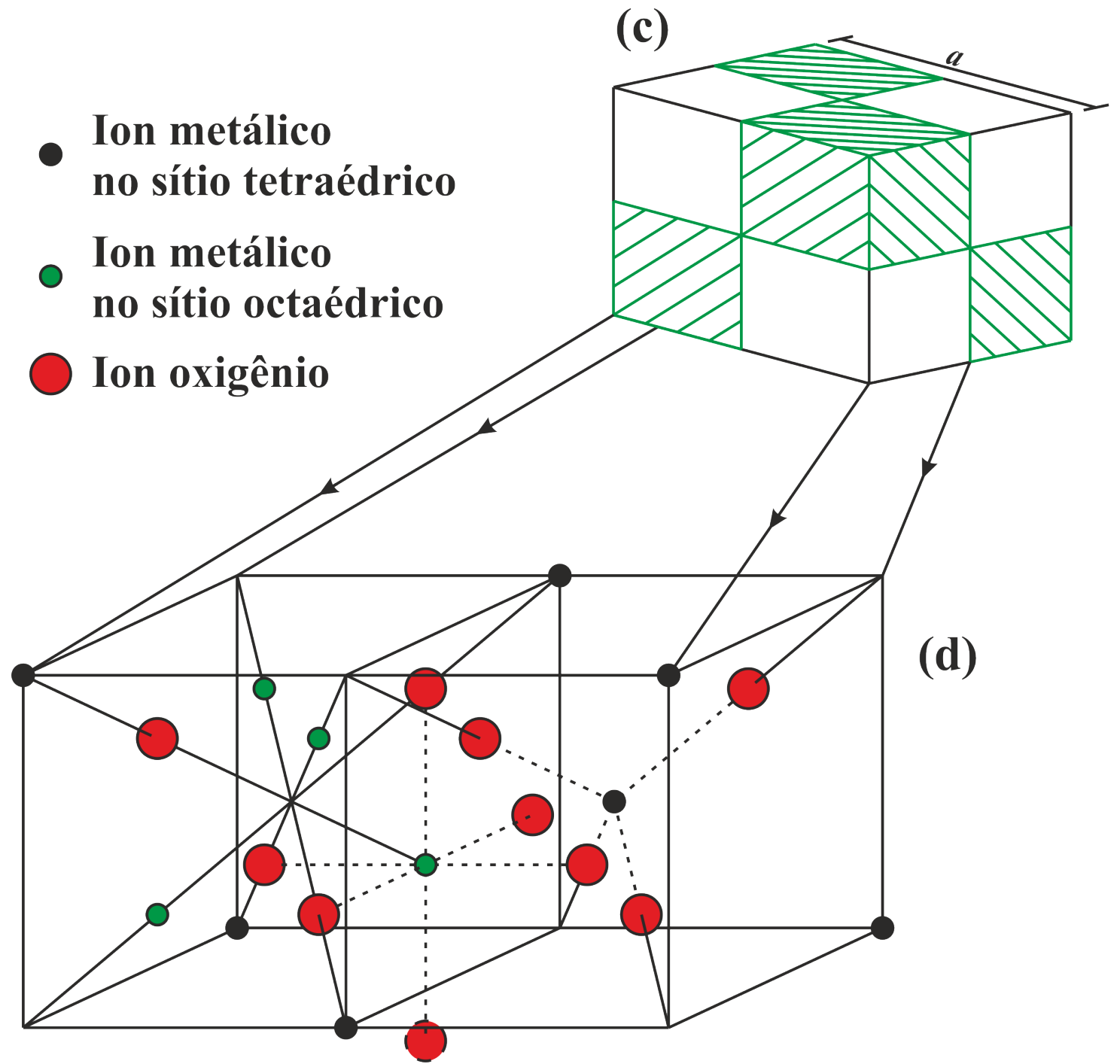

Figura 1.2: (a) Sítio tetraédrico (Sítio A) da estrutura espinélio; (b) Sítio octaédrico (Sítio B) da estrutura espinélio; (c) Cela unitária da estrutura espinélio e (d) Ampliação de 2/8 da cela unitária da estrutura espinélio. Figura extraída da referência [44]. 


\section{Espinélio Normal}

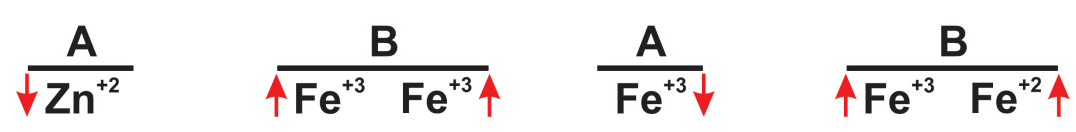

\section{Espinélio Inverso}

Figura 1.3: Distribuição catiônica na estrutura espinélio normal (como exemplo: $\mathrm{ZnFe}_{2} \mathrm{O}_{4}$ ) e espinélio inverso (como exemplo: a magnetita, $\mathrm{Fe}_{3} \mathrm{O}_{4}$ ). No espinélio normal, o cátion $\mathrm{Zn}^{2+}$ ocupa o sítio tetraédrico (A) e o íon $\mathrm{Fe}^{3+}$ ocupa o sítio octaédrico (B); no espinélio inverso, o cátion $\mathrm{Fe}^{3+}$ ocupa o sítio tetraédrico (A) e os íons $\mathrm{Fe}^{2+}$ e $\mathrm{Fe}^{3+}$ ocupam o sítio octaédrico (B).

A estrutura é denominada de espinélio normal quando cátions semelhantes ocupam a mesma sub-rede. A Figura 1.3 apresenta um exemplo para $\mathrm{ZnFe}_{2} \mathrm{O}_{4}$. A magnetita apresenta estrutura espinélio inverso: os sítios tetraédricos (sítios A) estão completamente ocupados pelo íon $\mathrm{Fe}^{3+}$ e os sítios octaédricos (sítios B) estão ocupados pelos íons $\mathrm{Fe}^{3+}$ e $\mathrm{Fe}^{2+}$ (Figura 1.3 .

A cela unitária da magnetita contém 8 íons metálicos de sítio A, 16 de sítio B e 32 oxigênios; esta cela unitária pode ser imaginada como um cubo de aresta $a$ ( $a=0,8396 \mathrm{~nm})$ [41] dividida em oito pequenos cubos iguais, cada um com aresta $a / 2$ como está apresentado na Figura 1.2 [44]. Devido às propriedades de simetria estrutural, a magnetita apresenta grupo espacial $F \overline{3} d m$ [41, 42]. Num difratograma de Raios-X, as reflexões permitidas dos planos cristalinos correspondem aos planos (220), (311), (222), (400), (422), (511), (440) e (531), conforme apresentado na Figura 1.4, sendo a reflexão (311) a mais intensa.

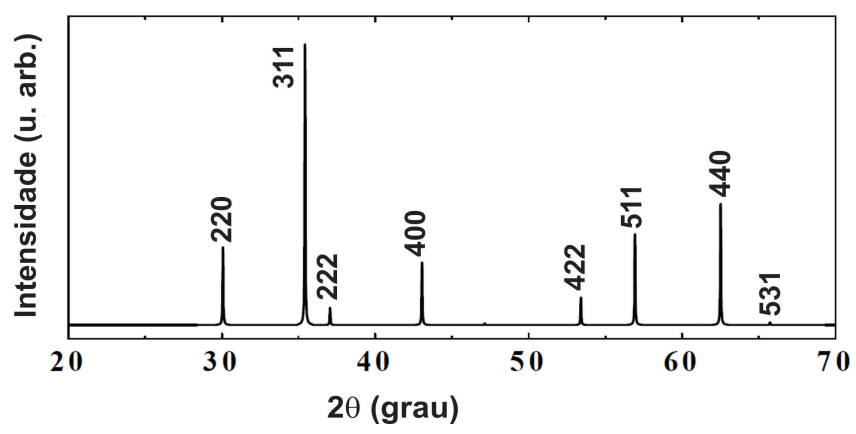

Figura 1.4: Difratograma da magnetita, obtida da ficha catalográfica JCPDF 19-0629. 


\subsection{Propriedades Magnéticas de NPMs}

O nanomagnetismo natural é encontrado, por exemplo em bactérias magnetostáticas, que tem vida em ambientes escuros e contém cadeias de partículas de magnetita; estas cadeias tem comprimentos de 40 a 100 nm e são usadas para a orientação vertical das bactérias [45]. Partículas semelhantes são encontradas nos cérebros de alguns outros animais como abelhas e pombos, e atualmente vem se estudando se estas partículas magnéticas contribuem nas suas orientaçôes de vôo devido às propriedades magnéticas que apresentam [45].

Para compreender as propriedades magnéticas que um determinado material pode apresentar, devemos levar em conta que todo material está constituido por átomos (que podem ser iguais ou diferentes). Os elétrons presentes nos átomos, devido ao seu movimento em torno do seu eixo e do núcleo (spin mais orbital), apresentam um momento magnético $\left(\mu_{i}\right)$. Os núcleos apresentam um outro momento magnético nuclear (que é desprezível comparado com o momento magnético dos elétrons) [45] e, portanto, não influencia considerávelmente nas propriedades magnéticas do material. Na interpretação clássica, o momento magnético associado ao giro de um elétron em órbita circular ao redor do núcleo é definido pelo magnéton de Bohr [46]:

$$
\mu_{B}=\mathrm{I} \mathrm{S}
$$

onde:

I: intensidade de corrente associada com o movimento do elétron (A).

$\mathrm{S}$ : área encerrada pela trajetória do elétron $\left(\mathrm{m}^{2}\right)$.

Com:

$$
\mathrm{I}=\frac{e \mathrm{v}}{2 \pi \mathrm{r}}
$$

e:

$$
\mathrm{S}=\pi \mathrm{r}^{2}
$$

onde:

$e$ : carga do elétron $\left(1,6 \times 10^{-19} \mathrm{C}\right)$.

$\mathrm{v}$ : módulo da velocidade do elétron $(\mathrm{m} / \mathrm{s})$.

$\mathrm{r}$ : raio da trajetória de giro $(\mathrm{m})$. 
Na Equação 1.1 podemos então reescrever:

$$
\mu_{B}=\frac{e \mathrm{r} \mathrm{r}}{2}
$$

Sabemos que do ponto de vista quântico, o momento angular está quantizado: $\mathrm{L}=\mathrm{n} \hbar$, e o momento angular orbital de valor unitário $(\mathrm{n}=1)$ é: $\mathrm{L}=\hbar=h / 2 \pi$. Na mecânica clássica, um elétron com massa $\left(m_{e}\right)$ que gira em uma órbita de raio «r» e velocidade «v»apresenta momento angular $\mathrm{L}=m_{e} \mathrm{v}$ r. Assim, das considerações clássica e quântica, temos: v r $=$ $h / 2 \pi m_{e}$. O magnéton de Bohr $\left(\mu_{B}\right)$ então pode ser descrito como:

$$
\mu_{B}=\frac{e h}{4 \pi m_{e}}=9,27 \times 10^{-24} \frac{\text { Joule }}{\text { Tesla }}
$$

onde:

$h$ : constante de Planck $\left(6,627 \times 10^{-27} \mathrm{Js}^{-1}\right)$.

$m_{e}$ : massa do elétron $\left(9,1 \times 10^{-31} \mathrm{~kg}\right)$.

Considerando um volume $V$ de material magnético composto de $N$ átomos, os elétrons destes átomos apresentam um momento magnético $\mu$ :

$$
\mu=\sum_{i}^{N} \mu_{i}
$$

Define-se Magnetização «M» de um material como o momento magnético total resultante $(\mu)$ por volume $(V)$ tal que [47]:

$$
M=\frac{\mu}{V}
$$

A unidade da magnetização é «unidade eletromagnética $/ \mathrm{cm}^{3} »$, ou simplesmente $\ll \mathrm{emu} / \mathrm{cm}^{3} »$ $\left(1 \mathrm{emu}=10^{-3} \mathrm{~J} / \mathrm{T}\right)$. Neste trabalho adotaremos a magnetização específica $\left(\sigma_{e}\right)$ definida como o momento magnético $(\mu)$ por unidade de massa $(m)$ :

$$
\sigma_{e}=\frac{\mu}{m}
$$

onde $m$ é a massa do material (em gramas). 
Quando um campo magnético externo é aplicado a um gás de elétrons com spin-up e spin-down, estes apresentam estados de energia diferentes devido à orientação dos mesmos em relação ao campo magnético. No caso dos momentos magnéticos, quando um campo magnético externo é aplicado, os momentos magnéticos são alinhados na mesma direção ou na direção oposta ao campo magnético externo e, como resultado, os momentos magnéticos formam sub-redes com populações diferentes. Para o gás de elétrons, o momento magnético de spin total $(\mu)$ é dado por [47]:

$$
\mu=\mu_{B}(n \uparrow-n \downarrow)
$$

onde $n \uparrow$ e $n \downarrow$ são o número de elétrons com spin-up e spin-down, respectivamente. Este fenômeno é conhecido como o Paramagnetismo de Pauli, e a correspondente susceptibilidade magnética é chamada a susceptibilidade de Pauli [47].

O momento magnético nos óxidos dos metais de transição ou óxidos $3 d$, como a magnetita, é medido em $\mu_{B}$ vezes o número de spins desemparelhados [45]. Assim, para compreender o fenômeno do magnetismo na magnetita, temos que levar em conta que em cada unidade estrutural da mesma (Figura 1.2 temos íons ferroso $\left(\mathrm{Fe}^{2+}\right)$, que contém seis elétrons no orbital $3 d$ e, portanto, apresentam um momento magnético $4 \mu_{B}$, e férrico $\left(\mathrm{Fe}^{3+}\right)$, com cinco elétrons na subcamada $3 d$ e apresentam um momento magnético $5 \mu_{B}$. Portanto, por cada unidade de fórmula da magnetita $\mathrm{Fe}_{3} \mathrm{O}_{4}$, ou $\mathrm{FeO} \mathrm{Fe}_{2} \mathrm{O}_{3}$, temos dois íons férrico $\left(\mathrm{Fe}^{3+}\right)$ com momentos magnéticos antiparalelos [47] e um íon ferroso $\left(\mathrm{Fe}^{2+}\right)$, produzindo um momento magnético total igual a $4 \mu_{B}$. O valor experimental do momento magnético da magnetita é $4,1 \mu_{B}$ [4].

No caso de um magneto, seu comportamento magnético pode ser tratado do ponto de vista clássico e quântico. Clássicamente o momento magnético é explicado a partir do alinhamento total dos momentos magnéticos quantificado através da magnetização de saturação $\left(M_{s}\right)$ e da função de Langevin $\left(L_{(x)}\right)$, sendo $x$ a razão entre as energias magnética e térmica do magneto $\left(x=\mu \mathrm{B} / k_{B} T\right)$, tal que [46, 47]:

$$
M=M_{s} L_{(x)}
$$

e:

$$
L_{(x)}=\operatorname{coth}(x)-\frac{1}{x}
$$


com: B: módulo da indução magnética (Tesla); $\mathrm{B}=\mu_{0} \mathrm{H}$, onde $\mu_{0}=4 \pi \times 10^{-7}$ Tesla metro/ Ampère e H: módulo do campo magnético (Ampère/metro).

Do ponto de vista quântico, a magnetização $(M)$ depende da magnetização de saturação $\left(M_{s}\right)$ e da função de Brillouin $B_{J}(x)$, sendo $J$ o momento angular total do sistema de spins tal que [47:

$$
M=M_{S} B_{J}(x)
$$

e:

$$
B_{J}(x)=\frac{2 J+1}{2 J} \operatorname{coth}\left[\frac{2 J+1}{2 J} x\right]-\frac{1}{2 J} \operatorname{coth}\left[\frac{x}{2 J}\right]
$$

No limite clássico, os momentos magnéticos podem ser alinhados continuamente e, assumindo todos os valores para o momento angular total $(J \rightarrow \infty)$, a função de Brillouin é simplificada, obtendo a função de Langevin (Equação 1.7). As deduções da função de Langevin e de Brillouin são desenvolvidas no Apêndice A.1, e A.2, respectivamente.

\subsubsection{Energia de Anisotropia Magnética - NPs e Superparamagne- tismo}

A direção de magnetização em relação aos eixos cristalinos é denominada de anisotropia magnética. Abaixo de um certo diâmetro crítico, NPs podem ser consideradas com um único domínio magnético (monodomínio) e apresentam contribuições anisotrópicas à sua energia total associadas com algumas direções preferenciais de magnetização, tensões sofridas ou à própria estrutura cristalina [47. No caso da magnetita, monomodínios são formados em partículas de 5 a 20nm de diâmetro [7], sendo a direção [111] a de fácil magnetização (Figura 1.5).

Em muitos casos, supõe-se uma anisotropia uniaxial, caracterizada por uma constante de energia anisotrópica magnetocristalina $« K_{a} »$. Neste caso, a energia de anisotropia $\left(\mathrm{E}_{A}\right)$, para uma partícula de volume $\langle V \gg$ se altera com ângulo $« \theta »$ formado pelo eixo de fácil magnetização e a direção do momento magnético (apresentada na Figura 1.6) e é escrita como [47:

$$
\mathrm{E}_{A}=K_{a} V \operatorname{sen}^{2} \theta
$$




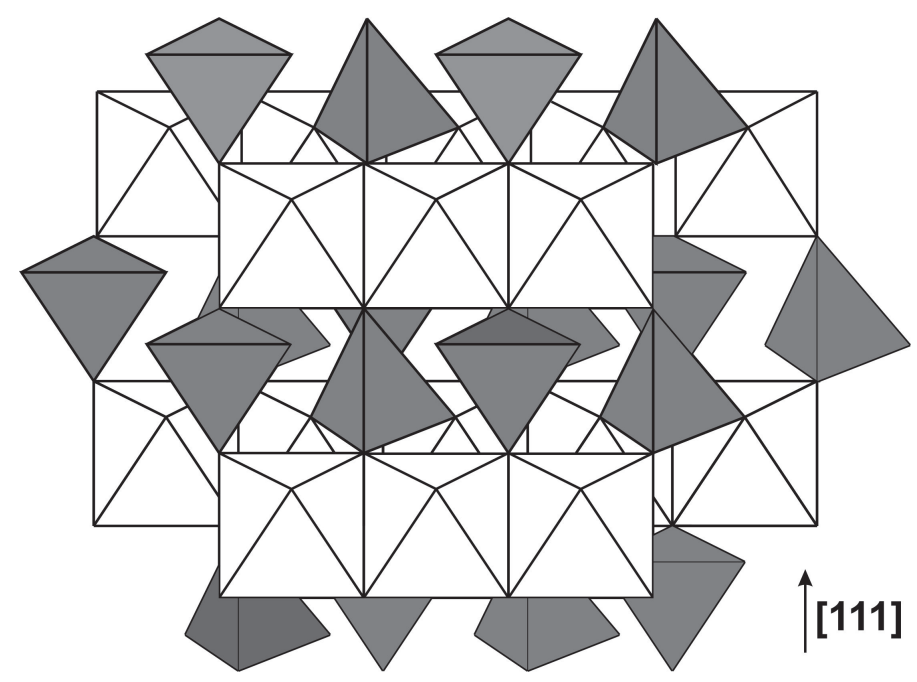

Figura 1.5: Modelo estrutural da magnetita indicando um eixo cristalino de fácil magnetização na direção cristalográfica [111] com espaçamento interplanar entre as sub-redes tetraédrica e octaédrica de $0,497 \mathrm{~nm}$. Na figura são apresentadas a sub-rede tetraédrica (cinza) e a sub-rede octaédrica (branca). Figura extraída de [41].

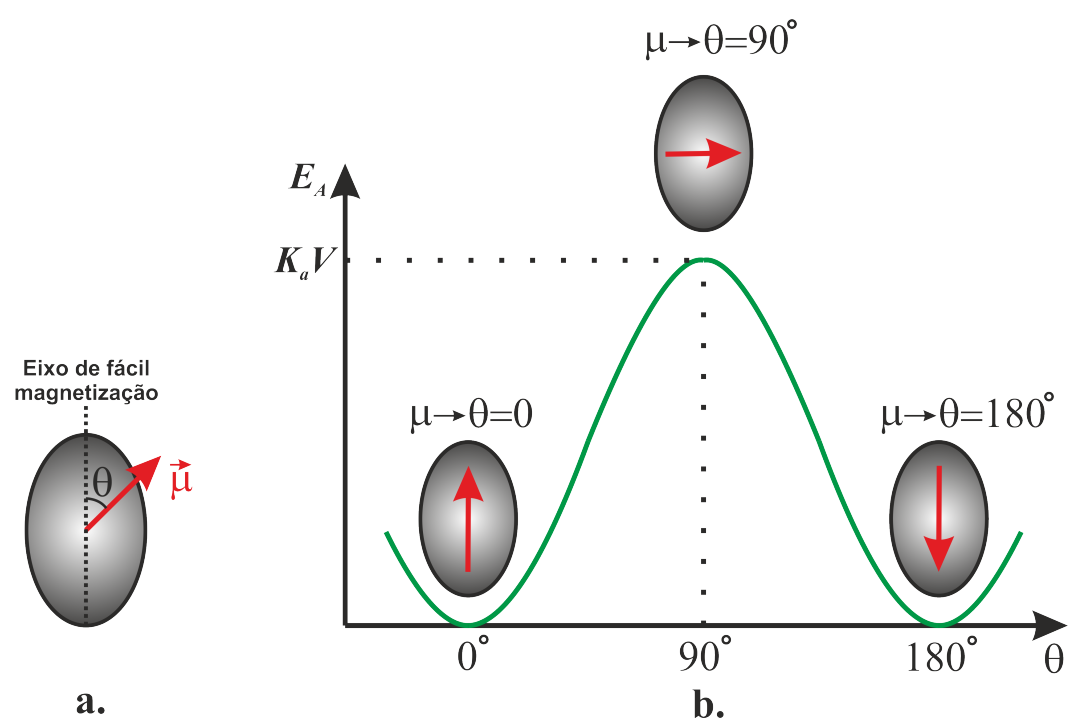

Figura 1.6: a. Partícula magnética com eixo de fácil magnetização bem definido; b. Energia de anisotropia em função de $\theta$. Figura extraída de [47]. 
A transição de um mínimo de energia para outro (Figura 1.6) pode ser térmicamente ativada para temperaturas «T» diferentes de $0 \mathrm{~K}$, na qual a probabilidade de transição é grande se a energia térmica $\left(k_{B} T\right)$ é comparável ou maior que a energia de anisotropia $\left(\mathrm{E}_{A}\right)$. Se considerarmos um conjunto de partículas magnetizadas a temperatura diferente de $0 \mathrm{~K}$, na ausência de um campo magnético externo, a magnetização evoluirá com o tempo desde que existam transições térmicamente ativadas entre os 2 mínimos de energia, tal que [47]:

$$
\frac{\mathrm{d} M}{\mathrm{~d} t}=-\frac{1}{\tau_{0}} M e^{-\left(\frac{K_{a} V}{k_{B} T}\right)}=-\frac{M}{\tau}
$$

onde $\tau$ é o tempo de relaxação, ou inverso da frequência de salto de um mínimo de energia para o outro. O pré-fator $\tau_{0}$ é conhecido como o inverso da frequência de tentativas, sendo da ordem de $10^{-12} \mathrm{~s}$ a $10^{-9} \mathrm{~s}$ [4]. Em termos simples, a Equação 1.11 descreve que sob a influência da energia térmica, o sistema realiza $\tau_{0}^{-1}$ tentativas por segundo para ultrapassar a barreira de energia. O tempo de relaxação é então dado por:

$$
\tau=\tau_{0} \exp \left(\frac{K_{a} V}{k_{B} T}\right)
$$

conhecido como lei de Neel-Arrhenius [47.

O comportamento magnético observado de uma particula magnética depende da escala de tempo da medida experimental. Para técnicas macroscópicas como medidas diretas de magnetização $M$, o tempo de medida $\mathrm{t}_{m}$ é normalmente da ordem de $100 \mathrm{~s}$ [47]. Em espectroscopia Mossbauer $\mathrm{t}_{m}=10^{-9}$ a $10^{-7} \mathrm{~s}$ [47]. Portanto, se o tempo de relaxação $\tau$ é menor que $\mathrm{t}_{m}$, a magnetização espontânea é zero, e a partícula é dita estar no estado superparamagnético. Se $\tau>\mathrm{t}_{m}$ a partícula está num estado bloqueado (ou ferromagnético) e a magnetização é diferente de zero.

Nota-se também que se o volume da partícula varia, a energia da barreira $\mathrm{E}_{A}$ também varia. Sendo assim, para uma dada temperatura $T$, a partícula pode estar num regime superparamagnético ou ferromagnético dependendo de seu tamanho. Assim, define-se um volume crítico superparamagnético como:

$$
V_{c r}^{s p m}=\frac{k_{B} \mathrm{~T}}{K_{a}} \ln \left(\frac{t_{m}}{\tau_{0}}\right)
$$


abaixo do qual, a uma certa temperatura $\mathrm{T}$, a partícula encontra-se num estado superparamagnético. Por exemplo, nanopartículas de magnetita exibem comportamento superparamagnético a T ambiente para diâmetros menores que $17 \mathrm{~nm}$ em uma medida de susceptibilidade magnética e menores que $9 \mathrm{~nm}$ em um experimento de Mossbauer [48].

Inversamente, para um dado volume $\mathrm{V}$, a temperatura abaixo da qual o comportamento ferromagnético é observado, é chamada de temperatura de bloqueio $\mathrm{T}_{B}$, dado por [47]:

$$
T_{B}=\frac{K_{a} V}{k_{B} \ln \left(\mathrm{t}_{m} / \tau_{0}\right)}
$$

As temperaturas de bloqueio para NPs de magnetita de dimensões entre 5 a $13 \mathrm{~nm}$ estão na ordem de $\sim 10$ a 30K [46, 47, 49].

Consideremos agora o sistema na presença de um campo magnético $\mathbf{H}$ aplicado ao longo do eixo de fácil magnetização. A energia livre total passa a ser [47]:

$$
\mathrm{E}_{A}=K_{a} V \operatorname{sen}^{2} \theta-\mu \mathrm{H} \cos \theta
$$

Nessas condições, os estados de mínima energia não são mais equivalentes, pois um deles será favorecido dependendo do sentido de aplicação do campo magnético, induzindo alguns dos momentos magnéticos de partículas a se reorientarem em sua direção. Assim, mede-se uma magnetização líquida $M$ não nula para o sistema e o grau de reorientação aumenta com o aumento na intensidade do campo até que, quando todos os momentos magnéticos estão orientados, a magnetização de saturação $M_{s}$ é atingida. Em materiais ferromagnéticos formados por múltiplos domínios, as interações entre eles faz com que, após a aplicação de um campo magnético, exista um valor não nulo para a magnetização, mesmo após a retirada do campo. Esse valor é denominado magnetização remanente ou remanência $\left(M_{r}\right)$. Para que esta se anule, é necessário a aplicação de outro campo magnético em sentido contrário, cujo valor é denominado campo coercivo ou coercividade $\left(\mathrm{H}_{C}\right)$. Em regime superparamagnético, espera-se ausência de histerese $\left(\mathrm{H}_{C}=0\right.$ e $\left.M_{r}=0\right)$ [47. 
Vale a pena frisar que durante a síntese produzimos nanopartículas magnéticas com uma certa polidispersão em tamanhos. Para analisar o comportamento da magnetização sob a ação de um campo externo aplicado numa certa direção, devemos ter em conta que a curva de magnetização $(M \times H)$ será resultado da superposição de diferentes curvas de Langevin (Equações 1.6 e 1.7) correspondentes aos diferentes volumes de partículas na amostra analisada. Portanto, neste caso a magnetização será dada por [47]:

$$
M_{(B, T)}=\mathrm{N}_{T} \int_{0}^{\infty} M_{s} L\left(\frac{\mu B}{k_{B} T}\right) \mathrm{f}(\mu) d \mu
$$

onde $\mathrm{f}(\mu)$ corresponde a uma função de distribuição de momentos magnéticos dos grãos da amostra, que pode ser representada através de uma função $\log$-Normal $\left(\mathrm{f}_{\mathrm{LN}}\right)$, e $\mathrm{N}_{T}$ corresponde ao número total de partículas magnéticas analisadas na amostra. Lembrando que: $\mu=M_{s} V$ (Equação 1.3 e $\mathrm{B}=\mu_{0} \mathrm{H}$, podemos reescrever a Equação 1.16 em função do diâmetro magnético $\mathrm{d}_{\text {mag }}$ das nanopartículas tal que:

$$
M_{(H, T)}=\mathrm{N}_{T} \int_{0}^{\infty} M_{s} L\left(\frac{\mu_{0} M_{s} \pi \mathrm{d}_{m a g}^{3} \mathrm{H}}{6 k_{B} T}\right) \mathrm{f}_{\mathrm{LN}}\left(\mathrm{d}_{m a g}\right) d\left(\mathrm{~d}_{m a g}\right)
$$

Assim, a função de distribuição de momentos magnéticos pode nos fornecer informações sobre a distribuição de tamanhos $\mathrm{f}_{\mathrm{LN}}\left(\mathrm{d}_{\text {mag }}\right)$ das NPs e ser comparada com aquelas fornecidas por outras técnicas, como por exemplo Microscopia Eletrônica de Transmissão, conforme abordaremos nesta dissertação (Capítulo 4). 


\section{3 Óxido Nítrico - NO}

O óxido nítrico ( $\mathrm{NO}^{*}$ ) possui um elétron desemparelhado, motivo pelo qual é considerado um radical livre. Foi obtido pela primeira vez pelo cientista belga Jan Baptist Van Helmont aproximadamente em 1620. As propriedades químicas do NO foram inicialmente caracterizadas por Joseph Priestly em 1772. Em meados de 1980, o NO foi considerado como um poluente atmosférico e metabólito bacteriano [50]. Em 1992 foi reconhecida a grande importância do NO pela revista Science, denominando ao NO como a Molécula do Ano; e em 1998, F. Futchgott, Louis J. Ignarro e Ferid Murad ganharam o Prêmio Nobel pela descoberta da complexa estrutura do NO [50, 51].

O NO é um molécula gasosa produzida no endotélio, devido à reação de L-Arginina com oxigênio molecular catalisado pela sintasa de óxido nítrico endotelial (eNOS), como apresentado na Equação 1.18 [52]:

$$
\mathrm{L}-\text { Arginina }+\mathrm{O}_{2} \stackrel{e N O S}{\longrightarrow} \mathrm{NO}+\mathrm{L}-\text { Citrullina }
$$

O óxido nítrico é incolor e tem tamanho da ordem de $\sim 1,4 \AA$ com tempo de vida médio de aproximadamente 3-5 segundos em água. A temperatura e pressão ambiente, NO ${ }^{*}$ existe como uma espécie monomérica. $\mathrm{NO}^{*}$ apresenta alta reatividade com componentes biológicos como superóxidos $\left(\mathrm{O}^{-2} \cdot\right)$, oxigênios, tióis, e outros [50]. O elétron desemparelhado do NO não reside completamente no nitrogênio, mas é compartilhado entre o oxigênio e nitrogênio [53]. Como o nitrogênio apresenta um coeficiente orbital alto, a reação do NO ${ }^{*}$ com outros radicais ocorre através do átomo de nitrogênio [54].

Para se medir a presença do NO várias técnicas foram desenvolvidas, como quimioluminiscência [55, 56], método de Griess, espectroscopia de ressonância paramagnética e imagem por ressonância [50, 51, 57].

A importância biológica da reatividade química do óxido nítrico e seus derivados tem sido foco de muitos trabalhos, além da sua dinâmica in vivo. Devido a seu pequeno tamanho, sua falta de carga e alta lipofilicidade, NO é uma molécula altamente difusível através de membranas celulares para agir com alvos intracelulares [38]. 
NO é aproximadamente nove vezes mais solúvel em solventes orgânicos que em água [53. Consequentemente, o NO se concentra em fases hidrofóbicas nos tecidos, inclusões em membranas lipídicas, e complexos lipoproteicos [53]. Isto traz consequências biológicas importantes, como a fácil movimentação do NO no tecido, que é muito importante nas suas ações biológicas.

\subsubsection{Funções do NO}

Em sistemas biológicos, o NO apresenta múltiplas aplicações em fisiologia, patologia e farmacologia. Desde a descoberta em 1987 do NO como responsável pelas ações fisiológicas do fator de relaxação derivado do endotélio (EDRF do inglês endothelium-derived relaxing factor), o NO tem sido envolvido em numerosos processos biológicos como, a comunicação molecular, regulação da pressão sanguínea, mediador em um amplo espectro de atividades tanto anti-tumorais como anti-bactericidas [58]. O NO tem sido ainda relacionado no tratamento de algumas doenças como mal de Alzheimer e Parkinson [59, 60].

Em relação a células, o NO apresenta duas funções divergentes: homeostática e citotóxica. O NO é produzido em pequenas quantidades (em $\mu \mathrm{g}$ ) em condições fisiológicas: regula a vasorelaxação, controla a adesão e agregação de plaquetas e neutrófilos (células sanguíneas leucocitárias que fazem parte do sistema imunológico), está relacionado em neurotransmissão [61] e proliferação e contração de músculo liso [62]. Enquanto aos efeitos citotóxicos do NO, estes são observados quando o NO é produzido em quantidades maiores pelos macrófagos, hepatócitos e outras células depois da exposição das mesmas às citoquinas ou produtos microbianos [61]. Altos níveis de NO inducem necrose celular [63].

O óxido nítrico se apresenta como agente neurotransmissor no sistema nervoso, difundindose a partir de um neurônio a outro para atuar diretamente sobre os componentes intracelulares. NO não encontra restrições espaciais encontradas normalmente em neurotransmissores clássicos, que mediam suas ações biológicas por ligação às proteinas associadas à membrana do receptor em pontos discretos. NO é armazenado em vesículas sinápticas que são pequenas esferas ligadas ao extremo dos axônios nos neurônios do sistema nervoso e apresentam um tamanho aproximado de 10 a $20 \mathrm{~nm}$. Tem sido demonstrado que o NO trabalha em conjunto com outros sistemas neurotransmissores no organismo, tais como norepinefrina, dopamina, serotonina e glutamato para produzir uma resposta fisiológica no organismo [51]. 
Existem relatos na literatura que o NO pode ser citotóxico às células de neurônios. Uma das principais causas é que o NO provoca a inibição mitocondrial, liberação de glutamato e subseqüente morte citotóxica dos neurônios [63]. Altas concentrações de glutamato extracelular (o principal neurotransmissor exitotóxico no cérebro) pode matar os neurônios por ativação dos receptores de glutamato; esta morte celular é conhecida como morte excitotóxica [63].

O óxido nítrico liberado por quase todas as células do coração exerce múltiplos efeitos sobre a função cardíaca. Modula as respostas inotrópica (aumento ou diminuição da força de contração do coração) e cronotrópica (aumento da frequência cardíaca) [36]. Os principais fatores de risco cardiovasculares, tais como hipertensão sistêmica, estão associados a uma disfunção endotelial, que é principalmente caracterizada por uma diminuição na bioatividade do NO derivado do endotélio [62].

Existem também pró-fármacos do NO, entre eles, aqueles da classe iônico diazeniumdiolate que espontaneamente se dissociam em taxas definidas para formar NO. Estes não só são amplamente utilizados em estudos biológicos, mas também são de interesse como possíveis agentes terapêuticos no tratamento de algumas doenças como câncer, por exemplo, dependendo do estágio das doenças [64].

A administracão tópica de doadores de NO para investigação de cicatrização do tendão em pacientes humanos, é apresentada como um tratamento muito mais simples e menos susceptível de perturbar o tecido circundante. O NO é gerado pelos osteoblastos e outras células dentro do osso em resposta a um gênero de hormônios esteroidais [65]. O uso potencial do NO para tratar lesão no tendão, apresenta a necessidade de controlar concentrações localizadas de NO para promover e não inibir a deposição de colágeno. Uma solução de albumina de soro bovino nitrosada tem sido utilizada como carreadora e liberadora de NO [66].

Em termos de cicatrização, NO tem sido implicado em todas as fases de cicatrização de feridas. Estudos demonstraram a capacidade do NO para modular citoquinas quimiotáticas (de ação proinflamatória) e controlar a deposição de colágeno, angiogênese, proliferação celular e apoptose [34, 35]. 
O NO na circulação sanguínea apresenta um tempo de meia vida de 1,8ms, o que significa que a molécula tem pouco tempo para começar a agir no organismo. Encapsulação em lipossomos vem sendo investigada para aumentar o tempo de vida médio do NO no sistema circulatório [67]. Encontrados endogenamente, os peptídeos contendo um tiol, como a glutationa (GHS), são considerados como carreadores e doadores de NO em mamíferos [68]. De fato, a GSH pode ser submetida à reação de nitrosação, produzindo S-nitroglutationa (GSNO), que é considerada um S-nitrosotiol (R-SNO) [68].

Em função de todas estas possíveis aplicações de NO em Biomedicina, nesta dissertação de mestrado sintetizamos nanopartículas magnéticas como possíveis carreadoras e liberadoras de óxido nítrico, conforme veremos a seguir. 


\subsection{Objetivos da dissertação}

O objetivo deste trabalho consiste na obtenção e caracterização de NPs de magnetita visando sua aplicação biomédica como carreadoras e liberadoras de óxido nítrico (NO).

\section{Objetivos Específicos:}

- Sintetizar NPs de magnetita através da síntese por coprecipitação química dos sais de ferro, seguida de recobrimento com ácido oleico (AO). Caracterizar as propriedades química (composição) e físicas (estrutura, morfologia e magnetismo) das NPs formadas.

- Funcionalizar as NPs com MSA e DMSA em diferentes razões de concentração (1/10, $1 / 40$ e 1/80), e avaliar as possíveis mudanças tanto na composição (FTIR), estrutura (XRD), morfologia (TEM), e magnetismo (VSM) destas.

- Avaliar a efetividade da ligação e liberação do NO das NPs funcionalizadas em diferentes razões de concentração de MSA e DMSA.

- Comparar os resultados obtidos de liberação de NO em NPs recobertas com MSA e DMSA.

\subsection{Estrutura da dissertação}

No Capítulo 1, apresentamos uma breve descrição das aplicações biomédicas das NPs de magnetita, assim como as propriedades estruturais e magnéticas que apresentam. Além disto, apresentamos brevemente o óxido nítrico (NO) e suas principais propriedades, funções e aplicações biomédicas.

No Capítulo 2, apresentamos a síntese das NPs pelo método de co-precipitação química dos sais de ferro, assim como o rol que cumprem o recobrimento com ácido oleico e funcionalização da sua superfície com ácido mercaptosuccínico (MSA) e ácido dimercaptosuccínico (DMSA). Apresentamos também o protocolo de nitrosação realizado em 2 etapas nesta dissertação. 
No Capítulo 3, apresentamos as técnicas experimentais utilizadas para as análises químicas (composição e ligações), assim como físicas (estruturais, morfológicas e magnéticas).

No Capitulo 4 apresentamos os resultados e discussões das caracterizações realizadas das NPs, assim como a liberação de óxido nítrico associada com a funcionalização das mesmas com MSA e DMSA.

No Capítulo 5 apresentamos as conclusões do trabalho.

O trabalho publicado durante o desenvolvimento desta dissertação de Mestrado está apresentado no Anexo I. Na parte final desta dissertação (Apêndices A.1 e A.2 foram descritas as funções de Langevin e Brillouin, a partir das considerações clássicas e quânticas, respectivamente, que permitiram definir Magnetização na Seção 1.2 . 


\section{Capítulo 2}

\section{Procedimento de Síntese e Nitrosação das nanopartículas magnéticas}

\subsection{Materiais utilizados para a Síntese}

Cloreto ferroso tetrahidratado $\left(\mathrm{FeCl}_{2} \cdot 4 \mathrm{H}_{2} \mathrm{O}\right)$ e o cloreto férrico hexahidratado $\left(\mathrm{FeCl}_{3} \cdot 6 \mathrm{H}_{2} \mathrm{O}\right)$ foram comprados da Sigma-Aldrich. Ácido clorídrico $(\mathrm{HCl})$, hidróxido de amônio $\left(\mathrm{NH}_{4} \mathrm{OH}\right)$, tolueno $\left(\mathrm{C}_{6} \mathrm{H}_{5}-\mathrm{CH}_{3}\right)$, dimetilsulfóxido $\left(\mathrm{CH}_{3} \mathrm{SOCH}_{3}\right)$, ácido oleico, assim como o ácido mercaptosuccínico (MSA: $\mathrm{C}_{4} \mathrm{H}_{6} \mathrm{O}_{4} \mathrm{~S}$ ), e o ácido dimercaptosuccínico (DMSA: $\mathrm{C}_{4} \mathrm{H}_{6} \mathrm{O}_{4} \mathrm{~S}_{2}$ ), também foram fornecidos pela Sigma-Aldrich.

\subsection{Método de Síntese por coprecipitação}

Para a realização deste trabalho utilizamos a infraestrutura do Laboratório de Processos Fotoinduzidos e Interfaces do Instituto de Química da Universidade de São Paulo.

As nanopartículas foram obtidas pelo método de coprecipitação de sais de ferro seguindo o protocolo descrito na literatura [18]. Inicialmente dissolvemos $0,2 \mathrm{~g}$ de cloreto ferroso tetrahidratado $\mathrm{FeCl}_{2} \cdot 4 \mathrm{H}_{2} \mathrm{O}$, e $0,5 \mathrm{~g}$ de cloreto férrico hexahidratado $\mathrm{FeCl}_{3} \cdot 6 \mathrm{H}_{2} \mathrm{O}$ separadamente em $1 \mathrm{ml}$ e $4 \mathrm{ml}$ de $\mathrm{HCl}(1 \mathrm{M})$, respectivamente, obtendo-se soluções com razões molares 1:2. Em seguida, as soluções foram misturadas sob agitação magnética, ao mesmo tempo em que $50 \mathrm{ml}$ de hidróxido de amônio $(0,7 \mathrm{M})$ era adicionado na solução. Após a adição da base, na 
solução estão presentes os íons $\mathrm{Fe}^{2+}, \mathrm{Fe}^{3+}$ e $\mathrm{OH}^{-}$que reagem químicamente (Equação 2.1) dando origem ao óxido de ferro [69]:

$$
\mathrm{Fe}^{2+}+2 \mathrm{Fe}^{3+}+8 \mathrm{OH}^{-} \longrightarrow \mathrm{Fe}_{3} \mathrm{O}_{4}+4 \mathrm{H}_{2} \mathrm{O}
$$

As NPs de óxido de ferro precipitam na solução dando origem a um sólido preto. Após cerca de 40 minutos, este precipitado foi centrifugado $(350 \mathrm{~g})$ por 5 minutos e lavado com acetona e etanol por 3 ou 4 vezes. Em seguida, este material foi colocado num dissecador por cerca de 8h, obtendo-se uma amostra em pó, a qual chamamos de nanopartículas recém sintetizadas $(\mathrm{NP})$.

Observa-se que durante a obtenção do precipitado, as nanopartículas eram fortemente atraídas pela barra magnética, indicando um caráter magnético para as mesmas que será avaliado nesta dissertação (Capítulo 4).

\subsection{Estabilidade e proteção das nanopartículas}

As NPs de magnetita obtidas na Seção 2.2 (já em pó), estão em contato com o ar. Conforme mencionado na introdução, este meio pode produzir a oxidação das mesmas. Para protegê-las realizamos um recobrimento inicial com ácido oleico [70, 71].

As NPs $(\sim 5 \mathrm{mg})$ foram misturadas com ácido oleico $(6 \mathrm{ml})$ no agitador magnético, durante 3 minutos, formando-se uma massa pastosa de cor preta. Após obtenção, esta mesma foi lavada e centrifugada $(350 \mathrm{~g})$ com acetona e etanol por três vezes, durante 5 minutos, sendo que o precipitado obtido foi colocado num dissecador. No final deste processo, as NPs devem estar recobertas com ácido oleico, que será identificado por Espectroscopia Infravermelho (Seção 4.1). Esta amostra é chamada NPAO.

\subsection{Funcionalização das NPs - Troca de Ligantes}

Num primeiro estágio, as NPs recobertas com ácido oleico $(\sim 10 \mathrm{mg})$ foram suspensas em $1 \mathrm{ml}$ de tolueno; enquanto 5,56g de MSA foi diluída em $10 \mathrm{ml}$ de dimetilsulfóxido (DMSO). As duas soluções foram misturadas sob agitação magnética por 14h. Em seguida, realizamos um procedimento de decantação e o precipitado obtido foi então lavado e centrifugado (13400g) 
com acetona e etanol por três vezes, durante 5 minutos. A centrigugação desta amostra foi realizada inicialmente em tubo de plástico. Observamos que as paredes do mesmo ficavam com uma cor marrom na superfície interna, indicando uma contaminação de nossa amostra no plástico. Sendo assim, decidimos utilizar tubos de vidro (COREX) durante a centrifugação das próximas amostras funcionalizadas tanto com MSA quanto com DMSA. Esta primeira amostra de razão molar 1:40 e foi objeto de estudo do trabalho publicado na referência [38].

Numa segunda etapa do trabalho, as nanopartículas recobertas com ácido oleico ( 20mg) foram suspensas em tolueno; enquanto MSA e DMSA foram dissolvidos em 10ml de DMSO, com massas proporcionais às razões molares NP:MSA ou NP:DMSA (1:10, 1:40 e 1:80). Misturamos as soluções de NP e MSA (ou DMSA) sob agitação magnética durante 16h. Nesta parte fixamos a massa das NPs para que a mudança fosse devida apenas à funcionalização com MSA ou DMSA. Após este periodo de tempo, o processo de lavagem e secagem foi realizado como mencionado no parágrafo anterior. Identificamos estas partículas em função da razão molar como NPMSA110 e NPDMSA110 para razões molares 1:10 respectivamente. De maneira análoga temos as amostras NPMSA140, NPDMSA140, NPMSA180 e NPDMSA180. O processo inteiro de obtenção, recobrimento com AO e troca de ligantes das NPs é representado na Figura 2.1.

O pH da solução foi medido no final de cada etapa realizada, como indica a Figura 2.1.

O fato mais importante na obtenção das NPs funcionalizadas com MSA e DMSA foi o intervalo de tempo empregado na centrifugação. No caso de MSA, as NPs levam de 10 a 15 min para precipitar, enquanto no caso das NPs com DMSA estas levam de 3 a 5 min para precipitar. 


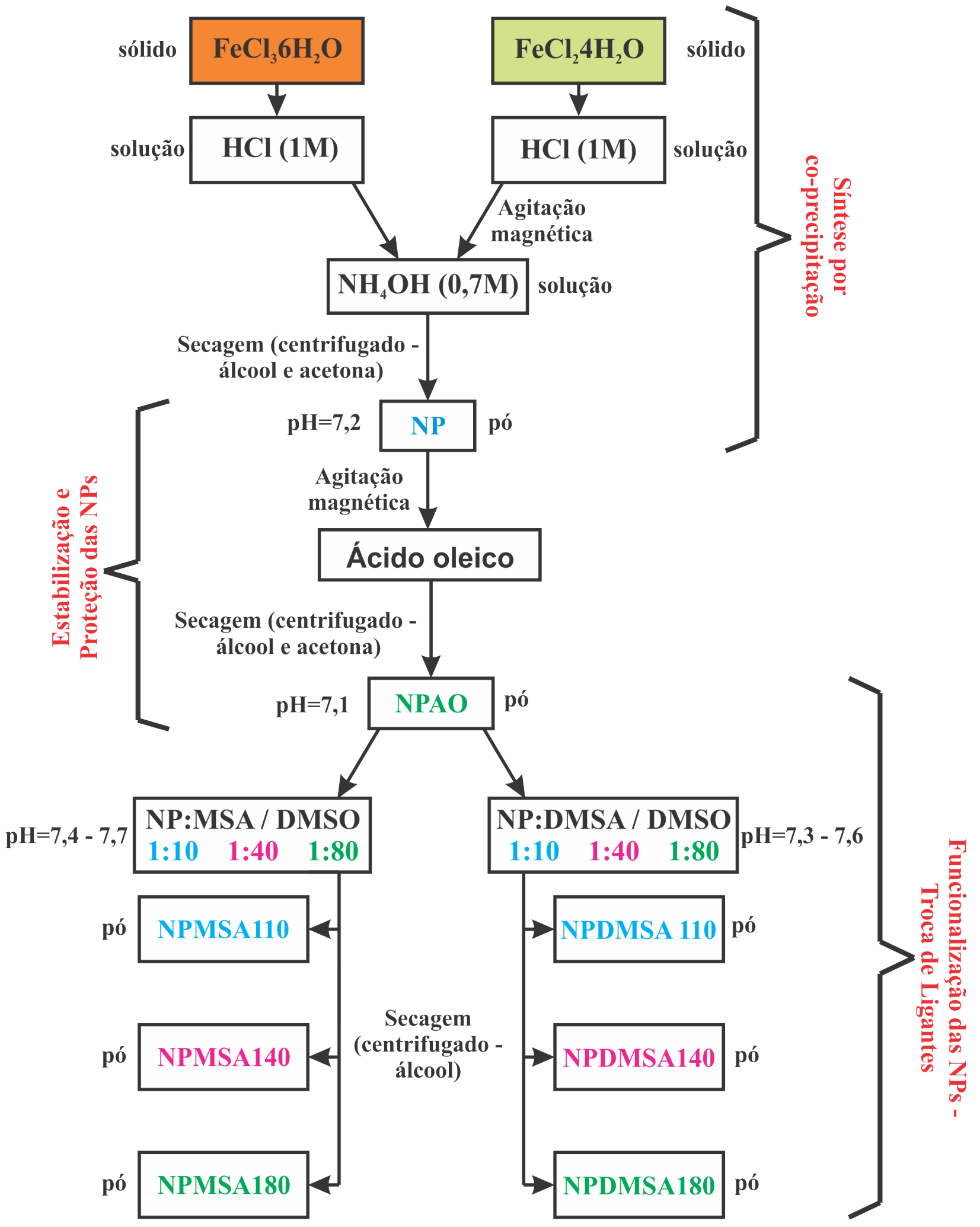

Figura 2.1: Esquema da obtenção das NPMs (NP), após serem recobertas com ácido oleico, antes da troca de ligantes(NPAO) e depois da troca de ligantes com MSA (NPMSA110, NPMSA140, NPMSA180) e com DMSA (NPDMSA110, NPDMSA140, NPDMSA180). 


\subsection{Nitrosação das NPs}

\subsubsection{Primeira Etapa}

Na primeira etapa, o processo de nitrosação foi realizado no Laboratório de Fisicoquímica do Instituto de Química da Universidade de Campinas (IQ-UNICAMP), sob coordenação do Dr. Marcelo G de Oliveira, e em colaboração com a Dra. Amedea Seabra (UNIFESP).

Uma suspensão aquosa das NPs funcionalizadas com MSA (NPMSA140) foi filtrada com filtros da Millipore (10kDa de massa molar de corte, Millipore, Billerica, MA, USA). As NPs (NPMSA140) foram lavadas com água deionizada e centrifugadas cinco vezes durante 10 minutos a $13400 \mathrm{~g}$ numa centrífuga RF Micromax (Thermo IEC, Milford, MA, USA). Os grupos tióis presentes na superfície das NPs foram nitrosados através da adição de uma solução acidificada de $\mathrm{NaNO}_{2}$, conforme será descrito na Seção 2.5.2.2. Neste passo, 4,6mg da amostra NPMSA140 filtrada foi suspensa em $1 \mathrm{ml}$ de água deionizada, contendo $5 \mu \mathrm{l}$ de $\mathrm{HCl}$ aquoso $(6 \mathrm{mM})$. Um volume de $200 \mu \mathrm{l}$ de $\mathrm{NaNO}_{2}$ aquoso $(60 \mathrm{mM})$ foi adicionado à suspenção de NPMSA140. Após 15 min de incubação à temperatura ambiente, a solução com as NPs em suspensão foi novamente filtrada e lavada com água deionizada [38].

\subsubsection{Segunda Etapa}

O segundo estágio desta experiência foi realizado no Laboratório de Fotoquímica Inorgânica no Departamento de Química da Faculdade de Filosofia, Ciências e Letras de Riberão Preto - USP, sob a coordenação do Dr. Elia Tfouni, conjuntamente com a colaboração da Dra. Amedea Seabra (UNIFESP), e auxílio das técnicas Ivana A. Borin e Aline N. Chiba.

\subsubsection{Materiais utilizados}

Nitrito de sódio $\left(\mathrm{NaNO}_{2}\right)$ foi utilizado para nitrosação das NPs, enquanto ácido ascórbico $\left(\mathrm{C}_{6} \mathrm{H}_{8} \mathrm{O}_{6}\right)$ e hidróxido de sódio $(\mathrm{NaOH})$ foram utilizados na preparação da solução redutora, todos fornecidos pela Sigma-Aldrich. 


\subsubsection{Nitrosação das NPs recobertas com MSA e DMSA}

Diluímos 0,0454g de $\mathrm{NaNO}_{2}$ em 10ml de água milli-Q, obtendo-se uma solução de $\mathrm{NaNO}_{2}$ (65,8mM). Em seguida, 5mg de cada uma das NPs funcionalizadas com MSA ou DMSA foram suspensas em $1 \mathrm{ml}$ de água milli-Q. A última solução foi misturada com $200 \mu \mathrm{l}$ da solução de $\mathrm{NaNO}_{2}$ (Figura 2.2).

Na nitrosação das NPs funcionalizadas tanto com MSA e DMSA (denotadas por NPSH na Figura 2.2), a formação dos nitrosotióis (NP-SNO) foi imediata após a mistura da suspensão das NP-SH com a solução de nitrito de sódio, aonde a solução apresentou uma cor rosa intensa (que pode ser também laranja) [72]. Na solução de nitrito de sódio estão presentes $\mathrm{H}^{+}$e $\mathrm{NO}_{2}^{-}$. Nesta solução acidificada o nitrito $\left(\mathrm{NO}_{2}^{-}\right)$está em equilíbrio químico com o ácido nitroso, tal que:

$$
\mathrm{NO}_{2}^{-}(a q)+\mathrm{H}^{+}(a q) \leftrightarrows \mathrm{HNO}_{2}(a q)
$$

O ácido nitroso agirá como agente nitrosador dos tióis, levando a formação das nanopartículas nitrosadas (NP-SNO) (Figura 2.2.

\subsubsection{Solução redutora utilizada para medidas de detecção de NO}

A solução redutora é uma solução aquosa preparada com 5ml de ácido ascórbico (160mM) ajustando seu pH $(\sim 11)$, com NaOH $(5 \mathrm{M})$. O ácido ascórbico $(\mathrm{pH} \sim 11)$ é utilizado para fazer tanto a calibração como a medida da liberação de NO, conforme será descrito na Seção 3.10 .

O ácido ascórbico (agente redutor) em meio básico favorece a conversão do nitrosotiol em óxido nítrico, conforme será descrito na Seção 3.9, que é detectado pelo Analisador de NO. Este redutor é fraco para reduzir somente os nitrosotióis, e não nitrito ou nitrato possívelmente presentes [73]. 


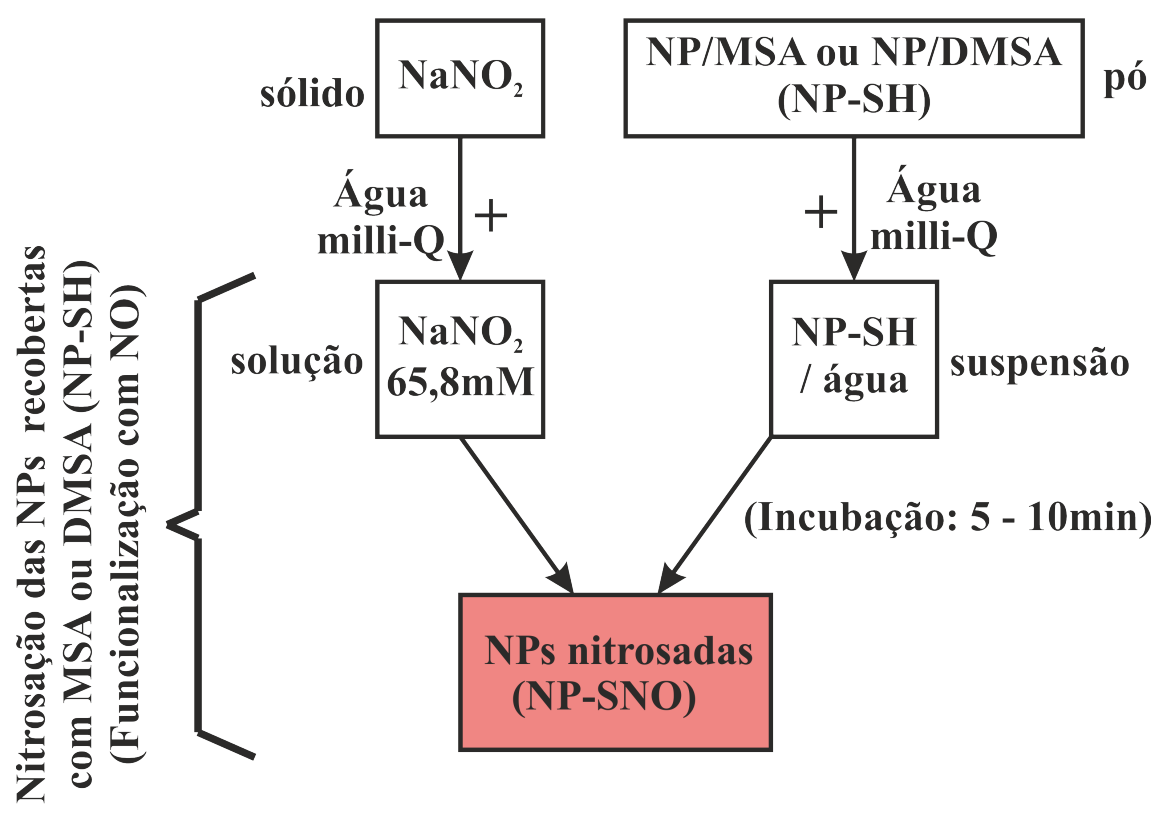

Figura 2.2: Esquema da nitrosação das NPs funcionalizadas com MSA ou DMSA (NP-SH) em solução aquosa acidificada, formando-se assim as NPs nitrosadas (NP-SNO). 



\section{Capítulo 3}

\section{Técnicas Experimentais}

\subsection{Espectroscopia Infravermelho - FTIR}

Os átomos das moléculas oscilam constantemente ao redor de suas posições de equilibrio. As amplitudes destas oscilações são extremamente pequenas $\left(10^{-10} \mathrm{a} 10^{-9} \mathrm{~cm}\right)$ e suas frequências são altas $\left(10^{13} \mathrm{a} 10^{14} \mathrm{~Hz}\right)$. Algumas destas frequências são da mesma ordem de grandeza da frequência de radiação infravermelho (comprimento de onda $\sim 10^{-5}$ a $10^{-1}$ $\mathrm{cm})$, conforme apresentado na Tabela 3.1 [74].

Tabela 3.1: Valores do comprimento de onda $(\lambda)$, número de onda $(\bar{\nu})$ e frequência $(\nu)$ na região IR. Extraído da referência [74].

\begin{tabular}{cccc}
\hline $\begin{array}{c}\text { Região } \\
\text { Infravermelho }\end{array}$ & $\lambda(\mathrm{cm})$ & $\bar{\nu}\left(\mathrm{cm}^{-1}\right)$ & $\nu(\mathrm{Hz})$ \\
\hline Próximo & $7,8 \times 10^{-5}-2,5 \times 10^{-4}$ & $4000-12800$ & $1,2 \times 10^{14}-3,8 \times 10^{14}$ \\
Médio & $2,5 \times 10^{-4}-5 \times 10^{-3}$ & $200-4000$ & $6 \times 10^{12}-1,2 \times 10^{14}$ \\
Longe & $5 \times 10^{-3}-1 \times 10^{-1}$ & $10-200$ & $3 \times 10^{11}-6 \times 10^{12}$ \\
\hline
\end{tabular}

Sabemos que a radiação eletromagnética pode ser caracterizada por seu comprimento de onda $(\lambda)$, sua frequência $(\nu)$, e seu número de onda $(\bar{\nu})$, onde:

$$
\bar{\nu}=\frac{\nu}{c / n}
$$


sendo $c$ a velocidade da luz no vácuo $\left(2,997925 \times 10^{8} \mathrm{~m} / \mathrm{s}\right)$, e $(c / n)$ a velocidade da luz no meio cujo índice de refração é $n$, no qual o comprimento de onda é medido. O índice de refração do ar é 1,0003. A frequência é independente do meio e sua unidade é Hertz $(\mathrm{Hz})$ e a unidade do número de onda $(\bar{\nu})$ é $\mathrm{cm}^{-1}$. No jargão técnico da espectroscopia de infra-vermelho (IV), o número de onda também pode ser chamado de frequência.

Uma amostra irradiada com radiação infravermelho, com número de onda $(\bar{\nu})$ variando entre 400 a $4000 \mathrm{~cm}^{-1}$, absorverá e transmitirá a radiação diferentemente para cada $\bar{\nu}$. Como resultado podemos graficar a porcentagem da radiação transmitida em função do número de onda $\bar{\nu}$, tal que bandas de absorção presentes neste gráfico são associadas a movimentos caracteríticos intramoleculares [75].

Na Tabela 3.2 apresentamos os valores do número de onda $\bar{\nu}$ reportados na literatura relativos às principais bandas de absorção esperadas neste trabalho, devido à adsorção de AO, MSA e DMSA na superfície das NPs de óxido de ferro.

Tabela 3.2: Modos vibracionais IV usados para análise de espectros das NPs de magnetita.

\begin{tabular}{|c|c|c|c|}
\hline Ligação & $\begin{array}{c}\text { Modo } \\
\text { Vibracional }\end{array}$ & $\begin{array}{c}\bar{\nu} \\
\left(\mathbf{c m}^{-1}\right)\end{array}$ & Referência \\
\hline \multirow{2}{*}{$\mathrm{Fe}-\mathrm{O}-\mathrm{Fe}$} & estiramento & $566-632$ & [18, 76, 77, 78] \\
\hline & deformação & $400-440$ & 77, 78 \\
\hline \multirow{2}{*}{$\mathrm{O}-\mathrm{H}$} & deformação & $920-1640$ & [20, 79 \\
\hline & estiramento & $3400-3500$ & [20, 49] \\
\hline $\mathrm{C}-\mathrm{O}$ & estiramento & $1000-1300$ & 20 \\
\hline $\begin{array}{c}\mathrm{COO}^{-} \\
\text {(simétrico-assimétrico) }\end{array}$ & estiramento & $1520-1600$ & [20, 80, 81] \\
\hline $\mathrm{S}-\mathrm{H}$ & estiramento & $2548-2570$ & {$[74,79,82,83$} \\
\hline
\end{tabular}




\section{$3.2 \quad$ Parte Experimental - FTIR}

As medidas FTIR foram realizadas em um Espectrômetro Shimadzu Prestige-21 (Shimadzu Corporation, Kyoto, Japan) com uma resolução de $2 \mathrm{~cm}^{-1}$; as medidas foram realizadas na Central de Análises da UNIFESP-Diadema. As medidas foram realizadas em pastilhas de $\mathrm{KBr}$ que apresentam transparência ao infravermelho na região de $400-4000 \mathrm{~cm}^{-1}$. Neste contexto, nanopartículas em pó foram trituradas com KBr (espectroscópico, de alta pureza). Para se formar as pastilhas, a mistura foi colocada em uma prensa hidráulica, ao mesmo tempo que o ar foi extraído com uma bomba mecânica.

Antes de se realizar cada medida de FTIR das NPs, realizamos uma medida de background (do ar), que foi descontada automáticamente pelo software do equipamento, obtendose assim o espectro de FTIR para cada uma das amostras analisadas. 


\subsection{Difração de Raios X - DRX}

A Difração de Raios X (X-Ray Diffraction ou XRD) desempenha um papel importante dentre as técnicas de determinação das propriedades estruturais de muitos materiais orgânicos e inorgânicos. Os difratogramas experimentais permitem a identificação de compostos cristalinos, bem como a determinação dos parâmetros de rede, tamanho de grão cristalino, orientação preferencial e grau de cristalinidade dos materiais.

O fenômeno de difração ocorre quando uma onda eletromagnética incide num conjunto de objetos espalhadores regularmente espaçados (apresentado na Figura 3.1) e quando o comprimento de onda da radiação é da mesma ordem de magnitude das distâncias entre os centros espalhadores [43], ou seja, da ordem de Angstrom para átomos e raios X. As primeiras considerações sobre o fenômeno de difração de raios X em cristais foram feitas pelo físico alemão Max von Laue em 1912. Num cristal, os centros espalhadores são formados por átomos contidos em planos virtuais, os quais são denominados planos cristalográficos e indexados através dos índices de Miller $(h k l)$, separados uma distância $\left(d_{h k l}\right)$. Por meio de relações geométricas entre o feixe incidente e o feixe difratado pelos planos, W. L. Bragg formulou a equação através da qual é possível obter o espaçamento entre os planos cristalinos sabendo-se o ângulo de incidência e o comprimento de onda do feixe incidente, conhecida como a lei de Bragg, e dada por [43]:

$$
n \lambda=2 d_{h k l} \operatorname{Sen} \theta_{h k l}
$$

onde:

$$
\begin{array}{llll}
n: & \begin{array}{l}
\text { ordem da difração } \\
\text { (normalmente considera-se } n=1) .
\end{array} & \lambda: & \begin{array}{l}
\text { comprimento de onda } \\
\text { da radiação incidente. }
\end{array} \\
d_{h k l}: & \text { distância interplanar. } & \theta_{h k l}: & \text { metade do ângulo de difração medido }
\end{array}
$$

Assim, num difratograma de R-X, conhecendo-se $\lambda$, para cada $\theta_{h k l}$ medido experimentalmente, determina-se o correspondente espaçamento interplanar $\mathrm{d}_{h k l}$. 


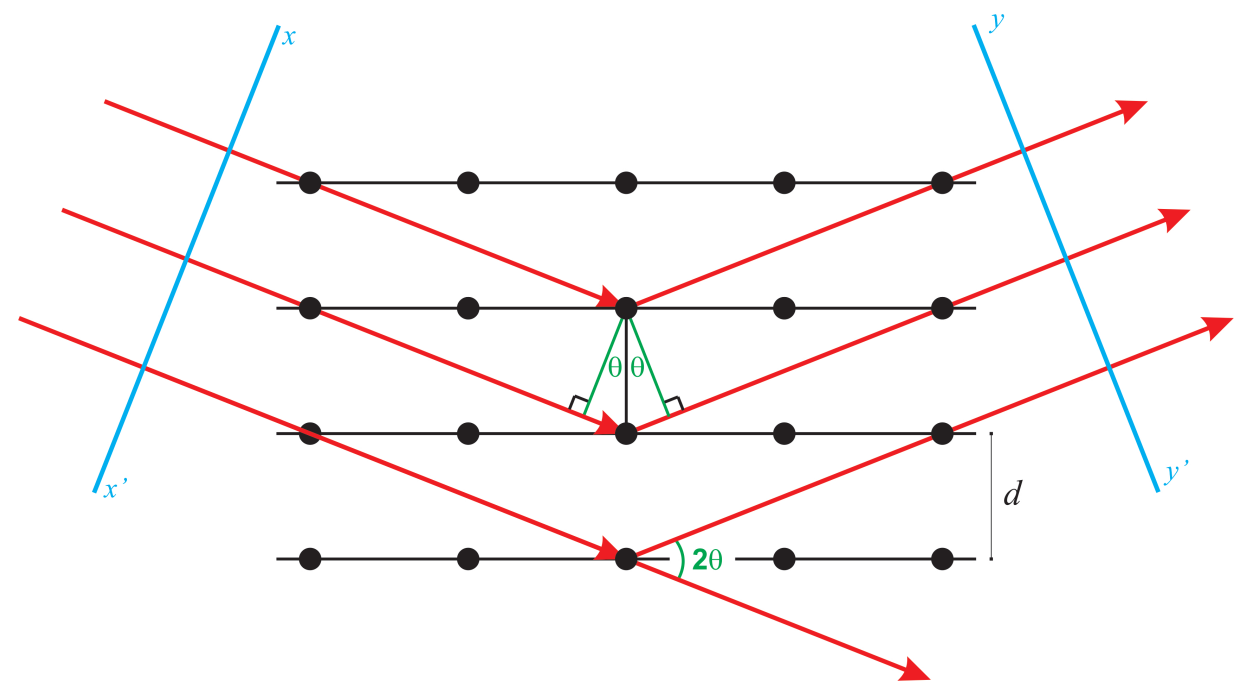

Figura 3.1: Interação dos Raios-X com os planos cristalográficos (com uma distância $d$ ) em um cristal, com frentes de onda $x x^{\prime}$ e $y y^{\prime}, \operatorname{com} \theta$ como ângulo de Bragg. Figura extraída da referência [43].

\subsection{Parte Experimental - DRX}

A identificação estrutural das amostras foi realizada através de medidas de Difração de Raios X (XRD - "X-Ray Diffraction") no Laboratório de Cristalografia do Instituto de Física da USP. O equipamento usado consiste de um difratômetro de pó da Rigaku-Denki (Rint2000) com um gerador de raios X convencional. A janela de saída dos raios X dispõe de um monocromador montado sobre um sitema de colimação para selecionar a radiação característica $\mathrm{CuK}_{\alpha}(\lambda=1,5418 \AA)$.

As NPs em pó são compactadas sobre uma lâmina de vidro em uma área de $\sim 2 \mathrm{~cm}^{2}$. $\mathrm{O}$ feixe de raios $\mathrm{X}$ difratado é registrado por um detetor de cintilação. A varredura angular compreendeu o intervalo de $20^{\circ}$ a $70^{\circ}$ com passos de $0,05^{\circ}$ a cada 5 segundos. Durante o tempo da medida, o difratômetro foi mantido nas condições de $40 \mathrm{kV}$ e $30 \mathrm{~mA}$. O espalhamento difuso do substrato de vidro foi subtraido como uma linha de base de cada difratograma.

Como vimos na Introdução (Seção 1.1) a estrutura da magnetita é cúbica de face centrada $(F \overline{3} d m)$, tal que o parâmetro de rede pode ser obtido a partir das reflexões de Bragg (hkl) [43]: 


$$
d_{h k l}=\frac{a}{\sqrt{h^{2}+k^{2}+l^{2}}}
$$

A partir das Equações 3.2 e 3.3 , o parâmetro de rede (a) numa cela cúbica é dado por:

$$
a=\frac{\lambda}{2 \operatorname{sen} \theta_{h k l}} \sqrt{h^{2}+k^{2}+l^{2}}
$$

Supondo que um cristal tenha uma certa espessura na direção perpendicular a um conjunto particular de planos de Bragg, os raios X incidentes chegam em cada um dos planos formando ângulos iguais ao ângulo de Bragg $\theta_{B}$, e alguns outros raios formam ângulos maiores e menores ao ângulo de Bragg. Como resultado, o pico de difração apresenta uma certa largura, que aumenta com a diminuição da espessura do cristal [43], como representado na Figura 3.2 .

O tamanho de grão cristalino $\left(\mathrm{D}_{R X}\right)$ pode ser obtido através da fórmula de Scherrer, tal que [43]:

$$
D_{R X}=\frac{0,89 \lambda}{\beta_{h k l} \operatorname{Cos} \theta_{h k l}}
$$

onde $\beta_{h k l}$ é a largura a meia altura do pico de difração, desconvoluido do alargamento instrumental $b$. Considerando que o pico de difração possa ser ajustado através de uma função Lorentziana (Equação 3.8), a largura a meia altura é (Figura 3.2):

$$
B^{2}=\beta_{h k l}^{2}+b^{2}
$$

Na fórmula de Scherrer (Equação 3.5), temos:

$$
D_{R X}=\frac{0,89 \lambda}{\sqrt{B^{2}-b^{2}} \operatorname{Cos} \theta_{h k l}}
$$

A função Lorentziana $\mathrm{L}_{(x)}$ (Equação 3.8] [49] é dada por:

$$
\mathrm{L}_{(x)}=\frac{1}{\pi} \frac{\Gamma / 2}{\left(x-x_{0}\right)^{2}+(\Gamma / 2)^{2}}
$$

onde:

$\Gamma$ : largura a meia altura.

$x_{0}$ : centro da função. 


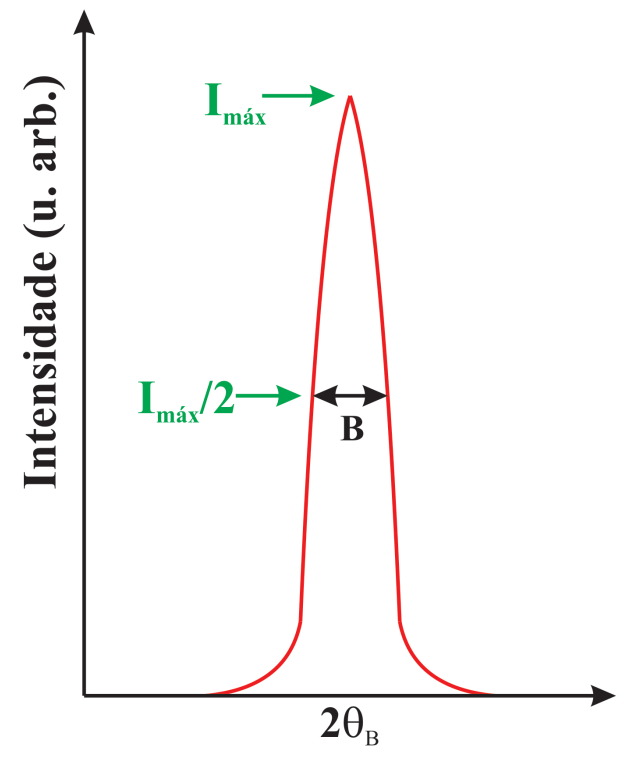

$\mathbf{a}$

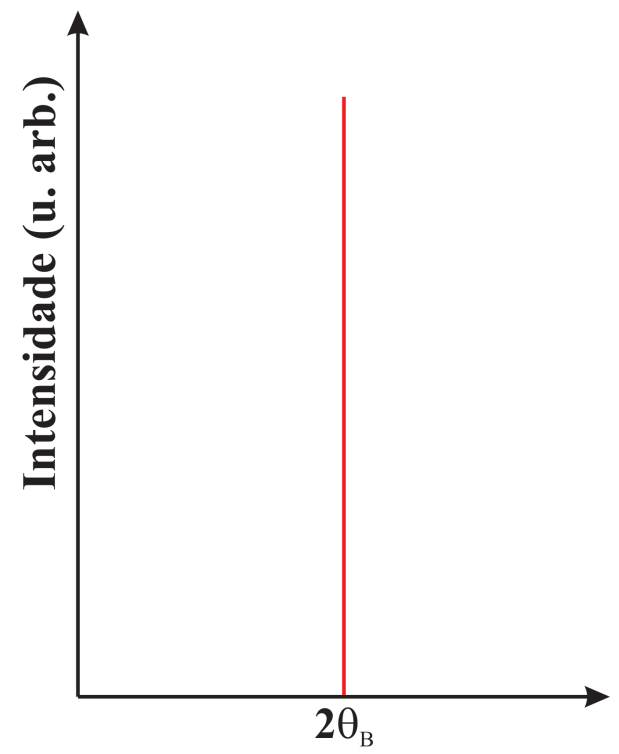

b

Figura 3.2: Efeito do tamanho de cristalito na curva de difração; a. Aumento da largura da curva de difração devido à diminuição da espessura do cristal. b. Pico de difração ideal no ângulo de Bragg que indica a distância entre os planos cristalinos. Extraído da referência [43].

No nosso caso, a largura a meia altura é $\Gamma=B$ ou $b$, dependendo se estamos considerando o pico de difração do difratograma obtido das NPs ou o alargamento instrumental obtido a partir de uma amostra de silício policristalino (fornecido no laboratório), respectivamente.

A identificação estrutural das NPs analisadas foi realizada comparando-se os difratogramas experimentais obtidos com o padrão cristalográfico disponível na ficha cristalográfica JCPDF 19-0629 (Figura 1.4). 


\subsection{Microscopia Eletrônica de Transmissão - MET}

No estudo de sistemas nanoestruturados é necessário conhecer a distribuição de tamanhos da nanopartícula. Para tal finalidade, no presente trabalho foi utilizada a técnica de Microscopia Eletrônica de Transmissão (MET) para, além de analisarmos a morfologia das NPs sintetizadas, podermos avaliar sua distribuição de tamanhos.

O Microscópio Eletrônico tem dois modos de operação: campo claro e campo escuro. Destas duas modadlidades a primeira é a mais comumente usada. Na formação da imagem em campo claro, o feixe direto não espalhado pela amostra atinge o plano da imagem, enquanto que as regiões escuras correspondem às regiões de maior espalhamento de elétrons (menor número de eletróns chega ao plano imagem). Na outra modalidade (campo escuro), a formação da imagem ocorre com o feixe direto sendo interceptado antes de atingir o plano da imagem (regiões escuras da imagem) e os elétrons espalhados pela amostra são direcionados para o sistema de formação da imagem final (regiões claras da imagem). A modalidade de campo escuro permite a observação dos planos cristalinos do material através de suas reflexões de Bragg, pois a imagem é formada apenas pelos elétrons espalhados pelo plano cristalino desejado [49]. Esta modalidade não foi utilizada neste trabalho.

Conforme mencionado, a análise de uma micrografia eletrônica nos permite avaliar a distribuição de tamanhos das NPs formadas. Os correspondentes histogramas de distribuição de tamanhos, podem ser ajustados por uma função Log-Normal (Equação 3.9] [84]:

$$
\mathrm{f}_{\mathrm{LN}}(d)=\frac{1}{\sigma \sqrt{2 \pi}} \frac{1}{\mathrm{~d}} \exp \left(-\frac{1}{2}\left(\frac{\log \left(\mathrm{d} / \mathrm{d}_{0}\right)}{\sigma}\right)^{2}\right)
$$

onde $\mathrm{f}_{\mathrm{LN}}$ indica a função de densidade da probabilidade (PDF do inglês Probability Distribution Function) das nanopartículas ter um diâmetro d; $\mathrm{d}_{0}$ é a mediana (posição que separa a população na metade $50 \%$ acima e $50 \%$ abaixo de um certo tamanho d) e $\sigma_{T E M}$ é o desvio padrão, conforme apresentados na Figura 3.3 . 
Existem três parâmetros importantes na análise de tamanhos através de uma função Log-Normal $\left(\mathrm{f}_{\mathrm{LN}}\right)$, indicados na Figura 3.3. São eles:

1. Valor típico: posição do máximo da densidade de probabilidade;

$$
\mathrm{D}_{T E M}=\mathrm{d}_{0} e^{\left(-\sigma_{T E M}^{2}\right)}
$$

2. Mediana $\left(\mathrm{d}_{0}\right)$, indica uma posição de equilíbrio da população;

3. Valor médio: centro de gravidade da distribuição.

$$
<\mathrm{D}_{T E M}>=\mathrm{d}_{0} e^{\left(-\frac{\sigma_{T E M}^{2}}{2}\right)}
$$

Quando os três valores anteriormente mencionados são iguais, a distribuição é simétrica. No caso da Figura 3.3 apresentamos uma distribuição Log-Normal assimétrica.

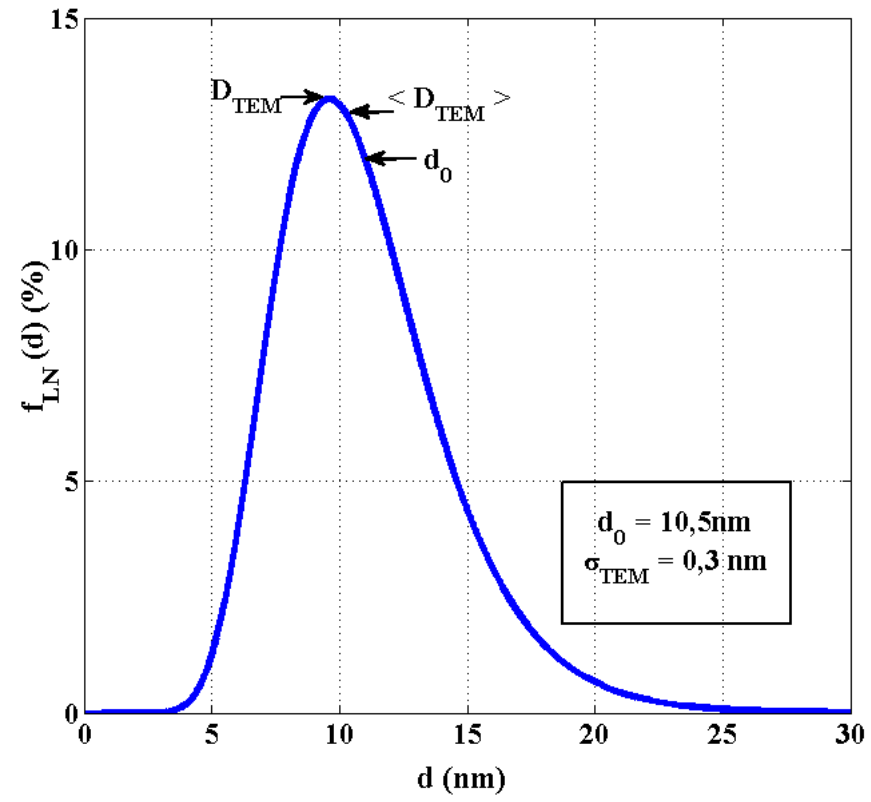

Figura 3.3: Distribuição Log-Normal da densidade de probabilidade de diâmetros representada através de $\mathrm{f}_{\mathrm{LN}}$ (Equação 3.9), indicando os valores típico $\left(\mathrm{D}_{T E M}\right)$, mediano $\left(\mathrm{d}_{0}\right)$ e médio $\left(\left\langle\mathrm{D}_{T E M}\right\rangle\right)$. 


\subsection{Parte Experimental - MET}

A identificação da morfologia das NPs e distribuição de tamanhos foi realizada utilizandose um Microscópio Eletrônico Jeol 220 com um canhão termoiônico de $\mathrm{LaB}_{6}$, com uma voltagem de trabalho de $150 \mathrm{kV}$, no Laboratório de Microscopia Eletrônica do Instituto de Física da Universidade de São Paulo. Este microscópio eletrônico dispõe de cinco lentes magnéticas: uma objetiva, duas condensadoras e duas projetoras.

As NPs colocadas no MET foram primeiro diluidas em água e/ou tolueno. As NPs recobertas com MSA e DMSA foram diluídas em água, devido ao comportamento hidrofílico (NPMSA110, NPMSA140, NPMSA180, NPDMSA110, NPDMSA140 e NPDMSA180), enquanto as NPs diluidas em tolueno, devido ao comportamento hidrofóbico, foram as amostras NP e NPAO.

Após as NPs serem diluídas no respectivo solvente, uma gotícula de cada diluição foi pipetada sobre grades de cobre de $3 \mathrm{~mm}$ de diâmetro recobertas com uma camada fina de parlodion $\left(\mathrm{C}_{12} \mathrm{H}_{16} \mathrm{~N}_{4} \mathrm{O}_{18}\right)$, as quais foram inseridas no MET.

De cada uma das micrografias obtidas, foram consideradas aproximadamente entre 200 e 400 nanopartículas de cada imagem cujos diâmetros foram avaliados pelo programa de análise de imagens "ImageJ v.1.45s". A partir dos resultados foi possível construir um histograma de distribuição de tamanhos que apresenta o comportamento típico de uma função Log-Normal $\left(\mathrm{f}_{\mathrm{LN}}\right)$ apresentado na Equação 3.9 [84].

As micrografias foram realizadas em duplicata para cada uma das NPs mencionadas neste trabalho. 


\subsection{Magnetometria de Amostra Vibrante - VSM}

Na técnica de magnetometria de amostra vibrante (VSM do inglês Vibrate Sample Magnetometry), um material magnético é colocado em um campo magnético uniforme (no nosso caso, entre os pólos de um eletroimã), inicialmente com campo magnético nulo $(\mathbf{H}=\mathbf{0})$ e o material desmagnetizado, com o qual a magnetização é nula $(\sigma=0)$. Com o aumento do campo magnético, os momentos magnéticos se alinhan produzindo um incremento no momento magnético $\mu$, e do mesmo modo na magnetização até atingir um valor constante, chamada magnetização específica de saturação $\left(\sigma_{s}\right)$. Nesta condição, pode se afirmar que todos (ou a grande maioria) dos momentos magnéticos do material estão alinhados na mesma direção com o campo H. No caso de materiais ferri ou ferromagnéticos, quando o campo magnético é reduzido até zero, a partir da saturação, a magnetização não se reduz a zero (Figura 3.4 a). Ao invés disto, o material permanece magnetizado, o qual é caracterizado por uma magnetização remanente $\sigma_{r}$. Invertendo a direção do campo magnético, a magnetização começa a se reduzir até atingir um valor de $\mathrm{H}$ onde a magnetização é nula (i.e., total desordem dos momentos magnéticos). Este valor do campo é chamado de campo magnético coercivo $\left(\mathbf{H}_{C}\right)$. O módulo do campo continua aumentando em direção oposta até que a magnetização atinge um valor valor mínimo $-\sigma_{s}$, e este ciclo vai se repetir. Esta curva $(\sigma \times$ H) é chamada de curva de histerese. Como comentado na Introdução (Seção 1.2), no caso de nanopartículas superparamagnéticas, espera-se que $\sigma_{r}=0$ e $\mathrm{H}_{C}=0$ (Figura 3.4 b). Maiores detalhes podem ser encontrados nas referências [45, 46, 47].

Como visto na Introdução, no caso de um conjunto de nanopartículas que apresentam uma certa polidispersão, a partir da Equação 1.17 temos que o momento magnético total das NPMs depende do seu tamanho e de sua magnetização de saturação, tal que [85]:

$$
\mu=\mathrm{N}_{T} \int_{0}^{\infty} M_{s} V L\left(\frac{\mu_{0} M_{s} \pi \mathrm{d}_{m a g}^{3} \mathrm{H}}{6 k_{B} T}\right) \mathrm{f}_{\mathrm{LN}}\left(\mathrm{d}_{m a g}\right) d\left(\mathrm{~d}_{\text {mag }}\right)
$$

A função $\mathrm{f}_{\mathrm{LN}}$ (Equação 3.9 é a função de distribuição de probabilidade de tamanhos das nanopartículas magnéticas representada por um diâmetro magnético característico $\left(\mathrm{d}_{\text {mag }}\right)$. 
onde:

$\mathrm{N}_{T}$ : número de nanopartículas magnéticas num volume $\mathrm{V}$.

$\mu_{0}$ : permeabilidade magnética do vácuo $\left(4 \pi \times 10^{-7} \mathrm{Tm} / \mathrm{A}\right)$.

$T$ : temperatura do sistema $(\mathrm{K})$.

d: diâmetro das nanopartículas magnéticas (nm).

$\mathrm{d}_{\text {mag }}$ : valor mediano do diâmetro das nanopartículas magnéticas (nm).

H: módulo do campo magnético aplicado no VSM (kOe).

A partir da Equação 3.12 ajustamos os momentos magnéticos das NPs obtidas experimentalmente, resultando na distribuição de tamanhos das mesmas (Seção 4.4).

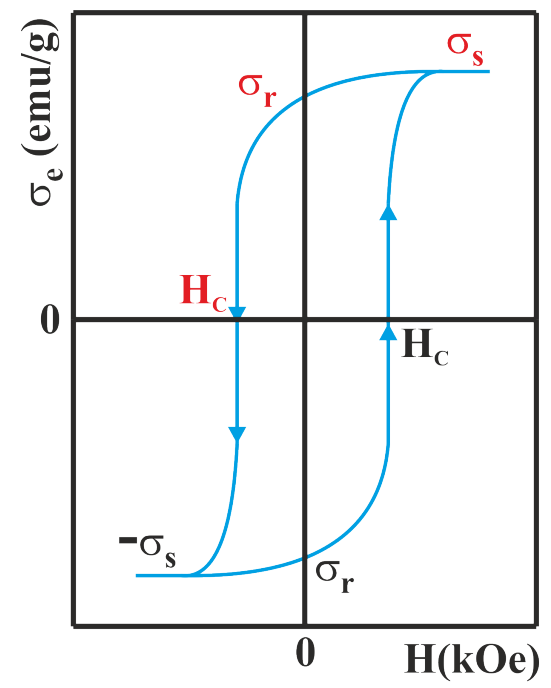

a.

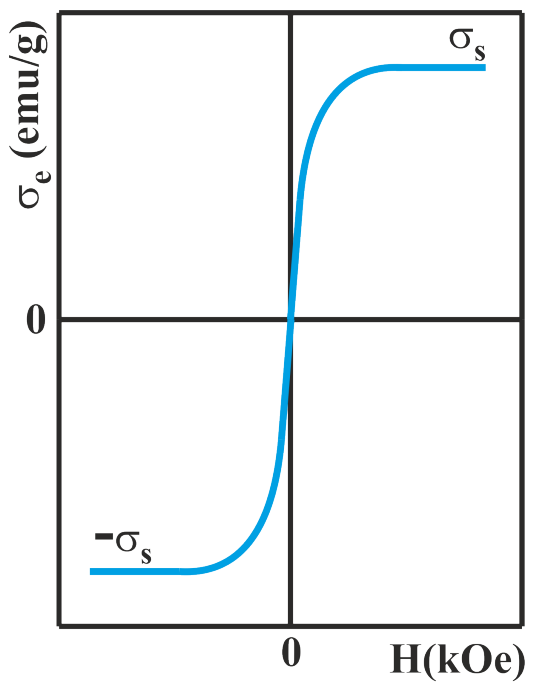

b.

Figura 3.4: a. Curva de histerese de um ferrimagneto ou ferromagneto, indicando sua magnetização específica de saturação $\left(\sigma_{s}\right)$, e campo coercivo $\left(\mathrm{H}_{C}\right)$, assim como sua magnetização específica remanente $\left(\sigma_{r}\right)$, b. Curva de histerese para um material superparamagnético $\left(\mathrm{H}_{C}\right.$ $=0$ e $\left.\sigma_{r}=0\right)[47]$. 


\subsection{Parte Experimental - VSM}

A caracterização das propriedades magnéticas das NPs foram realizadas no Magnetômetro de Amostra Vibrante (VSM - Vibrating Sample Magnetometer) Modelo EGG550 no Laboratório de Materiais Magnéticos do Instituto de Física da Universidade de São Paulo (IF-USP).

A magnetização específica $\sigma_{e}(\mathrm{em}$ emu/g) é obtida dividindo-se o momento magnético pela massa da amostra (Equação 1.4). O equipamento experimental foi calibrado com um material de momento magnético total $(\mu)$ conhecido, neste caso com Niquel $\left(\mu_{s}=1,883 \mathrm{emu}\right)$, fornecido no laboratório.

Numa primeira etapa, as NPMs ( 10-20mg) foram colocadas em frascos de acrílico, que apresentam um comportamento diamagnético, e não interferem na medida do momento magnético das NPs. Numa segunda etapa foram utilizados canudos de plástico, devido a uma melhora no sinal detectado. Cada medida experimental de VSM foi realizada $\sim 30$ min, no qual a varredura do campo magnético foi de -20kOe a $20 \mathrm{kOe}$.

Após a calibraçaõ do equipamento de VSM, colocamos as NPs no interior do campo magnético fornecido pelo eletroimã (-20kOe-20kOe); o aparelho registra a mudança dos valores do momento magnético com respeito ao campo magnético. A partir destes valores calculamos a magnetização específica de saturação, que são apresentados na Seção 4.4 . Os resultados obtidos por VSM foram realizados em duplicata. 


\subsection{Liberação de NO}

A liberação de NO em fase gasosa é quantificada através de uma reação de quimioluminescência [55, 56]. O reagente mais usado em quimioluminescência em fase gasosa é o ozônio, de tal maneira que:

$$
\begin{gathered}
\mathrm{NO}+\mathrm{O}_{3} \longrightarrow \mathrm{NO}_{2}^{*}+\mathrm{O}_{2} \\
\mathrm{NO}_{2}^{*} \longrightarrow \mathrm{NO}_{2}+\mathrm{h} \nu
\end{gathered}
$$

A última reação exotérmica libera $200 \mathrm{~kJ} / \mathrm{mol}$, correspondente aos fótons emitidos num intervalo de comprimentos de onda ente 600 e 3000nm. Para comprimentos de onda menores a 800nm, os fótons liberados, na faixa de $600 \mathrm{~nm}$ a $800 \mathrm{~nm}$, são detetados com alta eficiência quântica, o que significa que só uma fração pequena é emitida e detectada eficientemente [86].

\subsubsection{Medida de Quimioluminescência}

A Figura 3.5 apresenta um esquema representativo do experimento realizado para detectar a liberação de óxido nítrico de moléculas ou nanopartículas contendo grupos nitrosotióis (representados aqui por R-SNO). Injeta-se uma solução com R-SNO dentro de uma célula (balão) contendo ácido ascórbico (solução redutora); como consequência, libera-se óxido nítrico (NO) em atmosfera inerte devido à presença do $\mathrm{N}_{2}$ na célula. A pressão da célula é de 5 a 6 Torr, mesma pressão do cilindro de $\mathrm{N}_{2}$. $\mathrm{O} \mathrm{N} \mathrm{N}_{2}$ é também responsável pelo arrastre do NO liberado dentro do equipamento. Este evita a possível oxidação dos compostos gerados na célula. Durante a medida de liberação de NO, o equipamento encontra-se numa sala escura. 


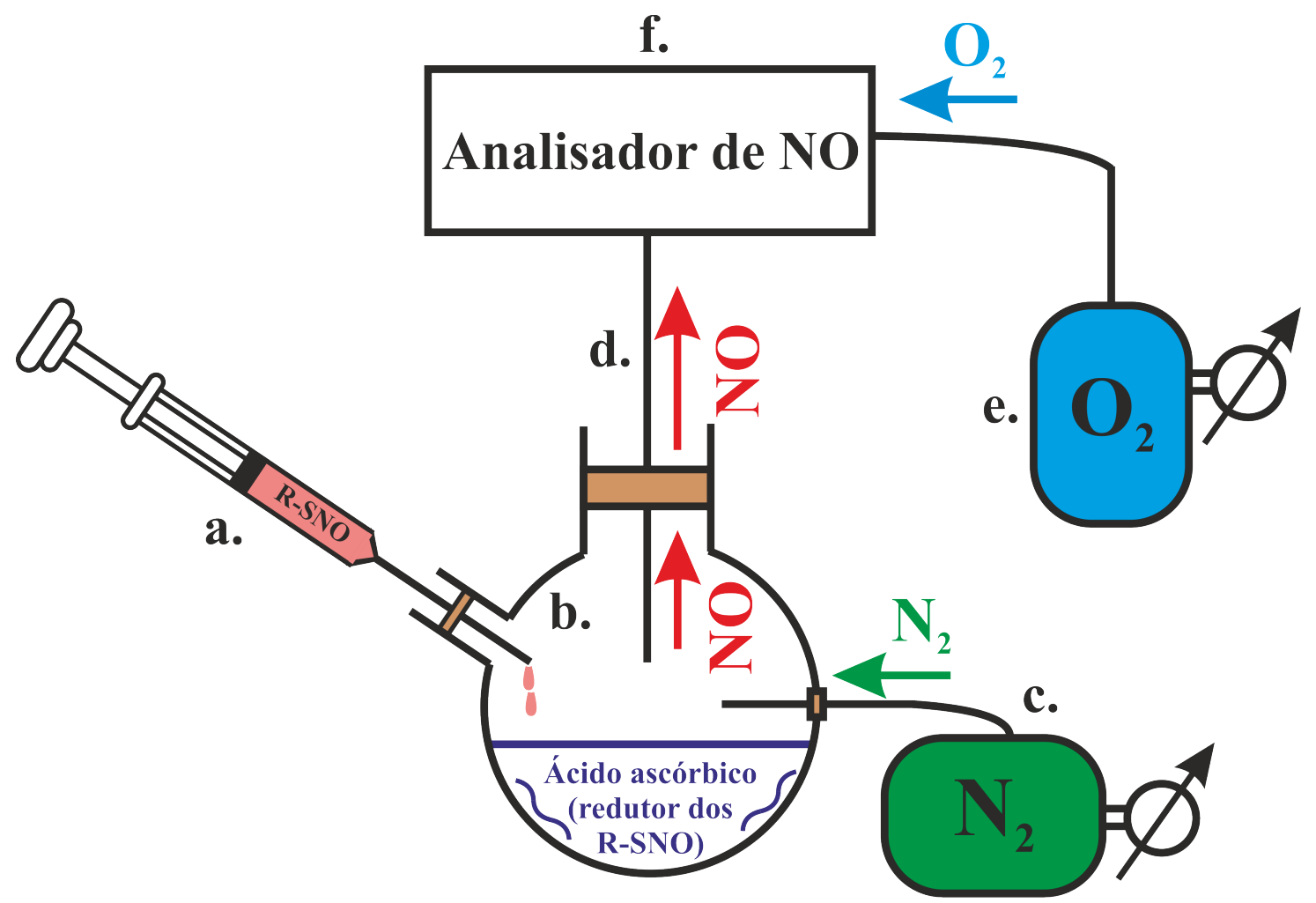

Figura 3.5: Esquema da liberação de NO no Analisador do Óxido Nítrico. a. Seringa utilizada para injetar soluções contendo nitrosotióis (R-SNO), b. Balão de vidro (célula do Analisador de NO) contendo ácido ascórbico (solução redutora dos R-SNO) na mesma pressão do $\mathrm{N}_{2}$, c. Cilindro de $\mathrm{N}_{2}$ a pressão de 5 - 6 Torr, d. Mangueira através da qual o NO liberado na célula vai para o Analisador de NO, e. Cilindro contendo $\mathrm{O}_{2}$ a pressão 421 Torr, f. Analisador de NO.

No interior do equipamento, o $\mathrm{O}_{2}$ fornecido pelo cilindro é mantido numa pressão de 6,1 psig (420,60 mbar). A partir do oxigênio inserido no equipamento é gerado o ozônio $\left(\mathrm{O}_{3}\right)$, que reage com o óxido nítrico formando-se como produto óxido nitroso excitado $\left(\mathrm{NO}_{2}^{*}\right)$ e oxigênio molecular $\left(\mathrm{O}_{2}\right)$, apresentado na Equação 3.13. O óxido nitroso excitado produz a liberação de energia proveniente do decaimento do elétron para um estado de menor energia formando-se $\mathrm{NO}_{2}$ (Equação 3.14). Este processo descrito corresponde ao mecanismo de quimioluminescência. O fóton liberado é detectado no interior do Analisador de NO, como representa o esquema na Figura 3.6 . 


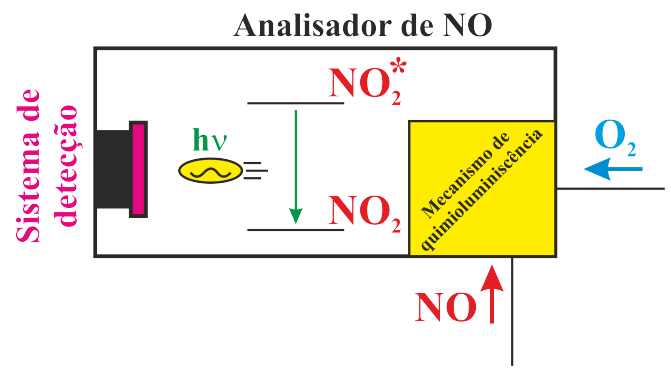

Figura 3.6: Mecanismo de quimioluminescência no interior do Analisador do NO. A liberação de energia proveniente do decaimento do $\mathrm{NO}_{2}^{*}$ para $\mathrm{NO}_{2}$ correspondente a um estado de menor energia produz um fóton com energia $\mathrm{h} \nu$, detectado pelo equipamento.

A quantidade de corrente redox (produzida no mecanismo de quimioluminescência) é típicamente gerada pela oxidação do $\mathrm{NO}$ (liberado pelos R-SNO) em $\mathrm{NO}_{2}$ (obtido depois da emissão do fóton). Em sistemas biológicos é extremamente pequena (da ordem de 1 10 pA). Então, o desenvolvimento de eletrodos para detecção amperimétrica de NO requer uma alta sensibilidade eletrônica e um circuito de ultra amplificação de baixo ruido [50].

O sinal devido à liberação do fóton é convertido no Analisador num sinal de voltagem $(\mathrm{mV})$. A quantidade de fótons chegando no detector é proporcional ao número de moles de NO que se oxidam no mecanismo de quimioluminescência. Pode-se dizer então que a partir de um volume inserido dos R-SNO, obtém-se uma certa quantidade de fótons (associada ao número de moles liberado de NO). Consequentemente, o sinal de voltagem $(\mathrm{mV})$, registrado no Analisador de NO, é diretamente proporcional à concentração de NO liberado pelos RSNO.

Como resultado deste processo, o Analisador do NO fornece a mudança do sinal de voltagem $(\mathrm{mV})$ em relação ao intervalo de tempo (min) medido. Este potenciograma (V-t) permite interpretar a medida de liberação de NO, em função do tempo, a partir de um volume dos R-SNO inserido na célula do equipamento (Figura 3.7).

Quanto mais vertical o pico (subida ou descida), significa uma detecção mais rápida no tempo; o processo de detecção é mais lento quando o pico apresenta uma certa largura, como apresentado na Figura 3.7 . 


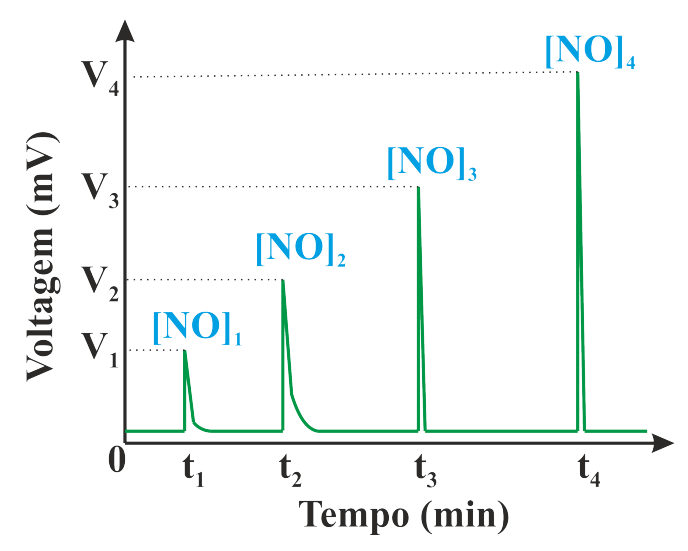

Figura 3.7: Esquema do potenciograma (V-t) obtido do Analisador de NO. Cada pico no potenciograma está relacionado com a concentração do óxido nítrico ([NO]) liberado a partir dos volumes $\left(\mathrm{V}_{R-S N O}\right)$ dos R-SNO injetados na célula do equipamento (Figura 3.5).

A área dos picos representa a concentração de óxido nítrico detectado. Para calcular esta área, delimitamos manualmente o início, fim e base dos picos. Feito isso, o programa Liquid (software do equipamento) faz a integração e converte o resultado em concentração (Figura 3.8). Como sabemos o volume de R-SNO injetado e sua concentração, podemos obter como resultado a concentração molar de NO liberado ou o número de moles.

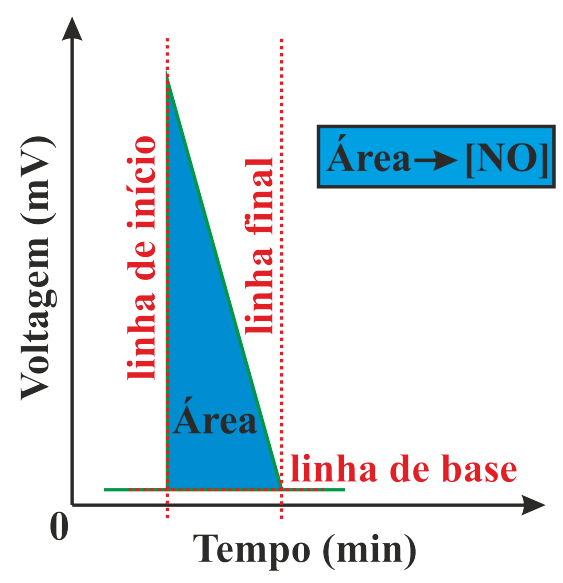

Figura 3.8: Delimitação manual da linha de início, linha final e linha de base para cada pico através do software ( Liquid) do equipamento. A área encerrada pelo potenciograma, e entre as linhas de delimitação para a integração. O software faz a integração e converte a área integrada em concentração (em $\mu \mathrm{M})$. 


\subsection{Parte Experimental - Liberação de NO}

Na primeira etapa deste trabalho, a calibração do equipamento assim como a medida de liberação de NO foram realizadas no Laboratório de Fisicoquímica do Instituto de Química da Universidade de Campinas (IQ-UNICAMP). O equipamento utilizado foi um analisador de quimioluminescencia de NO (NOA 280i, GE Analytical, Boulder, CO, USA).

Na segunda parte deste trabalho, a calibração assim como a medida de liberação de NO foram realizadas no Laboratório de Fotoquímica-Inorgânica no Departamento de Química da Faculdade de Filosofia, Ciências e Letras de Riberão Preto - USP. O equipamento utilizado foi um analisador de quimioluminescência de NO (Sievers 280i Nitric Oxide Analyser - General Electric, USA).

Para ambos analisadores de NO, o limite inferior de detecção é de $1 n M$.

\subsubsection{Calibração do Analisador de NO}

Para realizar a curva de calibração do Analisador de NO foi utilizada uma solução padrão (solução estoque) contendo R-SNO. A partir da curva de calibração, pode-se medir a liberação de NO de alguma outra solução contendo R-SNO.

\subsubsection{Primeira Etapa}

Na primeira etapa, as curvas de calibração foram obtidas com soluções aquosas de Sglutatotiona (solução estoque), que foram preparadas no momento da realização da medida e imediatamente inseridas no Analisador de NO [38].

\subsubsection{Segunda Etapa}

Utilizamos uma solução equimolar de MSA e $\mathrm{NaNO}_{2}$. Com esta finalidade, foram dissolvidos $0,015 \mathrm{~g}$ de MSA ( $\mathrm{n}=0,0001 \mathrm{~mol})$ em $1 \mathrm{~mL}$ de água milli-Q, resultando em uma concentração de 0,1M; adicionamos, então, 0,0069g de $\mathrm{NaNO}_{2}(\mathrm{n}=0,0001 \mathrm{~mol})$. A solução obtida apresentou uma cor rosa intenso, o qual indicou a presença dos S-nitrosotióis (R-SNO) [72]. A solução foi então diluída a $100 \mu \mathrm{M}$ (solução estoque).

A partir da solução estoque foram injetados no equipamento volumes crescentes $(1 \mu \mathrm{l}, 3 \mu \mathrm{l}$, $5 \mu \mathrm{l}$ e $7 \mu \mathrm{l}$ ) com a finalidade de calibrar o equipamento. O analisador forneceu as concentrações de NO liberado ([NO]) para cada injeção, conforme apresentado na Tabela 3.3 . 
Tabela 3.3: Volume injetado da solução estoque e o número de moles correspondentes, assim como a concentração do NO liberado ([NO]) fornecida pelo equipamento.

\begin{tabular}{ccc}
\hline $\begin{array}{c}\text { Volume injetado da } \\
\text { solução estoque de } 100 \mu \mathrm{M} \\
(\mu \mathrm{l})\end{array}$ & $\begin{array}{c}\text { Número de moles } \\
\text { correspondentes } \\
(\mathrm{mol})\end{array}$ & $\begin{array}{c}{[\mathrm{NO}]} \\
(\mu \mathrm{M})\end{array}$ \\
\hline 1 & $1 \times 10^{-10}$ & 457,9 \\
3 & $3 \times 10^{-10}$ & 1288,9 \\
5 & $5 \times 10^{-10}$ & 1734,4 \\
7 & $7 \times 10^{-10}$ & 3305,0 \\
\hline
\end{tabular}

Com os dados da Tabela 3.3, construimos uma curva de calibração do equipamento (Figura 3.9). A partir desta curva, determinou-se um fator de correção experimental para a concentração nominal da solução estoque e a indicada pelo aparelho devido à quantificação de liberação de NO (área do pico no potenciograma, Figura 3.8). No caso de MSA, para uma solução estoque de $100 \mu \mathrm{M}$ de R-SNO, o Analisador de NO resultou numa concentração de $106,24 \mu \mathrm{M}$. Portanto, aplicamos um fator de correção de 0,94 para as concentrações fornecidas pelo aparelho das concentrações molares de NPs nitrosadas. No caso de NPs funcionalizadas com DMSA, o fator de correção foi de 0,88 .

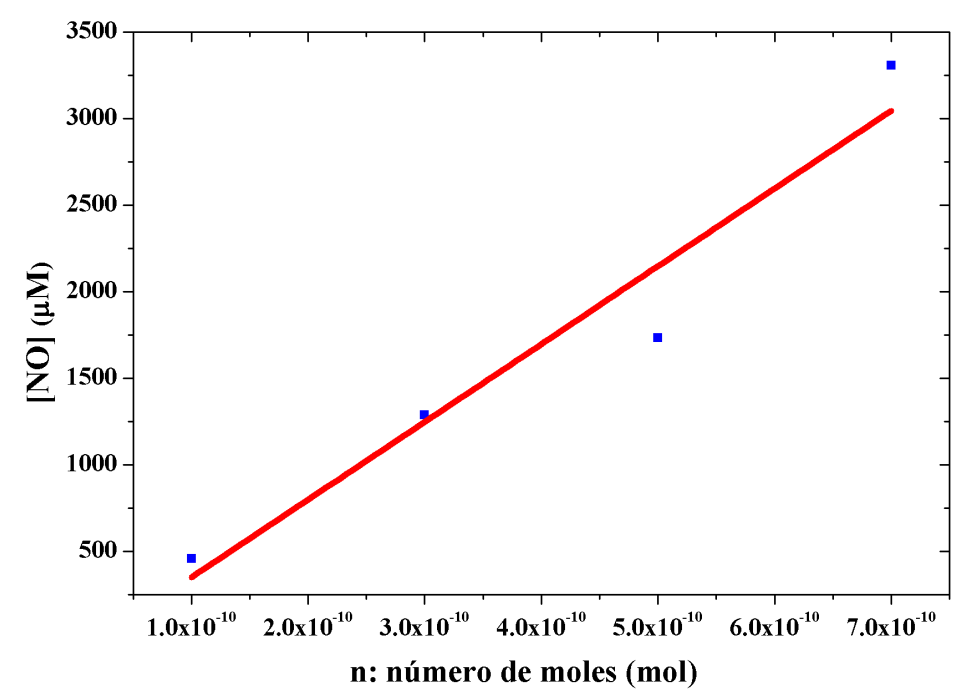

Figura 3.9: Curva de calibração do Analisador de NO, que relaciona a concentração molar de NO ([NO]) liberado em relação ao número de moles (n) de R-SNO contidos nos volumes injetados da solução estoque. 


\subsubsection{Medida de liberação de NO}

Após a calibração do equipamento com determinação do fator de correção para as soluções estoques utilizadas contendo MSA, procedemos com as medidas de liberação de NO das NPs funcionalizadas com MSA e DMSA, respectivamente. Para isto, injetamos as NPs nitrosadas (NP-SNO) no analisador de NO (Figura 3.5) e como resultado obtivemos picos de emissão de luminescência (Figura 3.7) em função da concentração das NPs injetadas. Conforme explicado no item anterior, a integral destes picos fornece a concentração molar de NO liberado de cada solução contendo NPs nitrosadas.

Como procedimento, realizamos dois tipos de experimentos a seguir.

\subsubsection{Primeira Etapa}

Cinética da liberação de NO a partir da NP funcionalizada com MSA (razão molar 1:40)

O perfil de liberação de NO das NP-SNO foi obtido em tempo real através da quimioluminescência. As NP-SNO foram obtidas a partir da adição de 2,2mg da NPMSA140 em $200 \mu \mathrm{l}$ de água deionizada. Após homogenização desta solução, alíquotas de $10 \mu \mathrm{l}$ desta supensão foram adicionadas a $3 \mathrm{ml}$ de água deionizada contendo $10 \mu \mathrm{l}$ de $\mathrm{HCl}(0,6 \mathrm{M})$. Um volume de $30 \mu \mathrm{l}$ da solução aquosa de $\mathrm{NaNO}_{2}(50 \mathrm{mM})$ foi adicionado à suspensão das NPSNO. A suspensão final foi homogenizada e protegida da luz com folha alumínio e mantida a temperatura ambiente $\left(25^{\circ} \mathrm{C}\right)$ para as medidas de cinética. A estabilidade dos grupos S-NO presentes na superfície das NPs foi cinéticamente monitorada a $25^{\circ} \mathrm{C}$, no escuro, injetando $5 \mu \mathrm{l}$ da solução das NP-SNO na célula do analisador de NO, para diferentes intervalos de tempo, num total de 6,7h. Antes de cada injeção das NP-SNO, estas foram fortemente homogenizadas num vórtex. A cinética de liberação de NO foi realizada em duplicata [38].

\subsubsection{Segunda Etapa}

\section{Liberação de NO a partir das NPs funcionalizadas com MSA e DMSA}

Injetamos volumes fixos de $5 \mu \mathrm{l}$ das soluções das NP-SNO na célula do Analisador. O tempo de medida foi de 1 a 2 min de aquisição. O software do equipamento forneceu a concentração de NO liberado ([NO]) assim como as concentrações experimentais destas soluções, que foram corrigidas conforme explicado no item anterior. 


\section{Capítulo 4}

\section{Resultados e Discussões}

\subsection{Espectroscopia Infravermelho - FTIR}

A Figura 4.1 apresenta os espectros de FTIR das NPs obtidas do processo de síntese (NP) e recobertas com ácido oleico (NPAO). Conforme Tabela 3.2, as bandas de estiramento $\left(\nu_{\mathrm{Fe}-\mathrm{O}}\right)$ e deformação $\left(\delta_{\mathrm{Fe}-\mathrm{O}}\right)$ da ligação Fe-O correspondentes à magnetita ocorrem na região entre $400 \mathrm{~cm}^{-1}$ e $650 \mathrm{~cm}^{-1}$ [78]. Através de uma ampliação desta região (Figura 4.2 , podemos identificar duas bandas em $440 \mathrm{~cm}^{-1}$ e $575 \mathrm{~cm}^{-1}$ correspondentes a $\delta_{F e-O}$ e $\nu_{\mathrm{Fe}-\mathrm{O}}$, que são associadas aos sítios octaédrico e tetraédrico da estrutura espinélio, respectivamente [78]. No espectro FTIR da NP, observamos também a presença de bandas em $1622 \mathrm{~cm}^{-1}$ e $3424 \mathrm{~cm}^{-1}$ (Figura 4.1) correspondentes à deformação $\delta_{O H}$ e estiramento $\nu_{O H}$, respectivamente [49, 79]. Observa-se também ombros em $1392 \mathrm{~cm}^{-1}, 2332 \mathrm{~cm}^{-1}$ e $2362 \mathrm{~cm}^{-1}$, que podem estar associados a alguma impureza. 


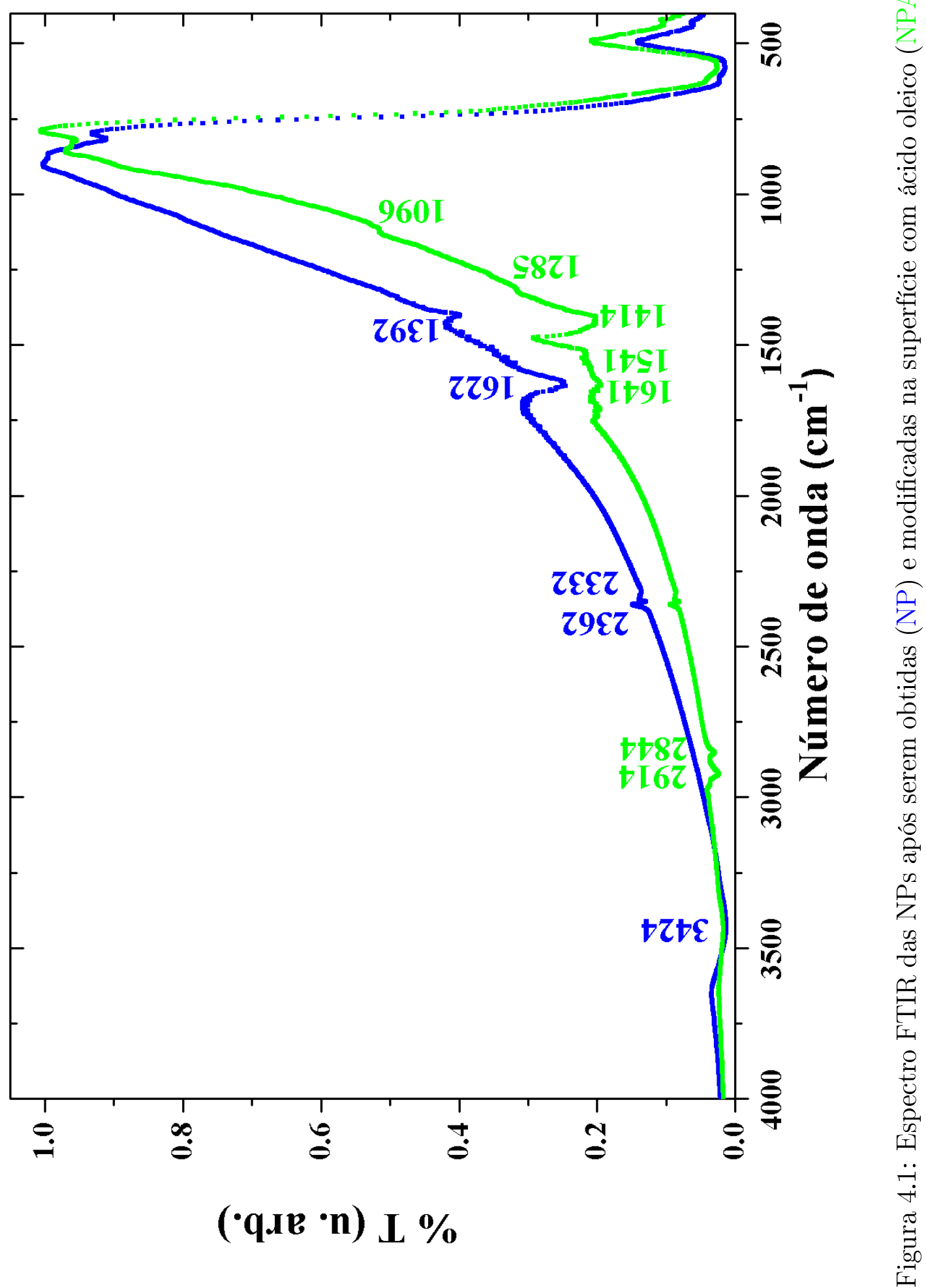




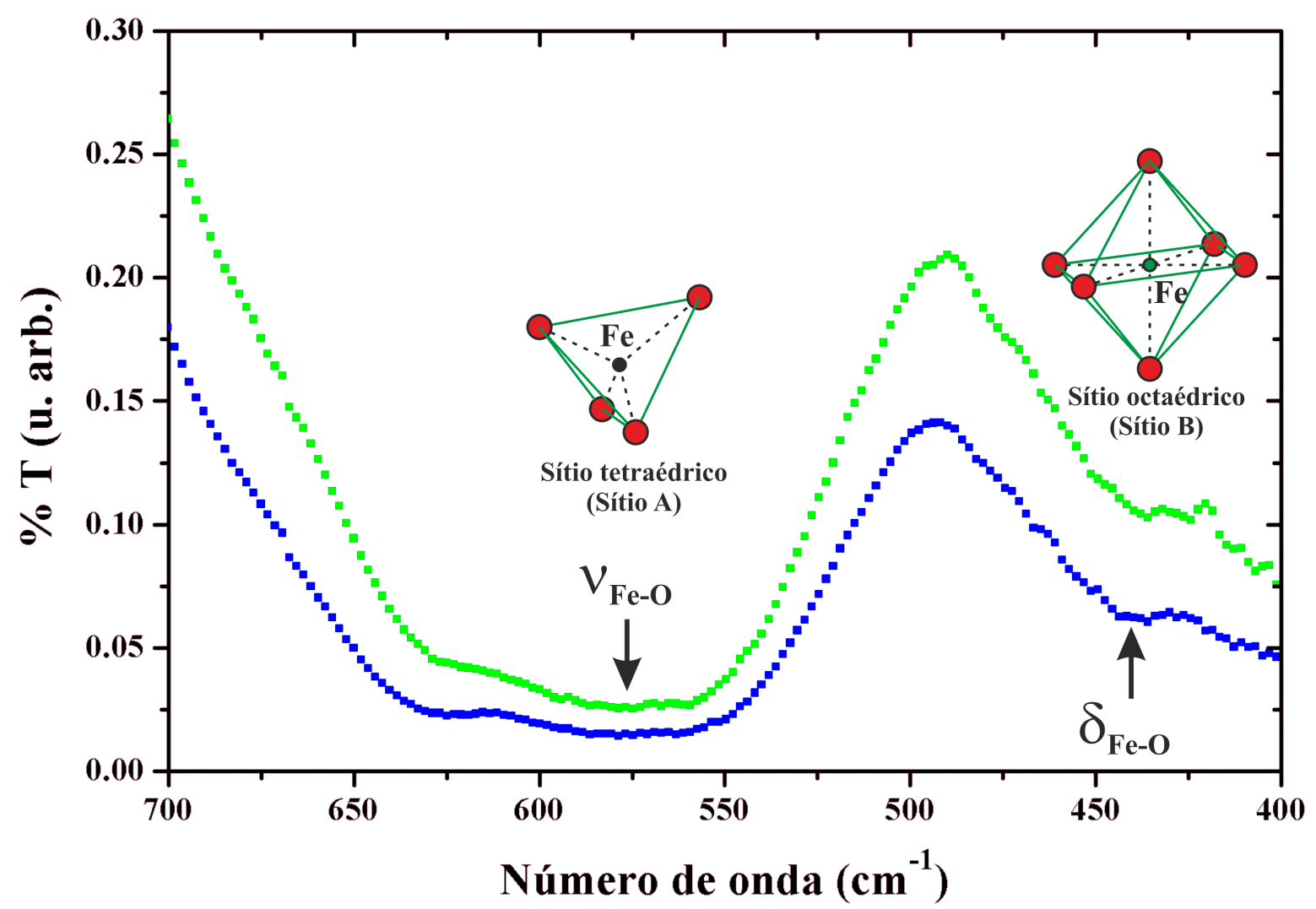

Figura 4.2: Ampliação da região entre $400 \mathrm{~cm}^{-1}$ e $700 \mathrm{~cm}^{-1}$ do espectro FTIR das NPs obtidas (NP) e recobertas com ácido oleico (NPAO), aonde são observadas as bandas de deformação $\left(\delta_{\mathrm{Fe}-\mathrm{O}} \sim 440 \mathrm{~cm}^{-1}\right)$ e estiramento $\left(\nu_{\mathrm{Fe}-\mathrm{O}} \sim 575 \mathrm{~cm}^{-1}\right)$ correspondentes ao sítio octaédrico (Sítio B) e tetraédrico (Sítio A), respectivamente [76].

Para NPs modificadas superficialmente com AO, aparecem duas pequenas bandas de absorção em $1096 \mathrm{~cm}^{-1}$ e $1285 \mathrm{~cm}^{-1}$ (Figura 4.1) associadas às bandas de estiramento da ligação C-O $\left(\nu_{C-O}\right)$ [20]; apresentam-se também bandas de absorção em $1541 \mathrm{~cm}^{-1}$ e $1641 \mathrm{~cm}^{-1}$ correspondentes aos estiramentos assimétrico $\nu_{a s}\left(\mathrm{COO}^{-}\right)$e simétrico $\nu_{s}\left(\mathrm{COO}^{-}\right)$, respectivamente [20]. As bandas em $2844 \mathrm{~cm}^{-1}$ e $2914 \mathrm{~cm}^{-1}$ correspondem aos estiramentos simétrico $\nu_{s}\left(\mathrm{CH}_{2}\right)$ e assimétrico $\nu_{a s}\left(\mathrm{CH}_{2}\right)$ da cadeia do surfactante. Observa-se também os ombros em $2362 \mathrm{~cm}^{-1}$ e $2332 \mathrm{~cm}^{-1}$, embora mais atenuados. A banda de estiramento $\nu_{O H}$ também é atenuada em relação ao observado para o espectro FTIR da NP. 
Portanto, a partir das bandas dos espectros de FTIR das NPs sintetizadas (NP) e recobertas com ácido oleico (NPAO) (Figura 4.1), podemos inferir uma interação de quelação bidentada entre o grupo $\mathrm{COO}^{-}$do ácido oleico e o átomo de Fe [20], apresentado na Figura 4.3. de acordo com a literatura [20]. Sendo assim, as NPs recobertas com AO devem apresentar certa estabilidade em solventes apolares devido à repulsão estérica entre as caudas hidrofóbicas presentes na sua superfície (Figura 4.4).

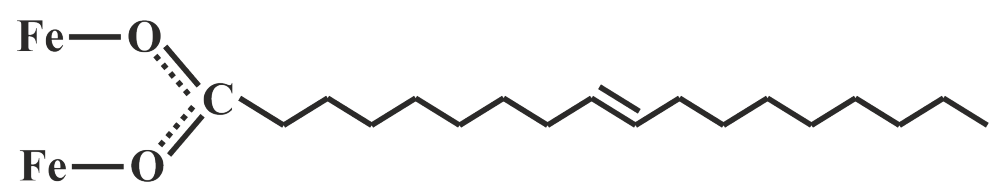

Figura 4.3: Interação quelante bidentada entre o grupo $\mathrm{COO}^{-}$do ácido oleico e o átomo de ferro. Figura extraída de [20].

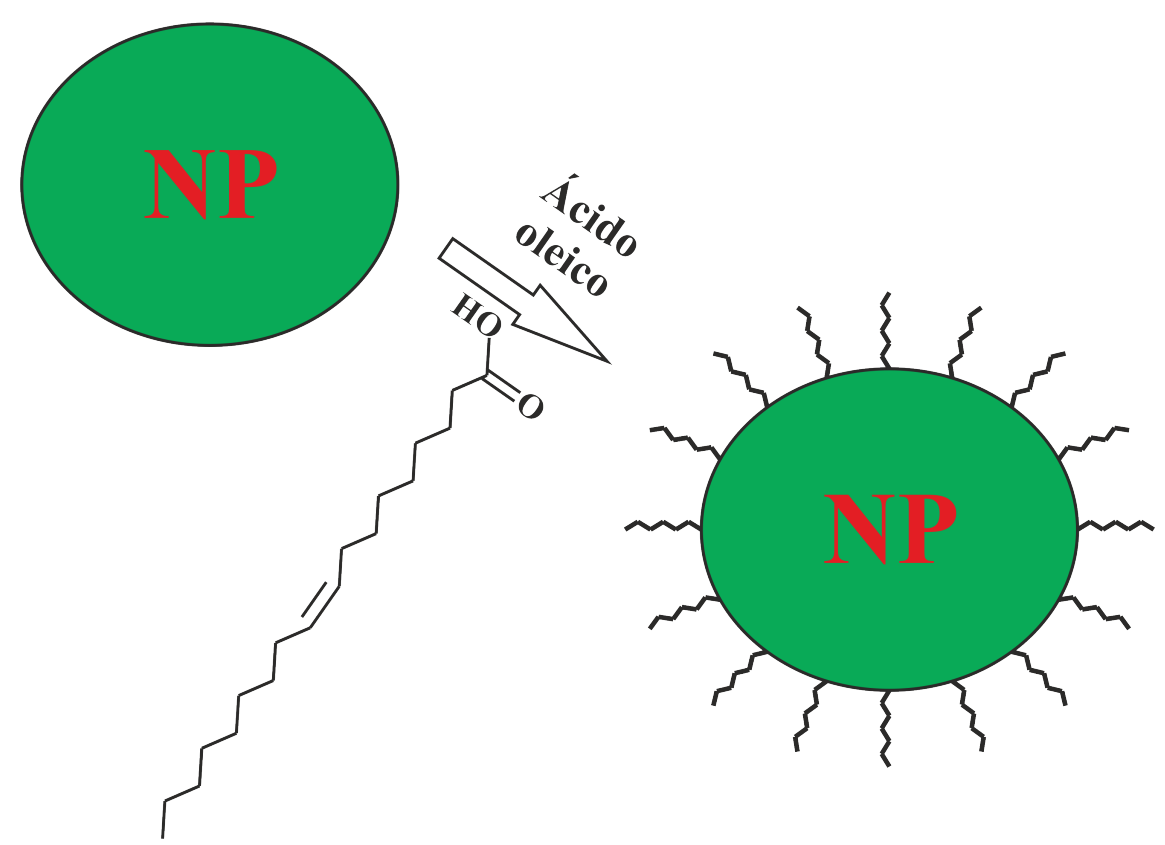

Figura 4.4: Esquema representativo do recobrimento das NPs com ácido oleico.

Nas Figuras 4.5 e 4.6 são apresentados os espectros de FTIR normalizados das moléculas de MSA e DMSA, respectivamente. 


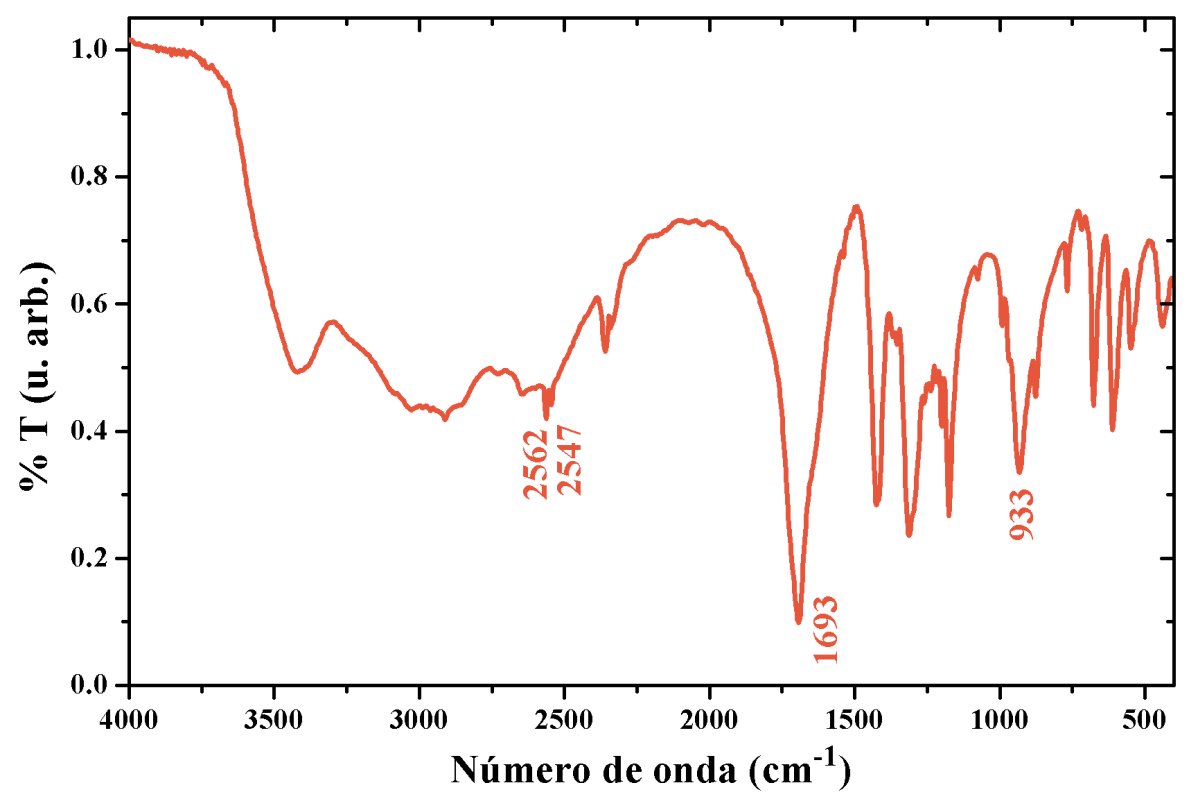

Figura 4.5: Espectro FTIR do ácido mercaptosuccínico (MSA).

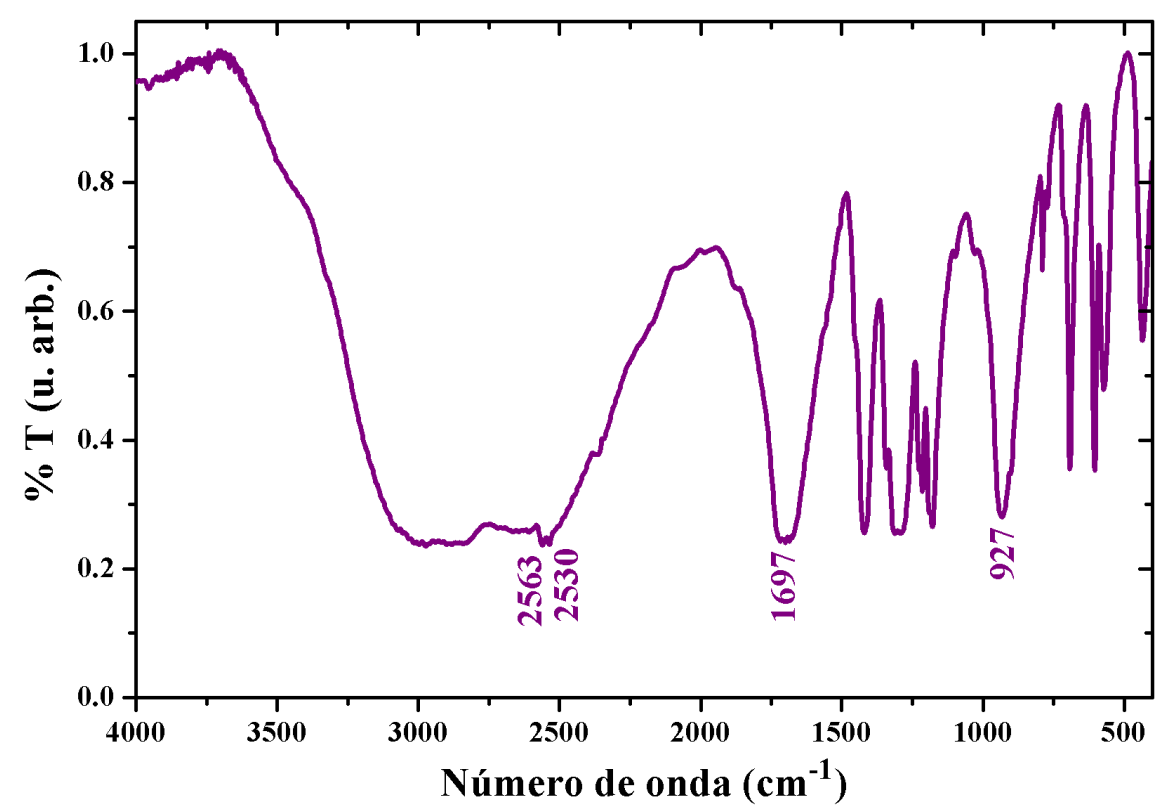

Figura 4.6: Espectro FTIR do ácido dimercaptosuccínico (DMSA). 
A partir das Figuras 4.5 e 4.6, e da Tabela 3.2, observamos bandas de absorção en torno de $927 \mathrm{~cm}^{-1}$ e $933 \mathrm{~cm}^{-1}$ associadas à deformação $\delta_{(O H)}$ fora do plano [20], em torno de $1693 \mathrm{~cm}^{-1} \mathrm{e}$ $1697 \mathrm{~cm}^{-1}$ referentes ao estiramento simétrico da ligação $\mathrm{COO}^{-}\left(\nu_{s}\left(C O O^{-}\right)\right)$[20, 80, 81], e em torno de $2530 \mathrm{~cm}^{-1}$ e $2563 \mathrm{~cm}^{-1}$ referentes ao estiramento da ligação $\mathrm{S}-\mathrm{H}\left(\nu_{S H}\right)$ [74, 79, 82, 83] presentes tanto na molécula de MSA como na de DMSA. Esta região está ampliada na Figura 4.7.

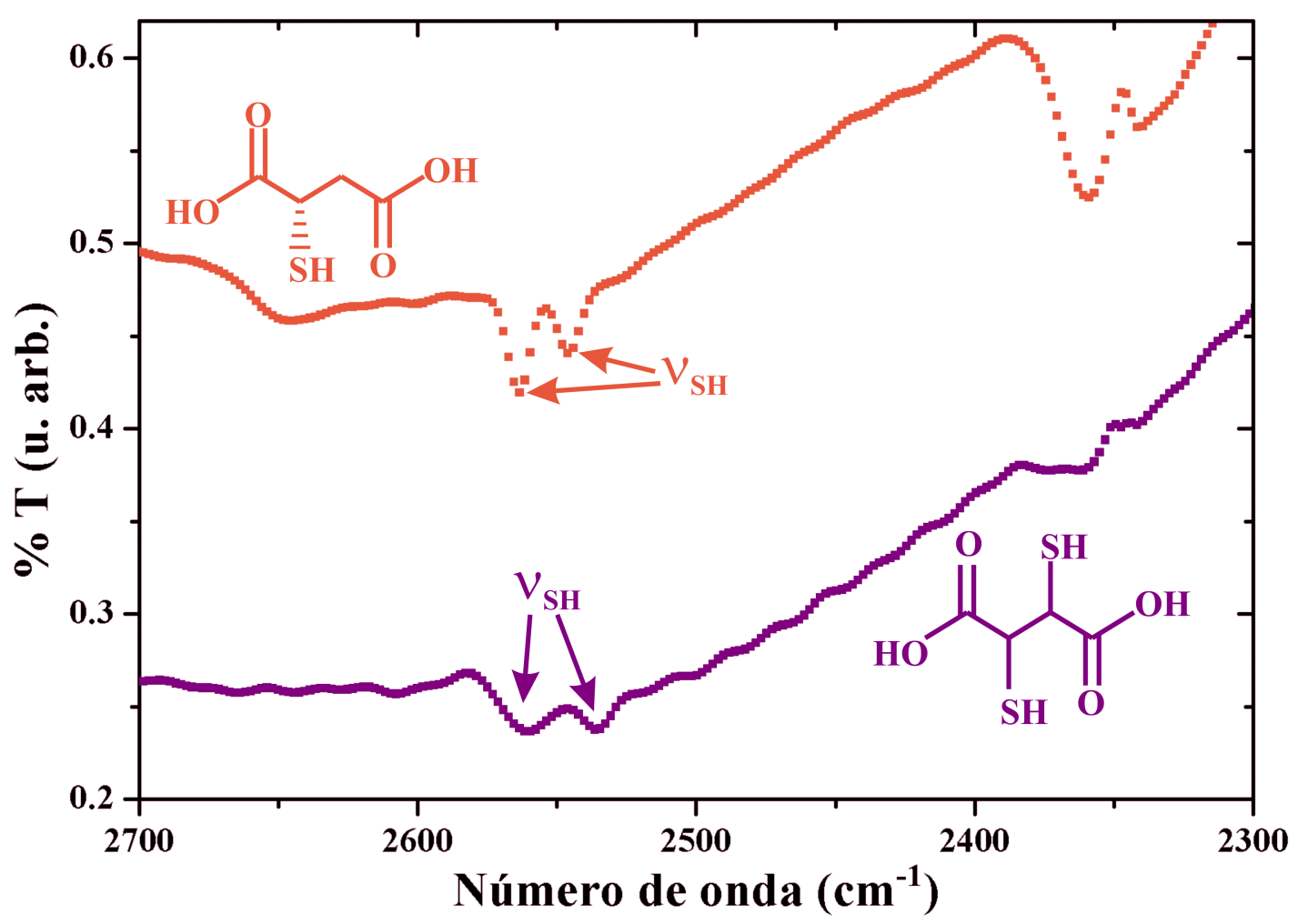

Figura 4.7: Ampliação da região entre $2300 \mathrm{~cm}^{-1}$ e $2700 \mathrm{~cm}^{-1}$ do espectro de FTIR normalizado para as moléculas de MSA e de DMSA. As bandas de absorção em torno de $2530 \mathrm{~cm}^{-1}$ e $2563 \mathrm{~cm}^{-1}$ (setas na figura) correspondem ao estiramento $\nu_{S H}$.

Da Figura 4.7, observamos uma diminuição na intensidade das bandas de estiramento $\left(\nu_{S H}\right)$ para o DMSA em relação ao MSA, provavelmente devido à dimerização dos grupos tióis [38].

As Figuras 4.8 e 4.9 apresentam os espectros de FTIR das NPs funcionalizadas com MSA e DMSA em diferentes razões molares (1:10, 1:40 e 1:80). 


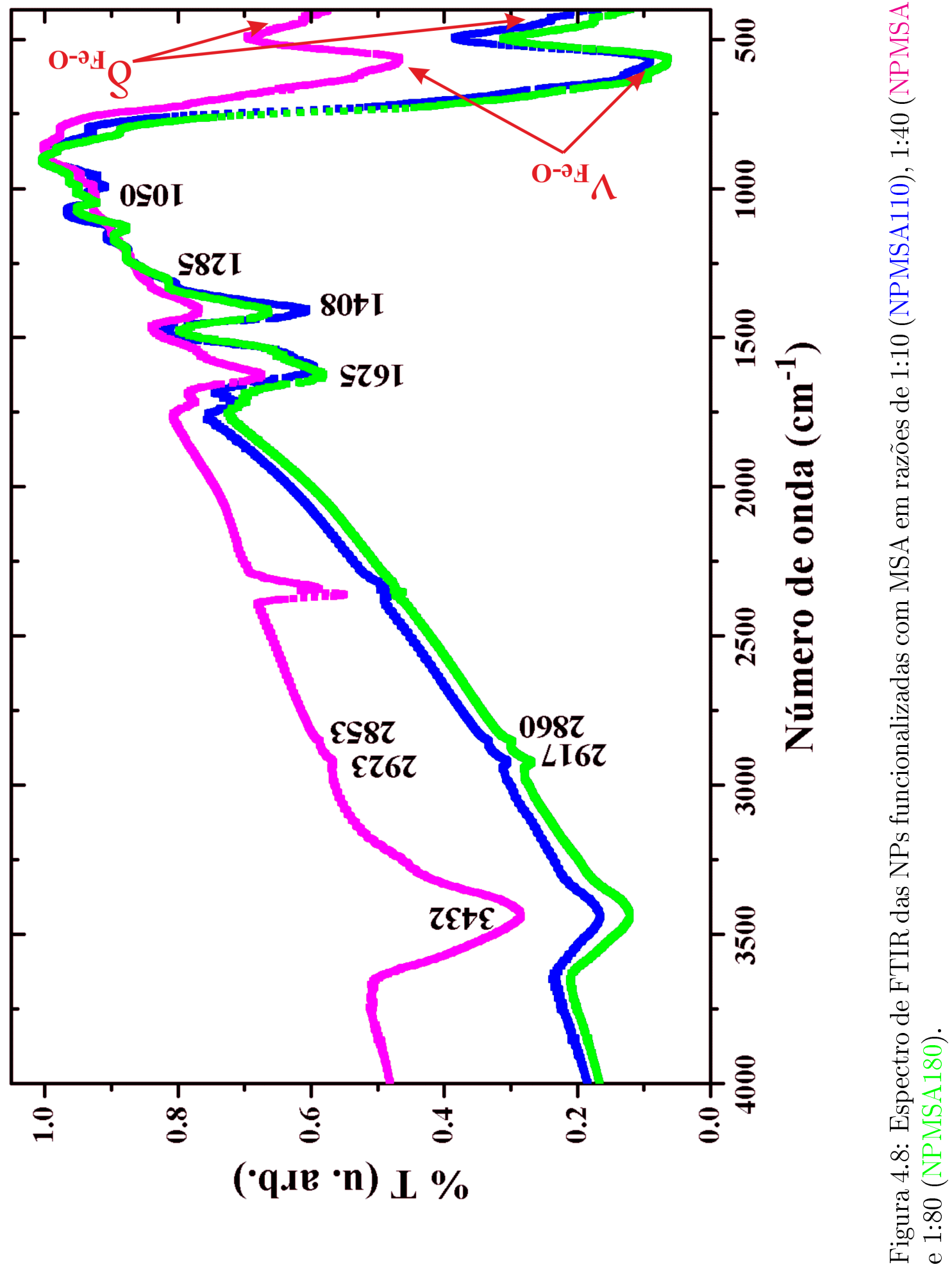




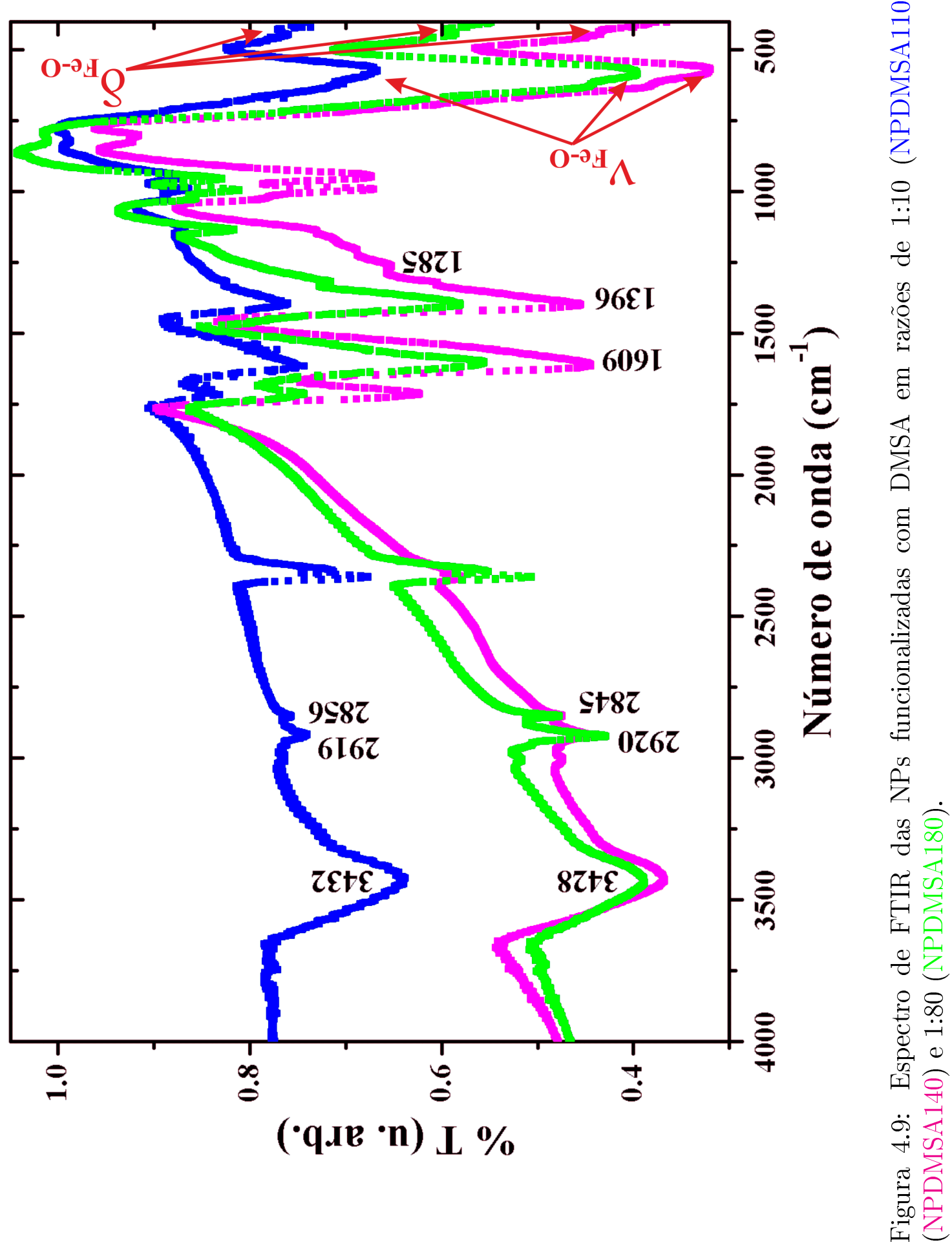


De maneira análoga, as duas bandas características das ligações $\left(\delta_{F e-O}\right.$ e $\left.\nu_{F e-O}\right)$ da estrutura espinélio do óxido de ferro aparecem na região entre $400 \mathrm{~cm}^{-1}$ e $600 \mathrm{~cm}^{-1}$ (Figuras 4.8 e 4.9, enquanto as bandas em torno de $1050 \mathrm{~cm}^{-1}$ e $1285 \mathrm{~cm}^{-1}$ são associadas ao estiramento da ligação C-O $\left(\nu_{C-O}\right)$, e a ligação do Ferro com o grupo carboxila das moléculas de MSA e DMSA (Figura 4.3).

A banda em torno de $3430 \mathrm{~cm}^{-1}$ é associada ao estiramento da ligação $\mathrm{OH}\left(\nu_{O H}\right)$, enquanto as bandas em torno de $1400 \mathrm{~cm}^{-1}$ e $1610 \mathrm{~cm}^{-1}$ correspondem aos estiramentos simétrico $\left(\nu_{a s}\left(C O O^{-}\right)\right)$e assimétrico $\left(\nu_{s}\left(C O O^{-}\right)\right.$dos grupos carboxila. Em particular, bandas de absorção associadas ao grupo tiol (SH) estão presentes em torno de $2860 \mathrm{~cm}^{-1}$ e $2920 \mathrm{~cm}^{-1}$ [18, 38] (Figuras 4.8 e 4.9), muito mais pronunciadas para as NPs funcionalizadas com DMSA. Ampliações desta região para as NPs recobertas com MSA e DMSA são apresentadas nas Figuras 4.10 4.11, respectivamente. Para ambas NPs, a ausência de bandas extras entre $400 \mathrm{~cm}^{-1}$ e $500 \mathrm{~cm}^{-1}$ indica que não houve dimerização dos grupos tióis (S-S) durante a funcionalização das superfícies das NPs [38].

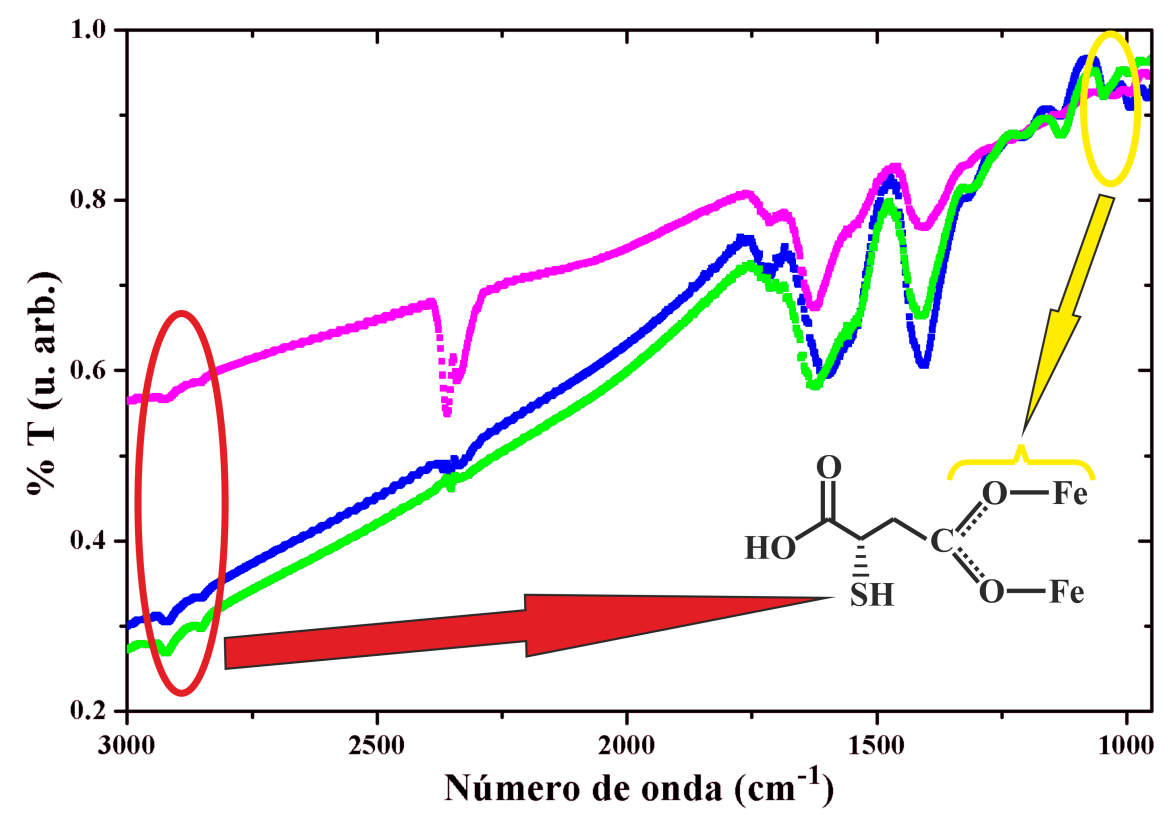

Figura 4.10: Ampliação da região entre $950 \mathrm{~cm}^{-1}$ e $3000 \mathrm{~cm}^{-1}$ do espectro FTIR das NPs funcionalizadas com MSA. Observa-se a troca de ligantes da nanopartícula através da banda em $1050 \mathrm{~cm}^{-1}$ referente ao estiramento $\nu_{C-O}$, que indica a ligação da molécula de MSA com a NP, e as bandas entre $2853 \mathrm{~cm}^{-1}$ e $2923 \mathrm{~cm}^{-1}$ referente ao estiramento $\nu_{-S H}$. 


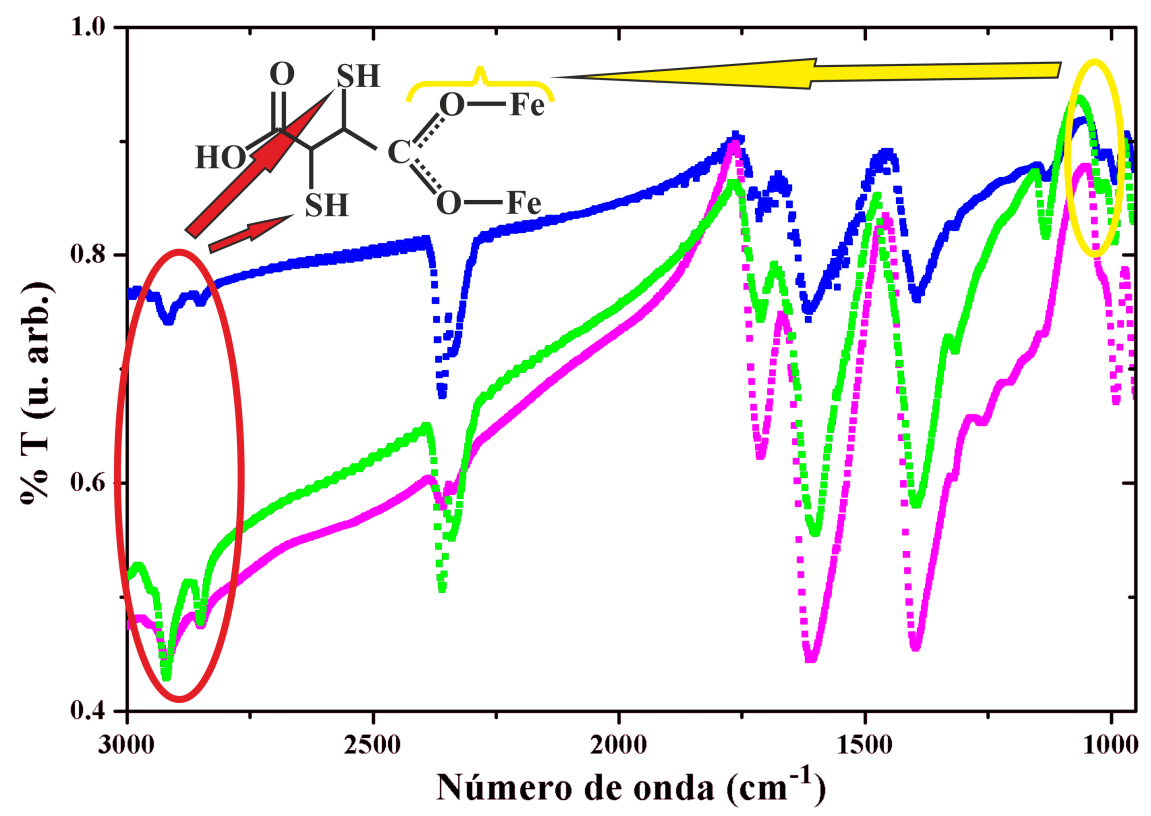

Figura 4.11: Ampliação da região entre $950 \mathrm{~cm}^{-1}$ e $3000 \mathrm{~cm}^{-1}$ do espectro FTIR das NPs funcionalizadas com DMSA. Observa-se a troca de ligantes da nanopartícula através da banda em $1050 \mathrm{~cm}^{-1}$ referente ao estiramento $\nu_{C-O}$, que indica a ligação da molécula de DMSA com a NP, e as bandas entre $2856 \mathrm{~cm}^{-1}$ e $2920 \mathrm{~cm}^{-1}$ referente ao estiramento $\nu_{-S H}$.

Assim, através da análise de FTIR concluimos que a troca de ligante na superfície das NPs foi eficiente. A Figura 4.12 propõe um esquema representativo de funcionalização da superfície das NPs com os grupos tióis.
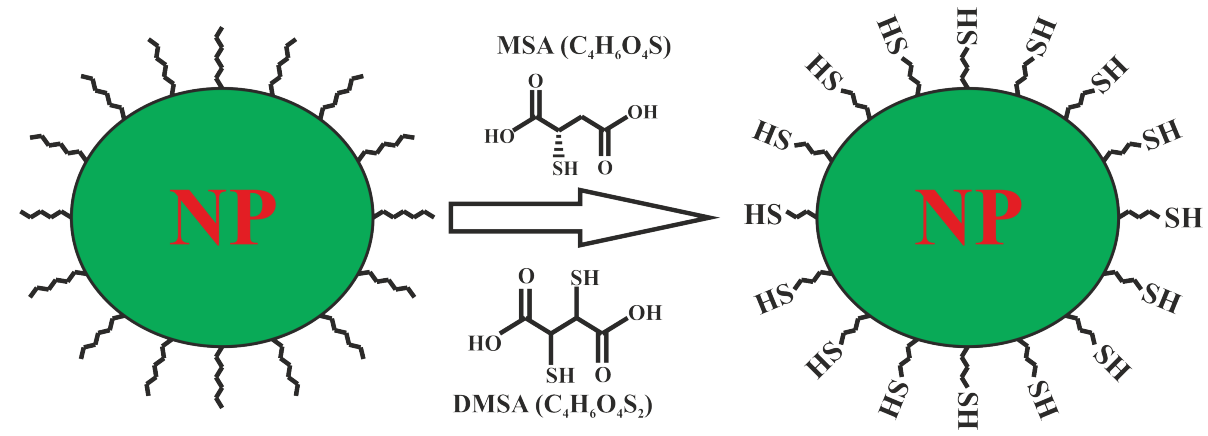

Figura 4.12: Recobrimento das NPs com MSA e DMSA, tendo como resultado final NPs funcionalizadas com grupos tióis na superfície. 


\subsection{Difração de Raios X - DRX}

A Figura 4.13 apresenta os difratogramas das nanopartículas obtidas após a síntese por coprecipitação (NP), e recobertas com ácido oleico (NPAO), assim como as Figuras 4.14 e 4.15 apresentam os difratogramas das nanopartículas obtidas após a troca de ligantes com MSA em razões de concentração de 1:10 (NPMSA110), de 1:40 (NPMSA140) e 1:80 (NPMSA180); e com ácido dimercaptosuccínico (DMSA) em razões de concentração de 1:10 (NPDMSA110), de 1:40 (NPDMSA140) e 1:80 (NPDMSA180), respectivamente. O padrão da estrutura espinélio da magnetita (ficha JCPD 19-0629) também é apresentado em cada um dos difratogramas para efeito comparativo. Assim, através das Figuras 4.13, 4.14 e 4.15. podemos inferir que as nanopartículas sintetizadas (NP) correspondem, de fato, à magnetita, e que a modificação realizada na superfície das mesmas por adsorção de $\mathrm{AO}$ e posterior troca por MSA e DMSA não alterou a estrutura cristalográfica das NPs. A partir dos ajustes da função Lorentziana (Equação 3.8) para cada pico de difração, temos os ângulos de Bragg para os planos cristalinos $(h k l)$. A Tabela 4.1 apresenta os ângulos de Bragg para cada plano cristalino identificado para as amostras NP e NPAO, enquanto as Tabelas 4.2 e 4.3 apresentam os ângulos de Bragg obtidos da difração das nanopartículas funcionalizadas com MSA e DMSA, respectivamente. As Tabelas 4.1, 4.2 e 4.3 também incluem os ângulos de Bragg esperados conforme o padrão da magnetita (ficha JCPD 19-0629). 


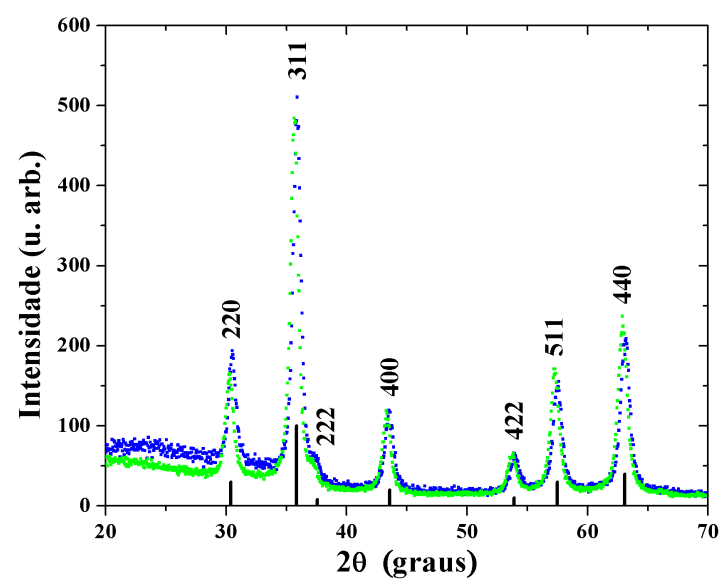

Figura 4.13: Curvas de difração de raios X das NPs após serem obtidas (NP) e após recobrimento com ácido oleico (NPAO). Os traços em preto, indicados na Figura, representam as posições angulares e as intensidades de difração esperadas correspondentes aos planos cristalinos $(h k l)$ da estrutura espinélio da magnetita (JCPD 19-0629 - Figura 1.2).

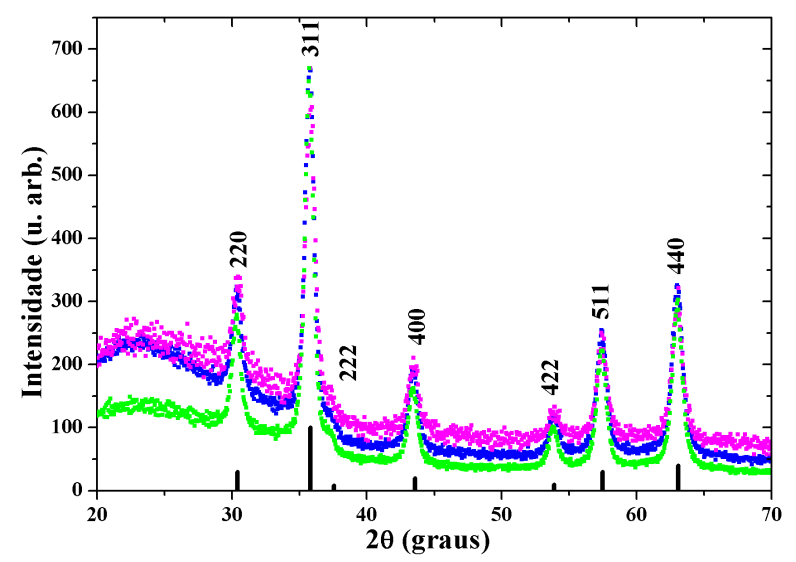

Figura 4.14: Curvas de difração de raios X das NPs, após serem funcionalizadas com ácido mercaptosuccínico (MSA) em razão de 1:10 (NPMSA110), de 1:40 (NPMSA140) e 1:80 (NPMSA180). Os traços em preto, indicados na Figura, representam as posições angulares e as intensidades de difração esperadas correspondentes aos planos cristalinos $(h k l)$ da estrutura espinélio da magnetita (JCPD 19-0629 - Figura 1.2). 


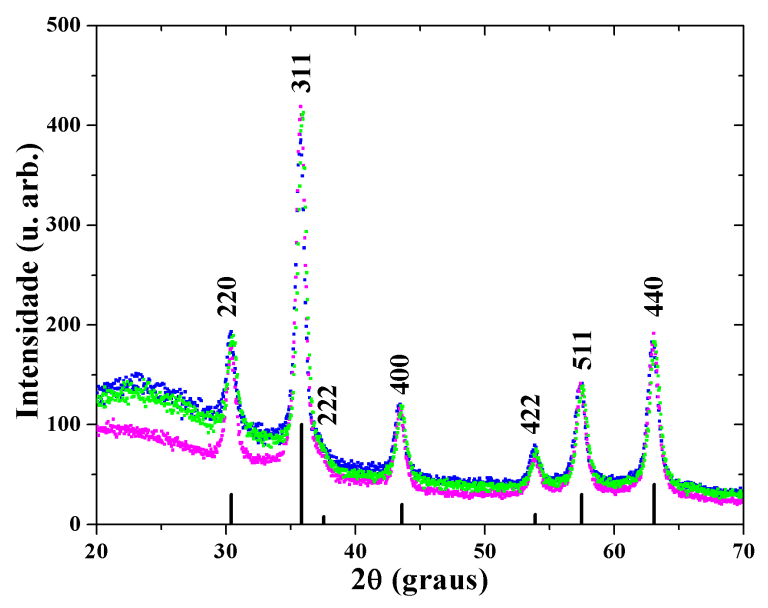

Figura 4.15: Curvas de difração de raios X das NPs, após serem funcionalizadas com ácido dimercaptosuccínico (DMSA) em razão de 1:10 (NPDMSA110), de 1:40 (NPDMSA140) e 1:80 (NPDMSA180). Os traços em preto, indicados na Figura, representam as posições angulares e as intensidades de difração esperadas correspondentes aos planos cristalinos $(h k l)$ da estrutura espinélio da magnetita (JCPD 19-0629 - Figura 1.2).

Tabela 4.1: Ângulos de Bragg correspondentes aos picos de difração obtidos dos difratogramas das nanopartículas após serem obtidas (NP) e recobertas com ácido oleico (NPAO) Figura 4.13 .

\begin{tabular}{cccc}
\hline Plano de & \multicolumn{2}{c}{$2 \theta$ (graus) } & \multicolumn{2}{c}{$2 \theta$ (graus) } \\
Reflexão & ficha catalográfica & \multicolumn{2}{c}{ experimental } \\
$h k l$ & JCPD 19-0629 & NP & NPAO \\
\hline 220 & 30,10 & $30,50(1)$ & $30,28(1)$ \\
311 & 35,42 & $35,89(1)$ & $35,67(1)$ \\
400 & 43,05 & $43,54(1)$ & $43,33(1)$ \\
422 & 53,39 & $53,97(1)$ & $53,76(1)$ \\
511 & 56,94 & $57,52(1)$ & $57,30(1)$ \\
440 & 62,52 & $63,14(1)$ & $62,91(1)$ \\
\hline
\end{tabular}


Tabela 4.2: Ângulos de Bragg para cada pico de difração obtidos dos difratogramas das nanopartículas funcionalizadas com MSA em diferentes razões de concentração.

\begin{tabular}{ccccc}
\hline $\begin{array}{c}\text { Planos de } \\
\text { Reflexão } \\
h k l\end{array}$ & $\begin{array}{c}2 \theta \text { (graus) } \\
\text { ficha catalográfica } \\
\text { JCPD 19-0629 }\end{array}$ & \multicolumn{3}{c}{$\begin{array}{c}2 \theta \text { (graus) } \\
\text { experimental }\end{array}$} \\
\hline 220 & 30,10 & $30,34(1)$ & $30,42(2)$ & $30,33(1)$ \\
311 & 35,42 & $35,76(1)$ & $35,82(1)$ & $35,73(1)$ \\
400 & 43,05 & $43,43(1)$ & $43,47(1)$ & $43,41(1)$ \\
422 & 53,39 & $53,89(1)$ & $53,92(3)$ & $53,84(1)$ \\
511 & 56,94 & $57,41(1)$ & $57,45(1)$ & $57,40(1)$ \\
440 & 62,52 & $63,02(1)$ & $63,03(1)$ & $63,02(1)$ \\
\hline
\end{tabular}

Tabela 4.3: Ângulos de Bragg para cada pico de difração obtidos dos difratogramas das nanopartículas funcionalizadas com DMSA em diferentes razões de concentração.

\begin{tabular}{ccccc}
\hline $\begin{array}{c}\text { Planos de } \\
\text { Reflexão } \\
h k l\end{array}$ & $\begin{array}{c}2 \theta \text { (graus) } \\
\text { ficha catalográfica } \\
\text { JCPD 19-0629 }\end{array}$ & NPDMSA110 & $\begin{array}{c}2 \theta \text { (graus) } \\
\text { experimental }\end{array}$ & \\
\hline 220 & 30,10 & $30,34(1)$ & $30,39(1)$ & $30,51(1)$ \\
311 & 35,42 & $35,74(1)$ & $35,78(1)$ & $35,90(1)$ \\
400 & 43,05 & $43,39(1)$ & $43,43(1)$ & $43,56(1)$ \\
422 & 53,39 & $53,84(1)$ & $53,89(1)$ & $53,98(1)$ \\
511 & 56,94 & $57,37(1)$ & $57,43(1)$ & $57,53(1)$ \\
440 & 62,52 & $62,98(1)$ & $63,05(1)$ & $63,14(1)$ \\
\hline
\end{tabular}

Conforme podemos observar, notamos um desvio sistemático nos valores de $\theta_{h k l}$ em relação aos tabelados em torno de $0,3^{\circ}$ a $0,4^{\circ}$ provavelmente devido a um pequeno desalinhamento do sistema de medida, mas que não afeta de maneira significativa a conclusão dos resultados. Este desvio na medida também pode ser atribuído à espessura da amostra colocada no difratômetro, pois a largura do pico muda com a espessura do cristal, como mencionado na Seção 3.4 .

A partir dos ângulos $\theta_{h k l}$ medidos experimentalmente, calculamos as distâncias $\mathrm{d}_{h k l}$ correspondentes através da lei de Bragg (Equação 3.2) e o parâmetro de rede (Equação 3.4). Os valores para cada amostra encontram-se nas Tabelas 4.4, 4.5 e 4.6. 
Tabela 4.4: Distância interplanar $\mathrm{d}_{h k l}$ (Equação 3.2) e parâmetro de rede $a$ (Equação 3.4 ) para as NPs após serem obtidas (NP) e após recobrimento com ácido oleico (NPAO).

\begin{tabular}{ccccc}
\hline $\begin{array}{c}\text { Plano de } \\
\text { Reflexão } \\
h k l\end{array}$ & $\begin{array}{c}\text { NP } \\
\mathrm{d}_{h k l}\end{array}$ & $\begin{array}{c}a \\
(\mathrm{~nm})\end{array}$ & $\begin{array}{c}\mathrm{d}_{h k l} \\
(\mathrm{~nm})\end{array}$ & $\begin{array}{c}a \\
(\mathrm{~nm})\end{array}$ \\
\hline 220 & $0,2931(1)$ & $0,8289(3)$ & $0,2923(1)$ & $0,8267(2)$ \\
311 & $0,2502(1)$ & $0,8299(1)$ & $0,2517(1)$ & $0,8348(1)$ \\
400 & $0,2078(1)$ & $0,8313(3)$ & $0,2088(1)$ & $0,8353(2)$ \\
422 & $0,1699(1)$ & $0,8323(3)$ & $0,1705(1)$ & $0,8353(2)$ \\
511 & $0,1602(1)$ & $0,8325(1)$ & $0,1608(1)$ & $0,8355(1)$ \\
440 & $0,1473(1)$ & $0,8330(1)$ & $0,1477(1)$ & $0,8356(1)$ \\
\hline
\end{tabular}

Tabela 4.5: Distância interplanar $\mathrm{d}_{h k l}$ (Equação 3.2) e parâmetro de rede $a$ (Equação 3.4) para as NPs após ser realizada a troca de ligantes com MSA em diferentes razões molares.

\begin{tabular}{ccccccc}
\hline $\begin{array}{c}\text { Plano de } \\
\text { Reflexão } \\
h k l\end{array}$ & \multicolumn{2}{c}{ NPMSA110 } & \multicolumn{2}{c}{ NPMSA140 } & \multicolumn{2}{c}{ NPMSA180 } \\
$(\mathrm{nm})$ & $(\mathrm{nm})$ & $\begin{array}{c}\mathrm{d}_{h k l} \\
(\mathrm{~nm})\end{array}$ & $\begin{array}{c}a \\
(\mathrm{~nm})\end{array}$ & $\begin{array}{c}\mathrm{d}_{h k l} \\
(\mathrm{~nm})\end{array}$ & $\begin{array}{c}a \\
(\mathrm{~nm})\end{array}$ \\
\hline 220 & $0,2945(2)$ & $0,8332(5)$ & $0,2938(3)$ & $0,8310(9)$ & $0,2947(1)$ & $0,8335(3)$ \\
311 & $0,2511(1)$ & $0,8328(2)$ & $0,2507(1)$ & $0,8314(3)$ & $0,2513(1)$ & $0,8334(2)$ \\
400 & $0,2084(1)$ & $0,8334(2)$ & $0,2082(1)$ & $0,8327(5)$ & $0,2084(1)$ & $0,8337(2)$ \\
422 & $0,1701(1)$ & $0,8333(3)$ & $0,1701(2)$ & $0,8331(7)$ & $0,1703(1)$ & $0,8342(2)$ \\
511 & $0,1605(1)$ & $0,8340(1)$ & $0,1604(1)$ & $0,8335(3)$ & $0,1605(1)$ & $0,8341(1)$ \\
440 & $0,1475(1)$ & $0,8344(1)$ & $0,1475(1)$ & $0,8343(2)$ & $0,1475(1)$ & $0,8344(1)$ \\
\hline
\end{tabular}

Tabela 4.6: Distância interplanar $\mathrm{d}_{h k l}$ (Equação 3.2) e parâmetro de rede $a$ (Equação 3.4) para as NPs após ser realizada a troca de ligantes com DMSA em diferentes razões molares.

\begin{tabular}{ccccccc}
\hline $\begin{array}{c}\text { Plano de } \\
\text { Reflexão } \\
h k l\end{array}$ & $\begin{array}{c}\text { NPDMSA110 } \\
\mathrm{d}_{h k l}\end{array}$ & $\begin{array}{c}\text { NPDMSA140 } \\
(\mathrm{nm})\end{array}$ & $\begin{array}{c}\mathrm{d}_{h k l} \\
(\mathrm{~nm})\end{array}$ & $\begin{array}{c}\text { NPDMSA180 } \\
(\mathrm{nm})\end{array}$ & $\begin{array}{c}\mathrm{d}_{h k l} \\
(\mathrm{~nm})\end{array}$ & $\begin{array}{c}a \\
(\mathrm{~nm})\end{array}$ \\
\hline 220 & $0,2946(2)$ & $0,8334(7)$ & $0,2941(1)$ & $0,8319(3)$ & $0,2930(2)$ & $0,8288(5)$ \\
311 & $0,2513(1)$ & $0,8333(2)$ & $0,2509(1)$ & $0,8322(1)$ & $0,2501(1)$ & $0,8296(2)$ \\
400 & $0,2086(1)$ & $0,8342(4)$ & $0,2083(1)$ & $0,8333(3)$ & $0,2078(1)$ & $0,8311(3)$ \\
422 & $0,1703(1)$ & $0,8341(3)$ & $0,1701(1)$ & $0,8334(4)$ & $0,1699(1)$ & $0,8322(3)$ \\
511 & $0,1606(1)$ & $0,8345(1)$ & $0,1605(1)$ & $0,8337(1)$ & $0,1602(1)$ & $0,8324(1)$ \\
440 & $0,1476(1)$ & $0,8348(1)$ & $0,1474(1)$ & $0,8341(1)$ & $0,1472(1)$ & $0,8330(1)$ \\
\hline
\end{tabular}


A partir dos resultados das Tabelas 4.4, 4.5 e 4.6, calculamos a média do parâmetro de rede $(\bar{a})$ obtida para cada amostra levando em conta todas as reflexões $(h k l)$ medidas em cada difratograma. A Tabela 4.7 apresenta os valores calculados.

Tabela 4.7: Média dos parâmetro de rede para as nanopartículas sem e com recobrimento.

\begin{tabular}{cc}
\hline NPs & $\bar{a}(\mathrm{~nm})$ \\
\hline NP & $0,831(2)$ \\
NPAO & $0,834(7)$ \\
\hline NPMSA110 & $0,834(1)$ \\
NPMSA140 & $0,833(2)$ \\
NPMSA180 & $0,834(1)$ \\
\hline NPDMSA110 & $0,834(1)$ \\
NPDMSA140 & $0,833(1)$ \\
NPDMSA180 & $0,831(2)$ \\
\hline
\end{tabular}

Portanto, os resultados de $\bar{a}$ concordam com o valor teórico esperado de $a=0,8396 \mathrm{~nm}$ 41] com desvio porcentual de $0,7 \%$.

A partir das Tabelas 4.4, 4.5 e 4.6, observa-se que as distâncias interplanares $\mathrm{d}_{h k l}$ estão próximas dos valores fornecidos pela ficha catalográfica JCPD 19-0629, dados para cada plano de reflexão: $(220) \longrightarrow 0,2967 \mathrm{~nm} ;(311) \longrightarrow 0,2532 \mathrm{~nm} ;(400) \longrightarrow 0,2099 \mathrm{~nm} ;(422) \longrightarrow$ $0,1715 \mathrm{~nm} ;(511) \longrightarrow 0,1616 \mathrm{~nm} ;(440) \longrightarrow 0,1485 \mathrm{~nm}$.

Para obtermos os valores de grão cristalino $\mathrm{D}_{R X}$ das amostras, ajustamos uma função Lorentziana (Equação 3.8) em cada um dos picos de difração, obtendo valores de largura a meia altura. A Figura 4.16 a. mostra um exemplo de ajuste para a reflexão (311) da amostra NP, enquanto a Figura 4.16 b. apresenta o mesmo ajuste para a reflexão (311) da amostra NPMSA140. A partir destes valores e conhecendo-se a largura intrínseca $b$ do feixe de R-X, calculamos $\beta$ e os respectivos tamanhos de grão através da Equação 3.5 para todas as reflexões medidas experimentalmente de cada amostra estudada. A Tabela 4.8 apresenta os resultados de $\mathrm{D}_{R X}$ para as amostras NP e NPAO, enquanto a Tabela 4.9 apresenta $\mathrm{D}_{R X}$ para as NPs recobertas com MSA e DMSA. 

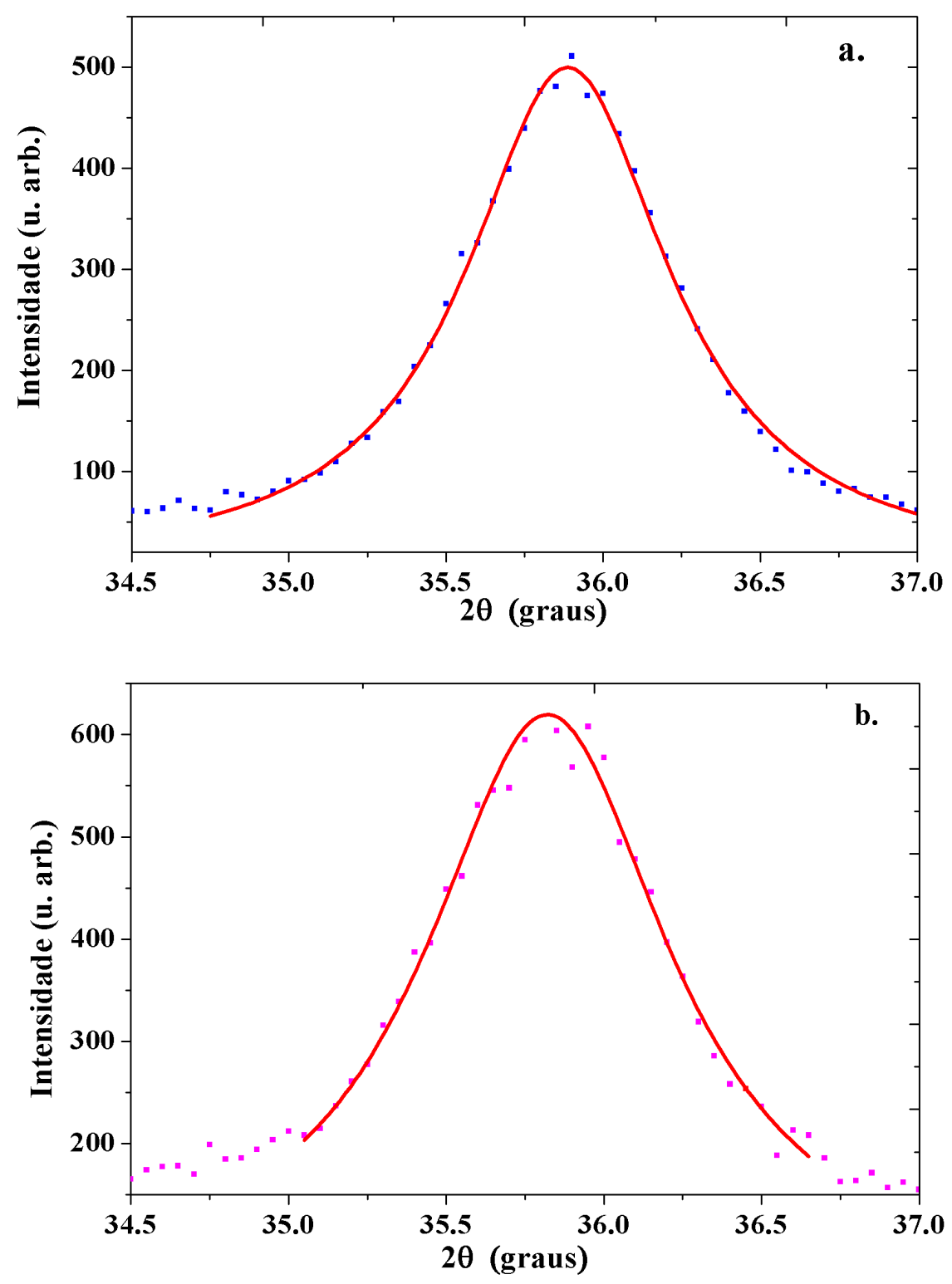

Figura 4.16: Ajuste do pico de difração no plano de reflexão (311) através de uma função Lorentziana (Equação 3.8) para: a. NPs após serem sintetizadas (NP), b. NPs funcionalizadas com MSA na razão molar 1:40 (NPMSA140). 
Tabela 4.8: Tamanho do grão cristalino das NPs antes (NP) e após recobrimento com ácido oleico (NPAO), calculado a partir de cada pico de difração.

\begin{tabular}{|c|c|c|}
\hline Plano de & \multicolumn{2}{|c|}{$\mathrm{D}_{R X}(\mathrm{~nm})$} \\
\hline Reflexão & $\mathrm{NP}$ & NPAO \\
\hline 220 & $11,9(4)$ & $10,8(2)$ \\
\hline 311 & $10,7(2)$ & $11,8(2)$ \\
\hline 400 & $9,7(7)$ & $11,3(2)$ \\
\hline 422 & $11,4(1,6)$ & $10,0(5)$ \\
\hline 511 & $10,2(3)$ & $11,0(2)$ \\
\hline 440 & $10,2(3)$ & $11,0(2)$ \\
\hline
\end{tabular}

Tabela 4.9: Tamanho do grão cristalino calculado a partir de cada pico de difração das NPs após ser realizada a troca de ligantes com MSA e DMSA em diferentes razões molares.

$\begin{array}{ccccccc} & & & & \\ \end{array}$

Conforme podemos observar das Tabelas 4.8 e 4.9, $\mathrm{D}_{R X}$ varia de cerca de $9 \mathrm{~nm}$ a $11 \mathrm{~nm}$, para todas as amostras considerando os valores obtidos de todas as reflexões cristalográficas. Ressaltamos, entretanto, que as reflexões em (422), (511), (440) são afetadas pelo fator de Debye-Waller (atenuação do espalhamento de Raios-X produzido pelo movimento térmico) [44, o que não estamos levando em consideração na análise dos dados. Assim, analisando o tamanho de grão $\mathrm{D}_{R X}$ obtido da reflexão (311), mais intensa e bem definida em cada difratograma (Tabela 4.10), percebemos que o tamanho de grão cristalino pode ser avaliado como $(11,1 \pm 0,7)$ nm dos dados de difração de R-X, sem nenhuma tendência a aumento ou diminuição com recobrimento por AO ou troca de ligantes por MSA ou DMSA em diferentes razões molares. 
Tabela 4.10: Tamanho de grão cristalino calculado para as reflexões (311) de todas as amostras.

\begin{tabular}{cc}
\hline NPs & $\mathrm{D}_{R X 311}(\mathrm{~nm})$ \\
\hline NP & $10,7(2)$ \\
NPAO & $11,8(2)$ \\
\hline NPMSA110 & $10,8(2)$ \\
NPMSA140 & $10,5(8)$ \\
NPMSA180 & $11,7(3)$ \\
\hline NPDMSA110 & $11,4(3)$ \\
NPDMSA140 & $10,6(2)$ \\
NPDMSA180 & $11,4(3)$ \\
\hline
\end{tabular}




\subsection{Microscopia Eletrônica de Transmissão - MET}

As Figuras 4.17 e 4.18 apresentam as micrografias e histogramas das NPs sintetizadas (NP) e recobertas com ácido oleico (NPAO), respectivamente. As Figuras 4.19, 4.20 e 4.21 apresentam as micrografias e histogramas de distribuição de tamanhos das NPs após serem funcionalizadas com ácido mercaptosuccínico (MSA) em razões de concentrações de 1:10 (NPMSA110), 1:40 (NPMSA140) e 1:80 (NPMSA180) respectivamente; enquanto as Figuras 4.22 , 4.23 e 4.24 apresentam os resultados para as NPs após serem funcionalizadas com ácido dimercaptosuccínico (DMSA) em razões de concentrações de 1:10 (NPDMSA110), 1:40 (NPDMSA140) e 1:80 (NPDMSA180), respectivamente.

O ajuste dos histogramas (linha vermelha contínua, Figura 4.17 a Figura 4.24) para cada distribuição de tamanhos das nanopartículas foi realizado através de uma função Log-Normal (Equação 3.9), da qual extraímos o valor mediano $\left(\mathrm{d}_{0}\right)$ da distribuição, e o desvio padrão $\left(\sigma_{T E M}\right)$. A partir destes valores e, utilizando as Equações 3.10 e 3.11, são obtidos o valor típico $\left(\mathrm{D}_{T E M}\right)$ correspondendo ao máximo da função de densidade de probabilidade, e o valor médio $\left(\mathrm{D}<_{T E M}>\right)$ dos diâmetros na distribuição de tamanhos, respectivamente. A Tabela 4.11 apresenta os resultados obtidos.

Para fins comparativos em cada um dos histogramas apresentados nesta seção, indicamos o tamanho de grão cristalino $\mathrm{D}_{R X}$ obtido a partir da análise do pico de difração da reflexão do plano cristalográfico (311) (Tabelas 4.8 e 4.9). 

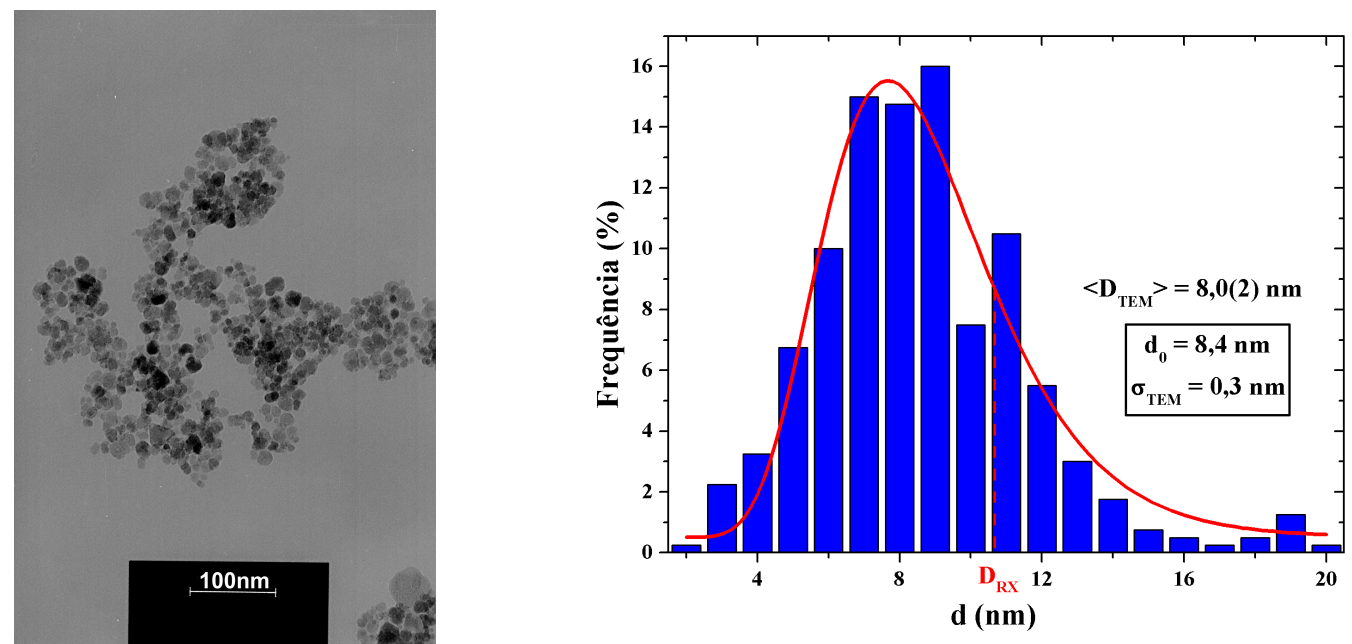

Figura 4.17: Micrografia das nanopartículas sintetizadas (NP) e sua distribuição de tamanhos. O tamanho de grão cristalino $\mathrm{D}_{R X}$ é destacado com a linha vermelha tracejada no histograma, $\mathrm{d}_{0},\left\langle\mathrm{D}_{T E M}>\mathrm{e} \sigma_{T E M}\right.$ correspondem à mediana, valor médio e desvio padrão da distribuição, respectivamente.
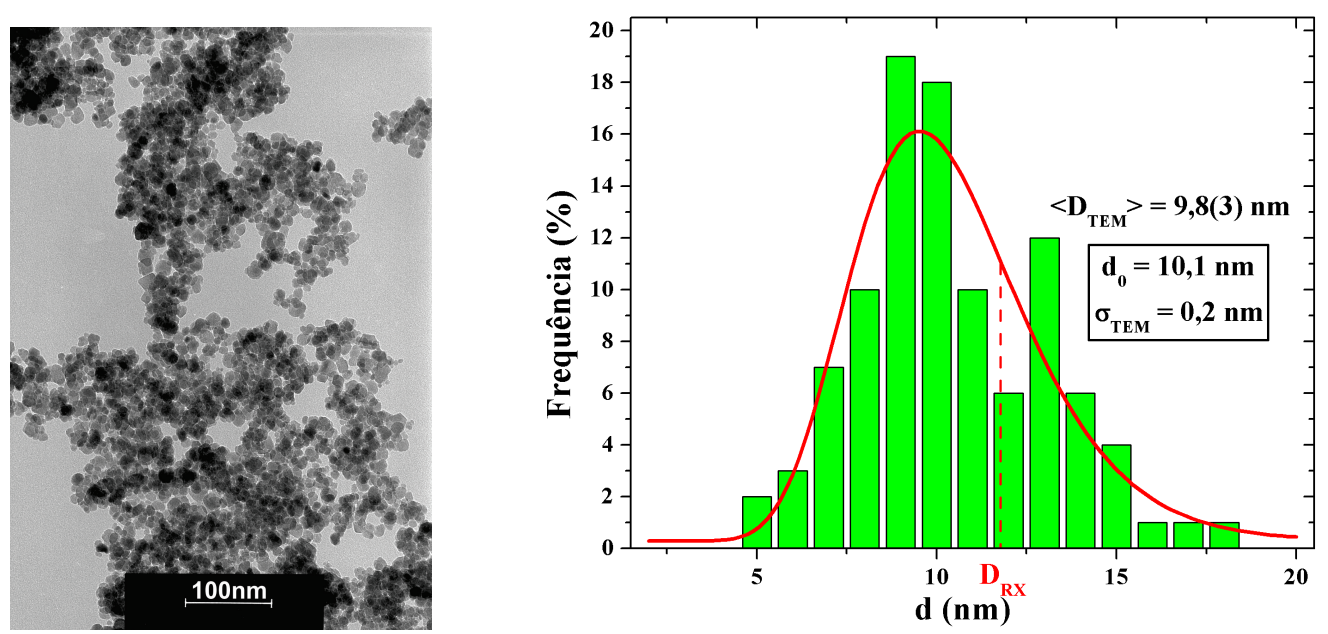

Figura 4.18: Micrografia das nanopartículas recobertas com ácido oleico (NPAO) e sua distribuição de tamanhos. O tamanho de grão cristalino $\mathrm{D}_{R X}$ é destacado com a linha vermelha tracejada no histograma, $\mathrm{d}_{0},\left\langle\mathrm{D}_{T E M}\right\rangle$ e $\sigma_{T E M}$ correspondem à mediana, valor médio e desvio padrão da distribuição, respectivamente. 

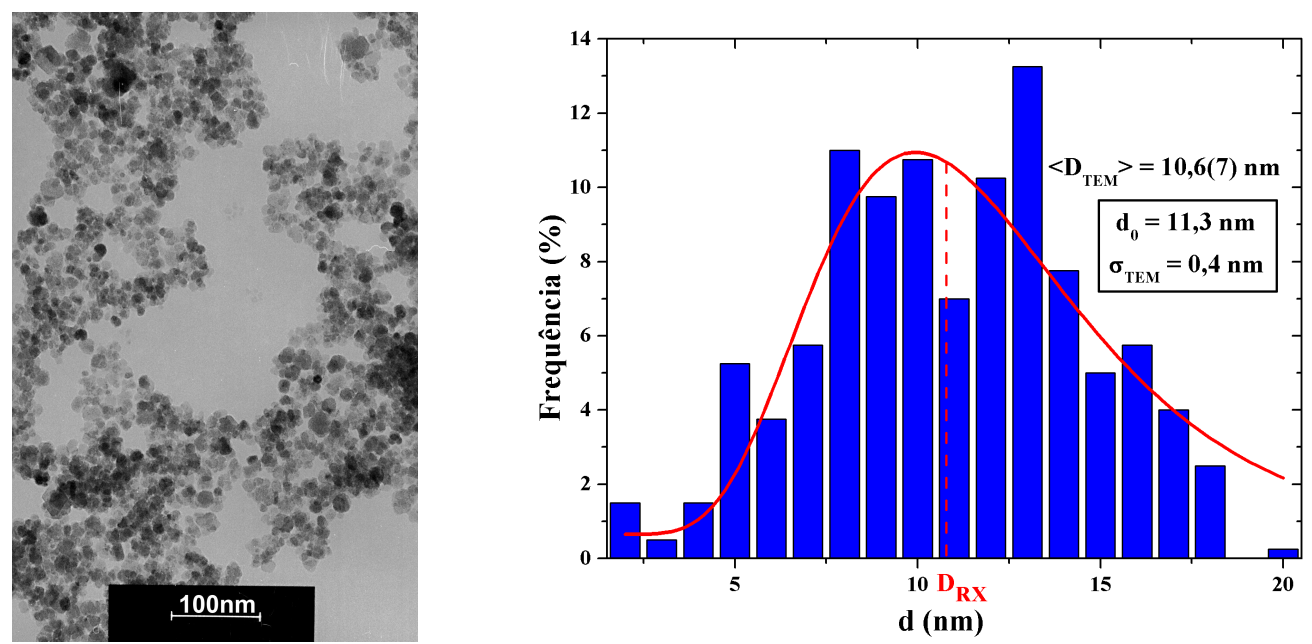

Figura 4.19: Micrografia das nanopartículas após serem funcionalizadas com ácido mercaptosuccínico em razão 1:10 (NPMSA110) e sua distribuição de tamanhos. O tamanho de grão cristalino $\mathrm{D}_{R X}$ é destacado com a linha vermelha tracejada no histograma, $\mathrm{d}_{0},\left\langle\mathrm{D}_{T E M}\right\rangle \mathrm{e}$ $\sigma_{T E M}$ correspondem à mediana, valor médio e desvio padrão da distribuição, respectivamente.
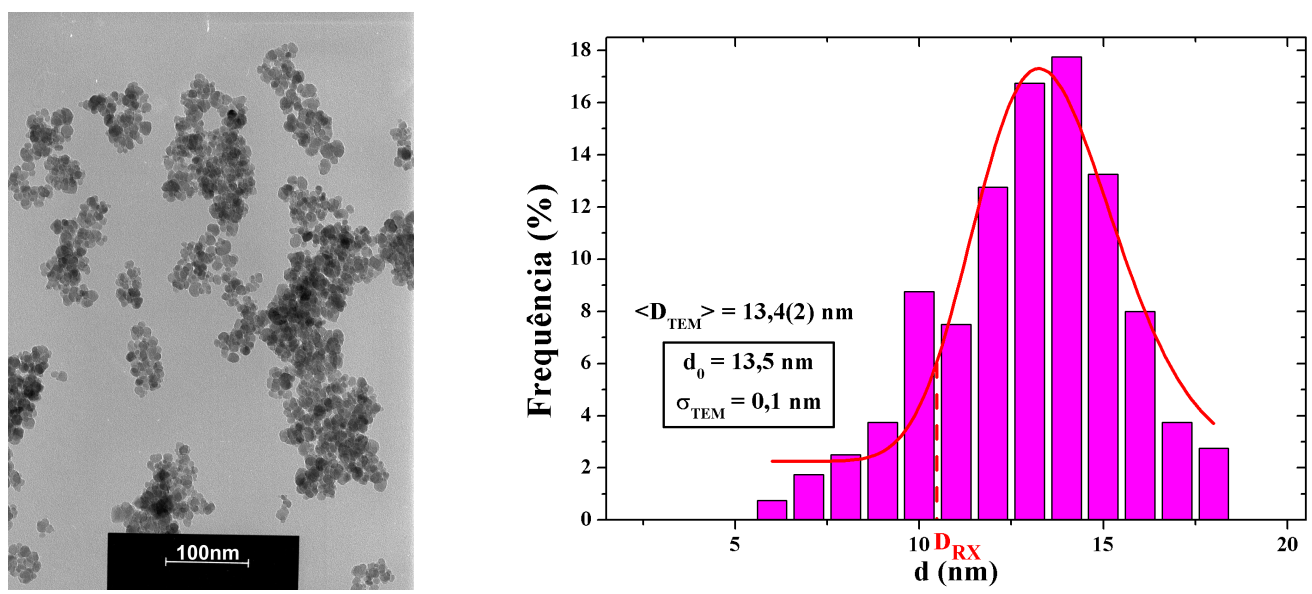

Figura 4.20: Micrografia das nanopartículas após serem funcionalizadas com ácido mercaptosuccínico em razão 1:40 (NPMSA140) e sua distribuição de tamanhos. O tamanho de grão cristalino $\mathrm{D}_{R X}$ é destacado com a linha vermelha tracejada no histograma, $\mathrm{d}_{0},\left\langle\mathrm{D}_{T E M}\right\rangle \mathrm{e}$ $\sigma_{T E M}$ correspondem à mediana, valor médio e desvio padrão da distribuição, respectivamente. 

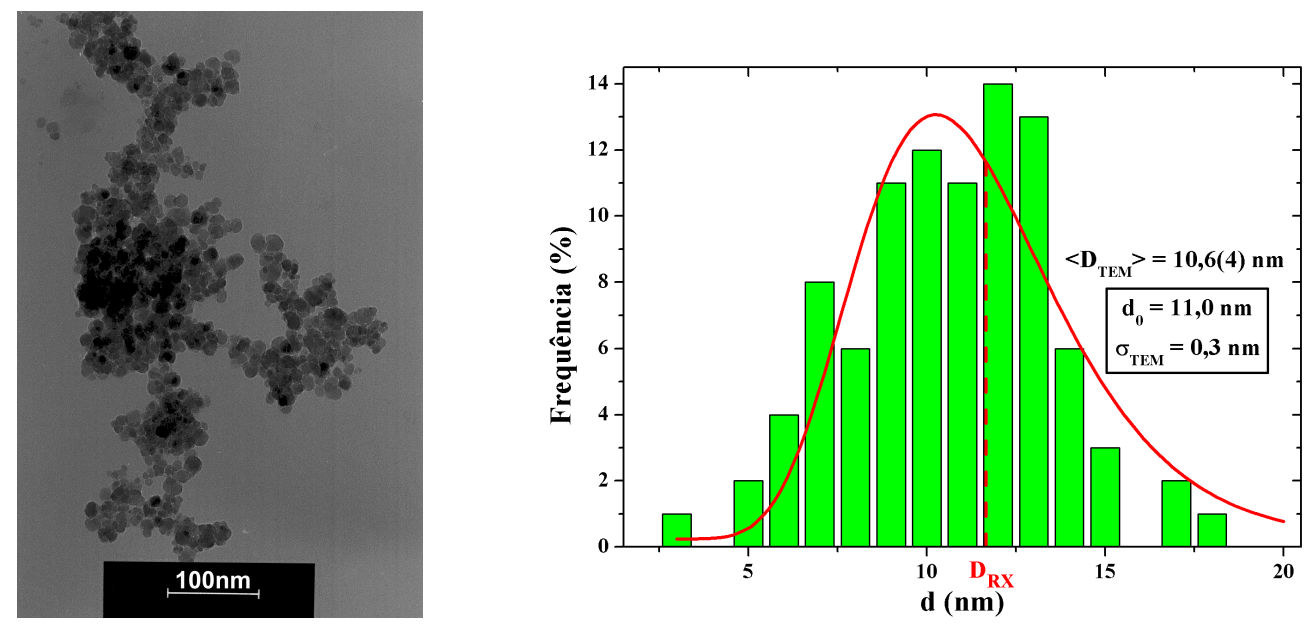

Figura 4.21: Micrografia das nanopartículas após serem funcionalizadas com ácido mercaptosuccínico em razão 1:80 (NPMSA180) e sua distribuição de tamanhos. O tamanho de grão cristalino $\mathrm{D}_{R X}$ é destacado com a linha vermelha tracejada no histograma, $\mathrm{d}_{0},\left\langle\mathrm{D}_{T E M}\right\rangle \mathrm{e}$ $\sigma_{T E M}$ correspondem à mediana, valor médio e desvio padrão da distribuição, respectivamente.
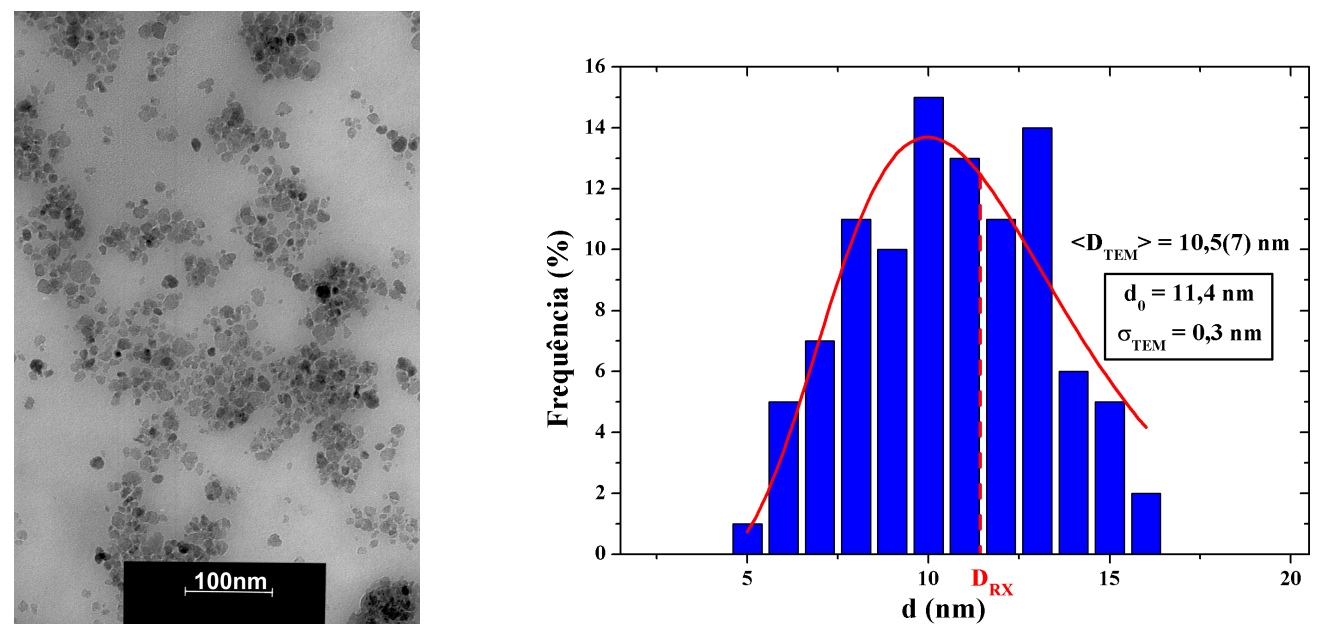

Figura 4.22: Micrografia das nanopartículas após serem funcionalizadas com ácido dimercaptosuccínico (DMSA) em razão 1:10 (NPDMSA110) e sua distribuição de tamanhos. O tamanho de grão cristalino $\mathrm{D}_{R X}$ é destacado com a linha vermelha tracejada no histograma, $\mathrm{d}_{0},\left\langle\mathrm{D}_{T E M}\right\rangle$ e $\sigma_{T E M}$ correspondem à mediana, valor médio e desvio padrão da distribuição, respectivamente. 

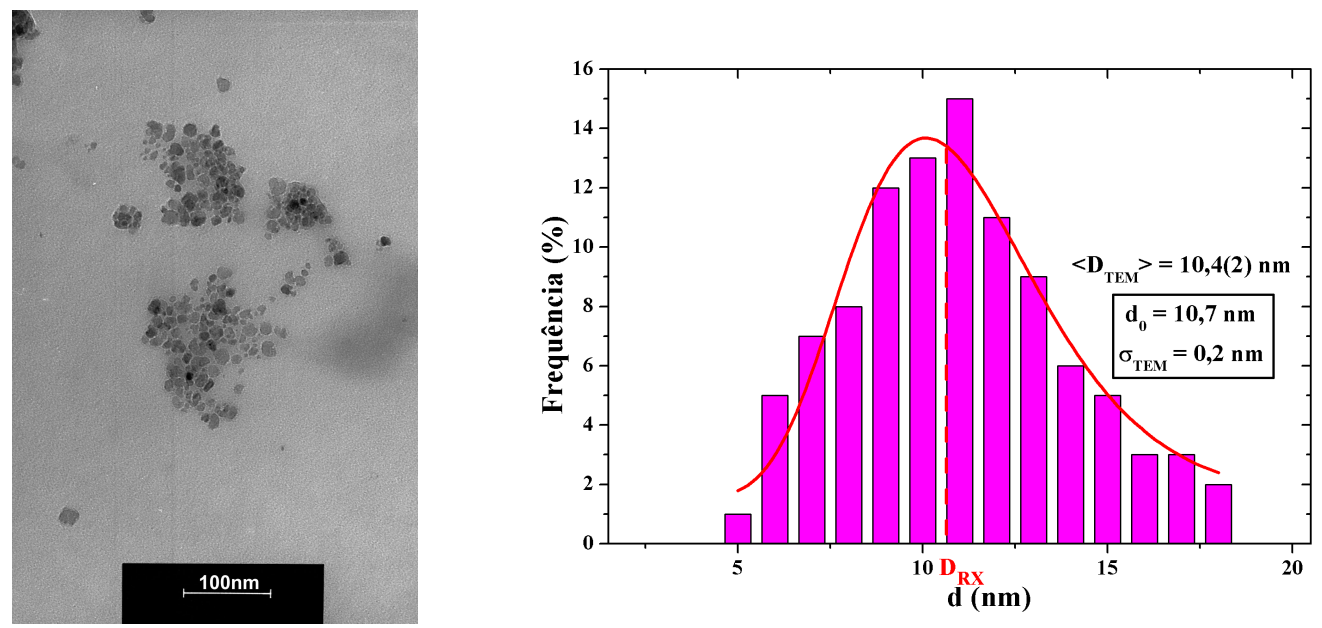

Figura 4.23: Micrografia das nanopartículas após serem funcionalizadas com ácido dimercaptosuccínico (DMSA) em razão 1:40 (NPDMSA140) e sua distribuição de tamanhos. O tamanho de grão cristalino $\mathrm{D}_{R X}$ é destacado com a linha vermelha tracejada no histograma, $\mathrm{d}_{0},\left\langle\mathrm{D}_{T E M}>\right.$ e $\sigma_{T E M}$ correspondem à mediana, valor médio e desvio padrão da distribuição, respectivamente.
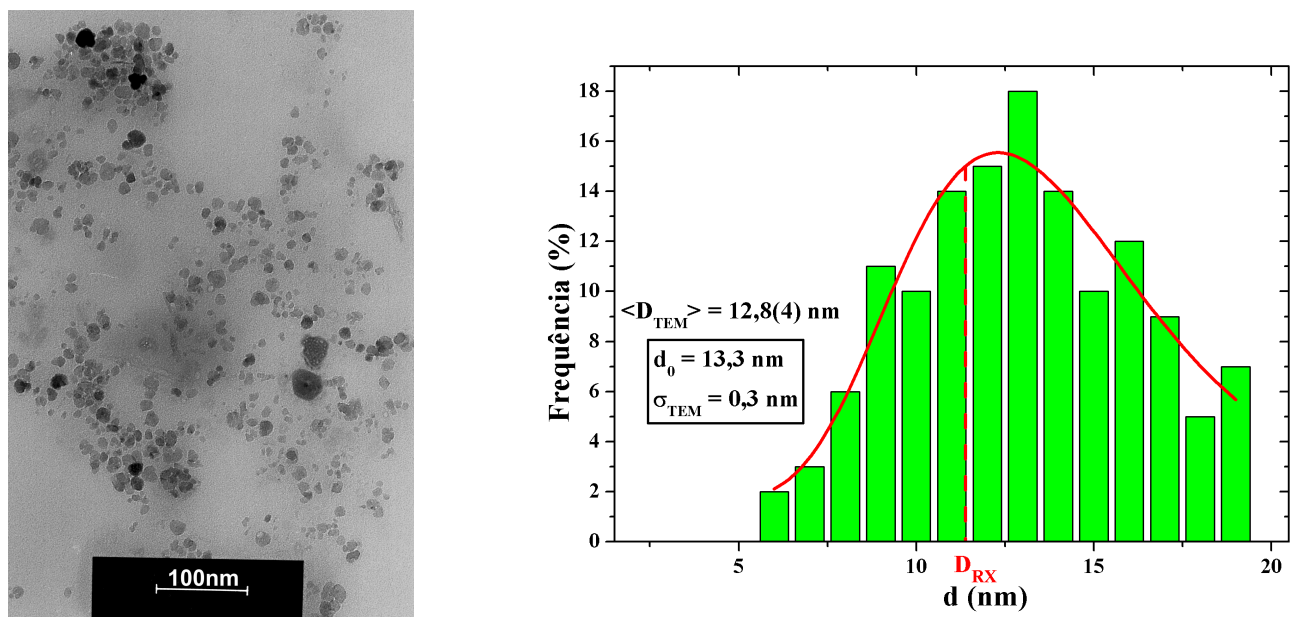

Figura 4.24: Micrografia das nanopartículas após serem funcionalizadas com ácido dimercaptosuccínico (DMSA) em razão 1:80 (NPDMSA180) e sua distribuição de tamanhos. O tamanho de grão cristalino $\mathrm{D}_{R X}$ é destacado com a linha vermelha tracejada no histograma, $\mathrm{d}_{0},\left\langle\mathrm{D}_{T E M}>\mathrm{e} \sigma_{T E M}\right.$ correspondem à mediana, valor médio e desvio padrão da distribuição, respectivamente. 
Tabela 4.11: Valor mediano $\left(\mathrm{d}_{0}\right)$ e desvio padrão $\left(\sigma_{T E M}\right)$ obtidos do ajuste da função $\log$ Normal (Equação 3.9) aos histogramas da distribuição de tamanhos para cada amostra. Valor típico $\left(\mathrm{D}_{T E M}\right)$ e valor médio $\left(\left\langle\mathrm{D}_{T E M}\right\rangle\right)$ obtidos a partir das Equações 3.10 e 3.11 . respectivamente.

\begin{tabular}{cccccc}
\hline NPMs & $\mathrm{d}_{0}(\mathrm{~nm})$ & $\sigma_{T E M}(\mathrm{~nm})$ & $\mathrm{D}_{T E M}(\mathrm{~nm})$ & $\left\langle\mathrm{D}_{T E M}\right\rangle(\mathrm{nm})$ & $\mathrm{D}_{R X 311}(\mathrm{~nm})$ \\
\hline $\mathrm{NP}$ & 8,4 & 0,3 & $7,7(2)$ & $8,0(2)$ & $10,7(2)$ \\
NPAO & 10,1 & 0,2 & $9,5(3)$ & $9,8(3)$ & $11,8(2)$ \\
\hline NPMSA110 & 11,3 & 0,4 & $9,9(8)$ & $10,6(7)$ & $10,8(2)$ \\
NPMSA140 & 13,5 & 0,1 & $13,3(2)$ & $13,4(2)$ & $10,5(4)$ \\
NPMSA180 & 11,0 & 0,3 & $10,2(4)$ & $10,6(4)$ & $11,7(3)$ \\
\hline NPDMSA110 & 11,4 & 0,3 & $10,0(9)$ & $10,5(7)$ & $11,4(3)$ \\
NPDMSA140 & 10,7 & 0,2 & $10,1(3)$ & $10,4(2)$ & $10,6(2)$ \\
NPDMSA180 & 13,3 & 0,3 & $12,3(5)$ & $12,8(4)$ & $11,4(3)$ \\
\hline
\end{tabular}

A partir da análise das Figuras 4.17 a 4.24 e os valores de $\mathrm{d}_{0}, \mathrm{D}_{T E M}$ e $\left\langle\mathrm{D}_{T E M}\right\rangle$ (Tabela 4.11) observamos que estes são valores próximos entre si, evidenciando, em todos os casos, uma distribuição de tamanhos aproximadamente simétrica. No caso da amostra NP sintetizada (sem recobrimento), a mesma apresenta o menor valor de diâmetro $\sim 8 \mathrm{~nm}$ em comparação com os valores observados para outras amostras (de 10 a $13 \mathrm{~nm}$ ) e aos tamanhos do grão determinados por $\mathrm{RX}\left(\mathrm{D}_{R X}\right)$. Vale a pena ressaltar, entretanto, que o valor de $\mathrm{D}_{R X}$ encontra-se dentro da distribuição para a amostra NP (Figura 4.17). Mais ainda, a frequência com que as NPs com tamanhos da ordem de 10 a $11 \mathrm{~nm}$ aparecem na distribuição (cerca de $50 \%$ da frequência das NPs de tamanho $\sim 8 \mathrm{~nm}$ - Figura 4.17) justifica que estas NPs maiores contribuam significativamente para a largura dos picos de difração observados. Como consequência, observamos $\mathrm{D}_{R X}>\mathrm{D}_{T E M}$ para NPs sem recobrimento.

Por outro lado, para NPs recobertas tanto com AO como com MSA e DMSA, observamos um deslocamento dos valores médios, máximos e medianos da distribuição para valores maiores mais próximos aos tamanhos de grão cristalino $\mathrm{D}_{R X}$ calculados. Note-se que, entretanto, para as amostras recobertas com MSA 1:40 (Figura 4.20) e DMSA 1:80 (Figura 4.24 , as correspondentes distribuições de tamanho são deslocadas para valores maiores que os valores de $\mathrm{D}_{R X}$. Talvez a presença destas partículas maiores esteja relacionada a um maior recobrimento da superfície das mesmas, sem alterar o tamanho do núcleo cristalino. 


\subsection{Magnetometria de Amostra Vibrante - VSM}

A Figura 4.25 apresenta a variação da magnetização específica com o campo magnético aplicado para as nanopartículas sintetizadas (NP) e recobertas com ácido oleico (NPAO), enquanto a Figura 4.26 apresenta as curvas de histerese das NPs após funcionalização com MSA na razão de 1:10 (NPMSA110), 1:40 (NPMSA140) e 1:80 (NPMSA180), e a Figura 4.27 apresenta as curvas de histerese das NPs funcionalizadas com DMSA na razão de 1:10 (NPDMSA110), 1:40 (NPDMSA140) e 1:80 (NPDMSA180).

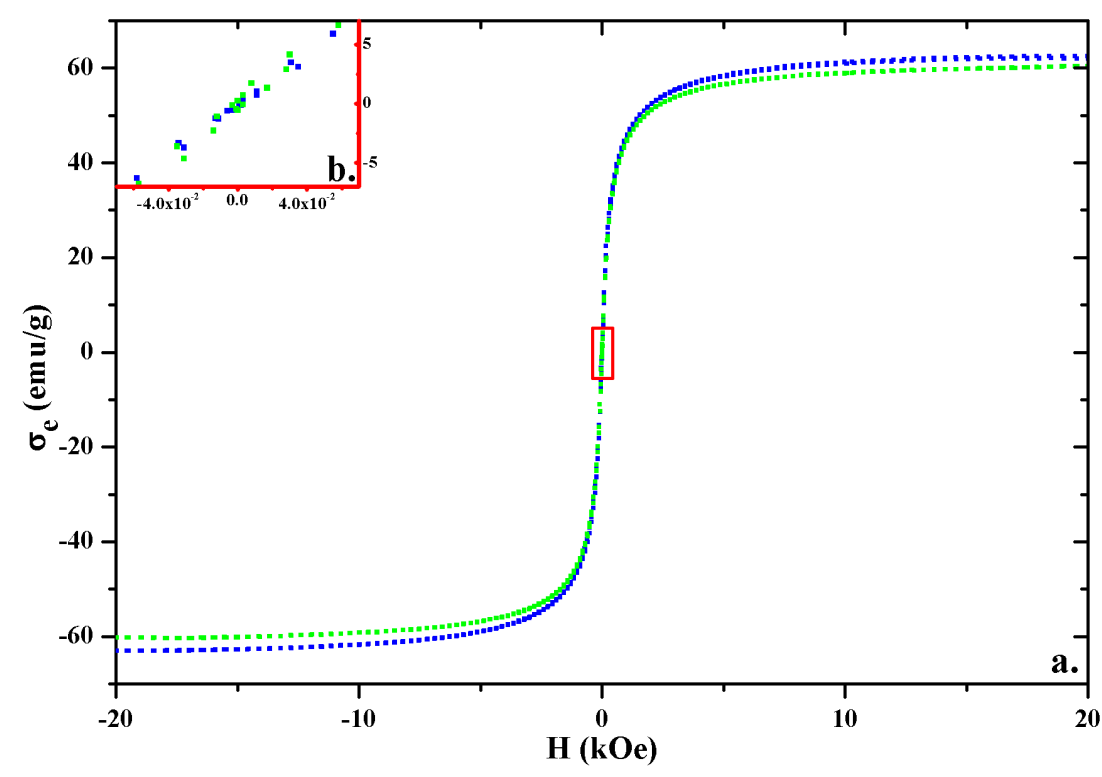

Figura 4.25: a. Curva de histerese das nanopartículas após serem obtidas (NP) e após recobrimento com ácido oleico (NPAO); b. Ampliação da região selecionada pelo retângulo vermelho. 


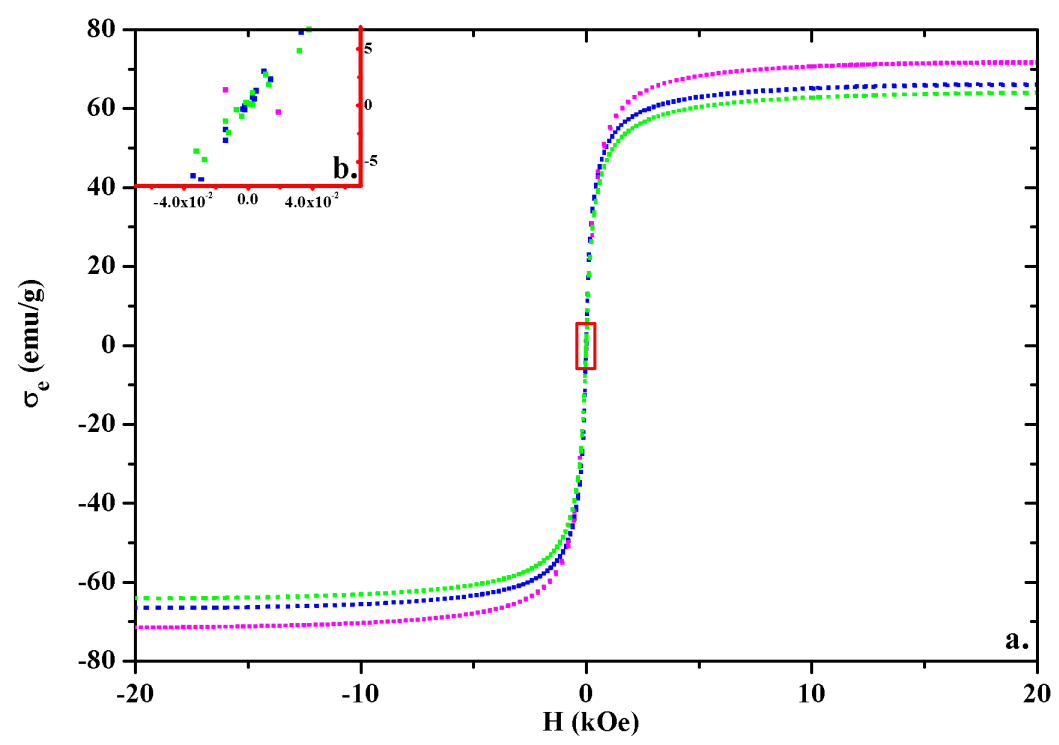

Figura 4.26: a. Curva de histerese das nanopartículas após serem funcionalizadas com MSA na razão de 1:10 (NPMSA110), 1:40 (NPMSA140) e 1:80 (NPMSA180); b. Ampliação da região selecionada pelo retângulo vermelho.

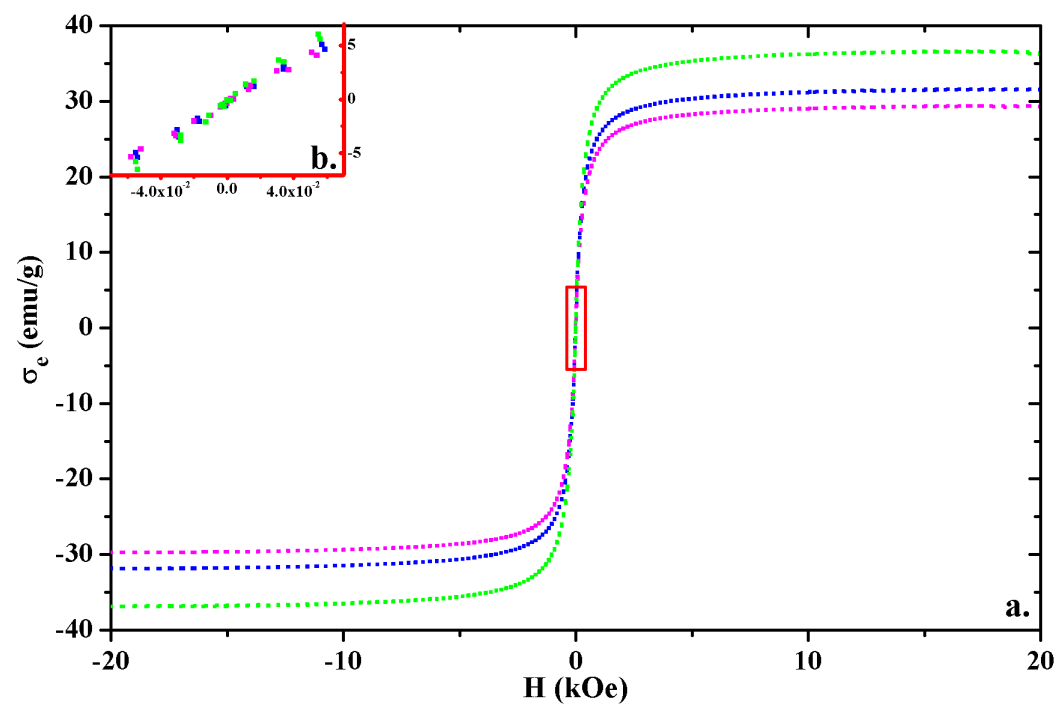

Figura 4.27: a. Curva de histerese das nanopartículas após serem funcionalizadas com DMSA na razão de 1:10 (NPDMSA110), 1:40 (NPDMSA140) e 1:80 (NPDMSA180); b. Ampliação da região selecionada pelo retângulo vermelho. 
Nas Figuras 4.25, 4.26 e 4.27, podemos observar um comportamento superparamagnético de todas as amostras estudadas. Uma ampliação da região em torno de $\mathrm{H}=0$ (exemplo na Figura 4.25 indica uma baixa magnetização específica remanente $\left(\sigma_{r} \sim 0,1-0,5 \mathrm{emu} / \mathrm{g}\right)$, evidenciando que os momentos magnéticos estão aleatoriamente orientados na ausência do campo magnético; já o campo coercivo (responsável pela anulação da magnetização remanente) apresenta também valores baixos $\left(\mathrm{H}_{c} \sim 5\right.$-10 Oe), como esperado para NPs superparamagneticas. Os valores de saturação da magnetização específica $\left(\sigma_{s}\right)$ foram obtidos através da média dos valores atingidos da magnetização específica para valores máximos do campo magnético, e são apresentados na Tabela 4.12 .

Tabela 4.12: Magnetização específica de saturação $\left(\sigma_{s}\right)$ das NPMs.

\begin{tabular}{cc}
\hline NPMs & $\sigma_{s}(\mathrm{emu} / \mathrm{g})$ \\
\hline NP & $62,2(2)$ \\
NPAO & $62,4(3)$ \\
\hline NPMSA110 & $66,0(1)$ \\
NPMSA140 & $71,6(1)$ \\
NPMSA180 & $63,9(1)$ \\
\hline NPDMSA110 & $31,6(1)$ \\
NPDMSA140 & $29,31(3)$ \\
NPDMSA180 & $36,4(2)$ \\
\hline
\end{tabular}

Sabemos da literatura que a magnetização específica da magnetita «bulk» é da ordem de $\sim 85$ a $100 \mathrm{emu/g}$ e um campo coercivo entre 115-150 Oe [87], enquanto para nanopartículas de magnetita não modificadas na superfície $\sigma_{s} \sim 92 \mathrm{emu} / \mathrm{g}$ [49, 87]. No nosso caso, estamos encontrando um valor de $\sigma_{s}$ menor que o reportado na literatura, provavelmente devido à formação de uma camada de spins desalinhados próxima à superfície.

Por outro lado, observamos que $\sigma_{s}$ não se alterou após o recobrimento com ácido oleico (Tabela 4.12). No caso das nanopartículas recobertas com MSA observa-se um pequeno incremento no comportamento magnético, o que poderia indicar um aparente recobrimento paramagnético com MSA; já no caso do DMSA, o valor de $\sigma_{s}$ decresce em quase $50 \%$, indicando que o DMSA deve estar contribuindo com uma camada diamagnética. Levando-se em conta que ambas NPs funcionalizadas com MSA e DMSA, independentemente das razões molares; apresentam comportamento superparamagnético a temperatura ambiente, aquelas recobertas com MSA apresentam-se como melhores candidatas pra aplicações biomédicas devido ao seu maior valor de magnetização de saturação $\left(\sigma_{s}\right)$. 
Como apresentamos na Introdução (Capítulo 1) e Metodologia (Capítulo 3), as curvas do momento magnético podem ser ajustadas através da Equação 3.12 , fornecendo funções de distribuição de tamanhos para NPMs. Os ajustes às curvas do momento magnético e os respectivos histogramas são apresentados nas Figuras 4.28 a 4.35 . Os valores de diâmetro magnético $\left(\mathrm{d}_{V S M}\right)$ correspondente à mediana da distribuição são apresentados na Tabela 4.13, em comparação aos valores de $\mathrm{D}_{R X}$ e $\mathrm{d}_{0}$ (TEM) 

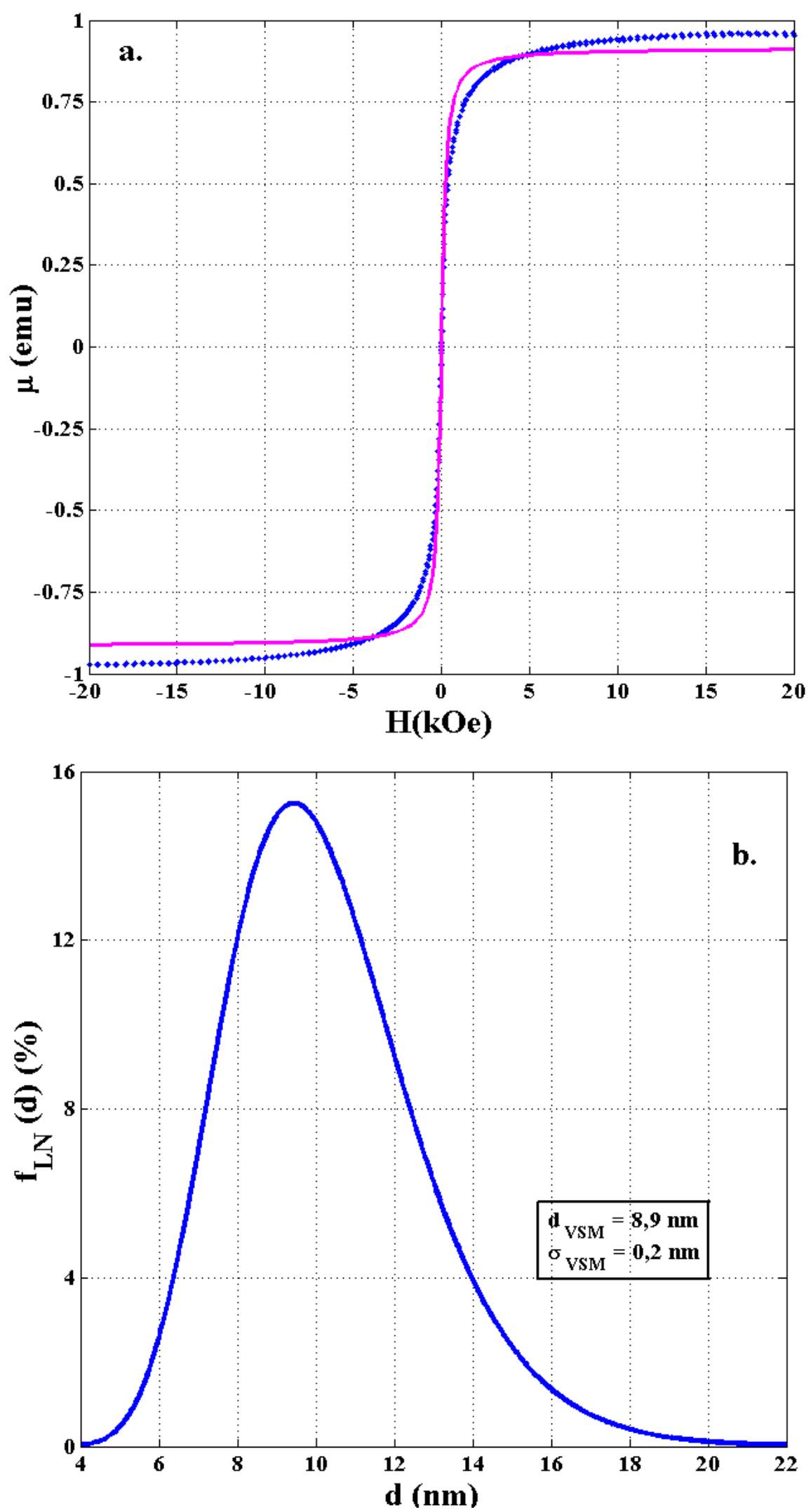

Figura 4.28: a. Ajuste do momento magnético (Equação 3.12 para as nanopartículas sintetizadas (NP). b. Distribuição de tamanhos, indicada pela função Log-Normal ( $\mathrm{f}_{\mathrm{LN}}$ Figura 3.9 obtida a partir do ajuste, onde $\mathrm{d}_{V S M}$ corresponde à mediana e $\sigma_{V S M}$ ao desvio padrão. 

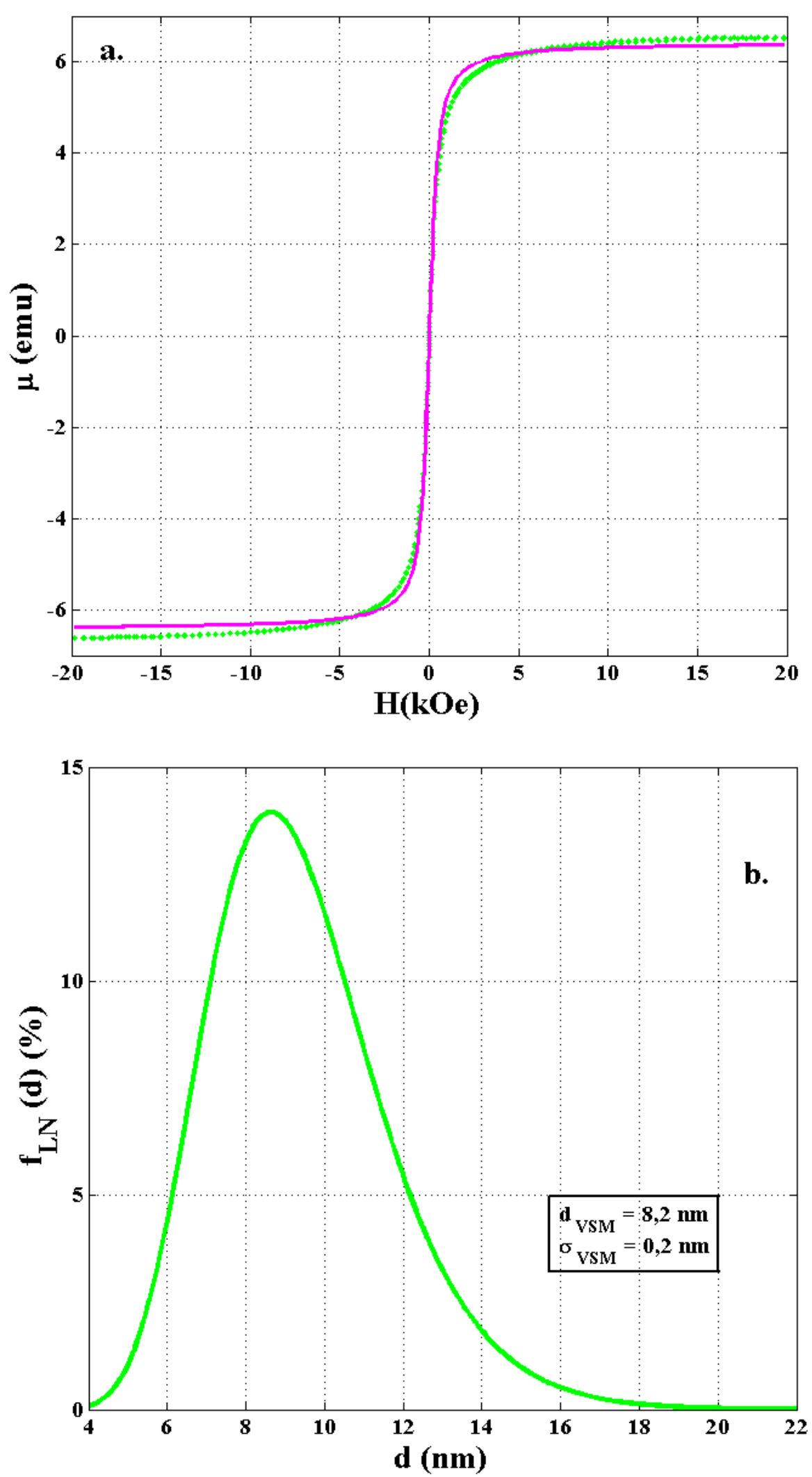

Figura 4.29: a. Ajuste do momento magnético (Equação 3.12 para as nanopartículas após recobrimento com ácido oleico $(\mathrm{NPAO})$. b. Distribuição de tamanhos, indicada pela função Log-Normal ( $\mathrm{f}_{\mathrm{LN}}$ - Figura 3.9 ) obtida a partir do ajuste, onde $\mathrm{d}_{V S M}$ corresponde à mediana e $\sigma_{V S M}$ ao desvio padrão. 

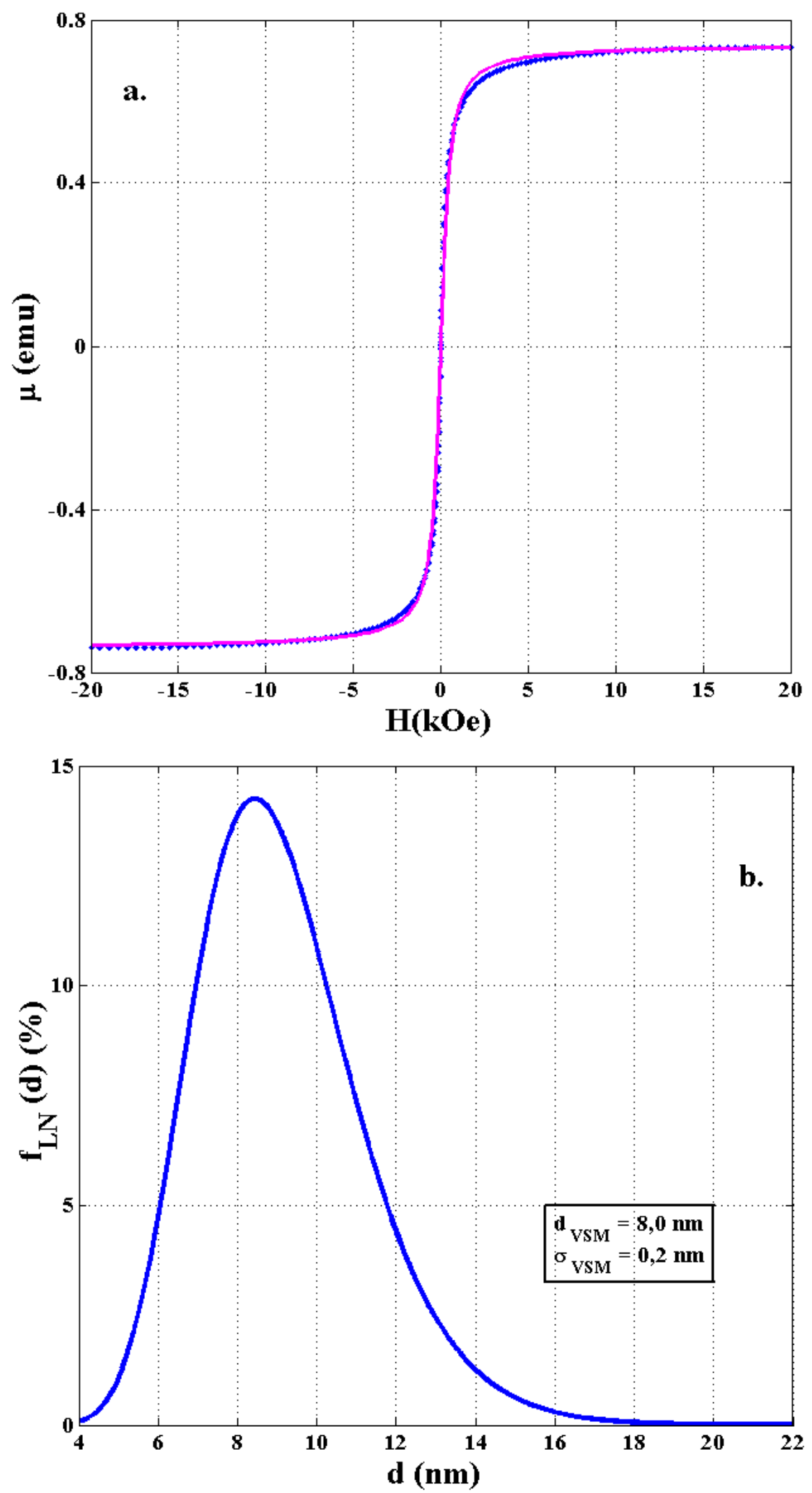

Figura 4.30: a. Ajuste do momento magnético (Equação 3.12 para as nanopartículas funcionalizadas com MSA em razão de 1:10 (NPMSA110). b. Distribuição de tamanhos, indicada pela função Log-Normal ( $\mathrm{f}_{\mathrm{LN}}$ - Figura 3.9) obtida a partir do ajuste, onde $\mathrm{d}_{V S M}$ corresponde à mediana e $\sigma_{V S M}$ ao desvio padrão. 

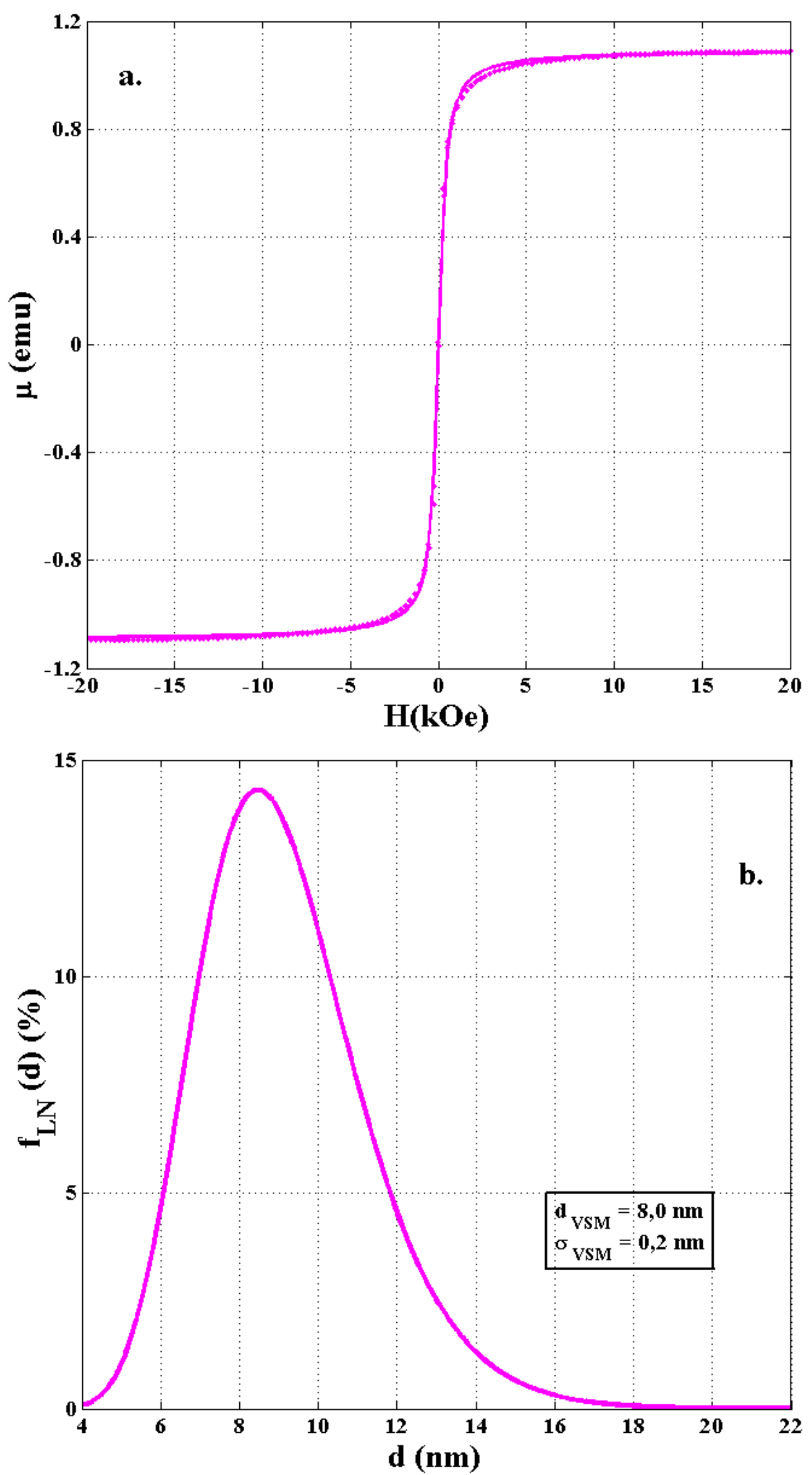

Figura 4.31: a. Ajuste do momento magnético (Equação 3.12) para as nanopartículas funcionalizadas com MSA em razão de 1:40 (NPMSA140). b. Distribuição de tamanhos, indicada pela função $\log$-Normal ( $\mathrm{f}_{\mathrm{LN}}$ - Figura 3.9 obtida a partir do ajuste, onde $\mathrm{d}_{V S M}$ corresponde à mediana e $\sigma_{V S M}$ ao desvio padrão. 

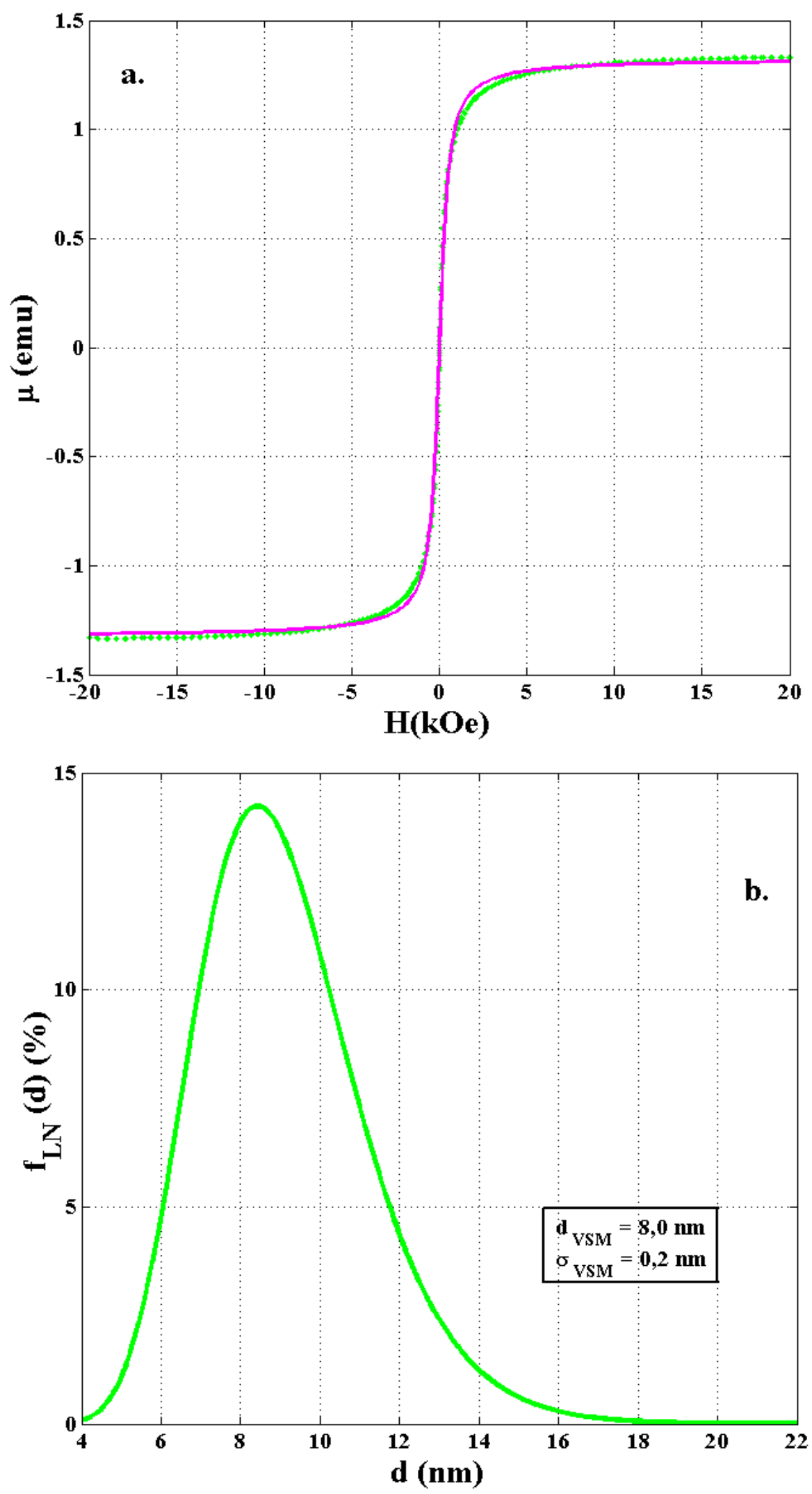

Figura 4.32: a. Ajuste do momento magnético (Equação 3.12 para as nanopartículas funcionalizadas com MSA em razão de 1:80 (NPMSA180). b. Distribuição de tamanhos, indicada pela função Log-Normal ( $\mathrm{f}_{\mathrm{LN}}$ - Figura 3.9) obtida a partir do ajuste, onde $\mathrm{d}_{V S M}$ corresponde à mediana e $\sigma_{V S M}$ ao desvio padrão. 

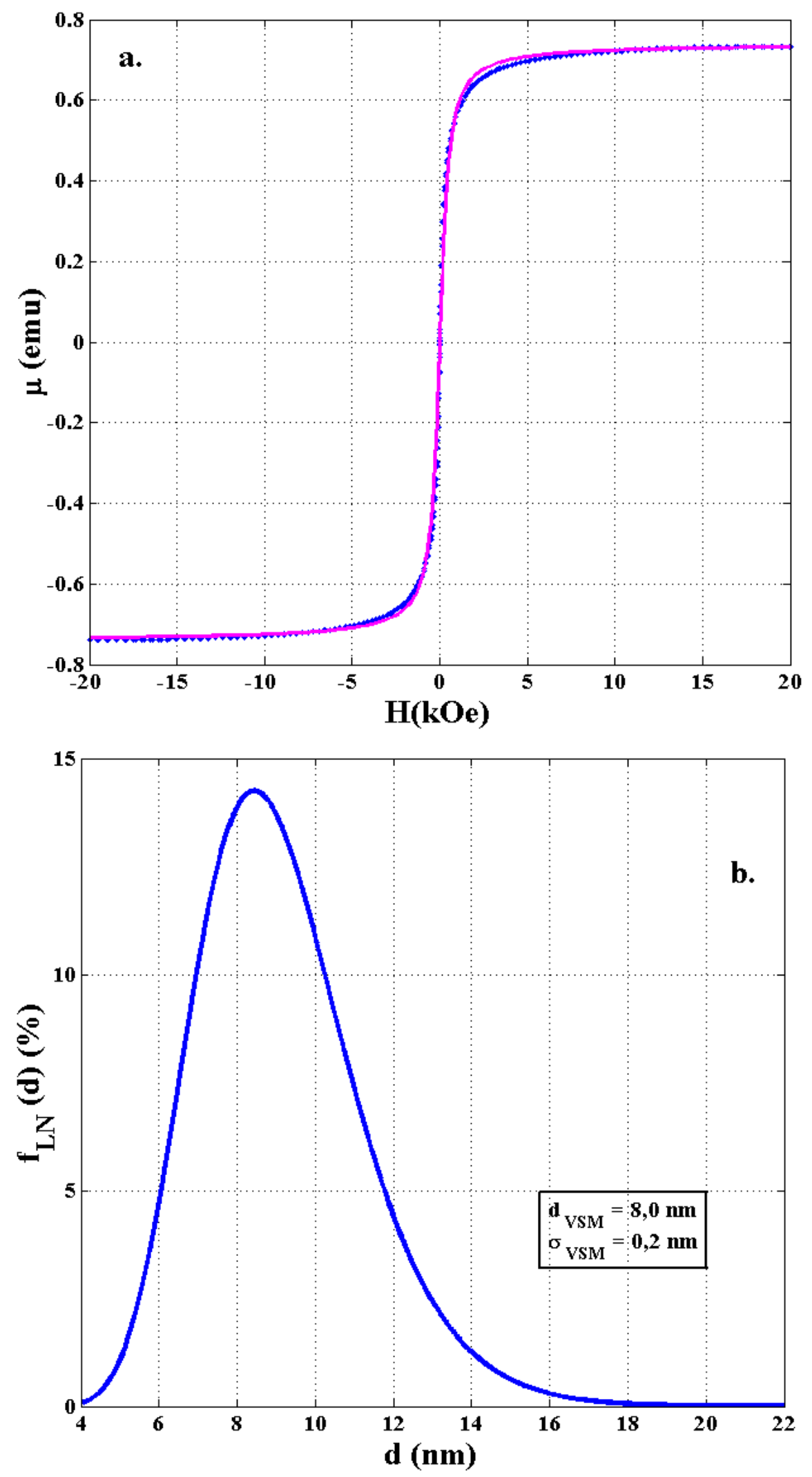

Figura 4.33: a. Ajuste do momento magnético (Equação 3.12) para as nanopartículas funcionalizadas com DMSA em razão de 1:10 (NPDMSA110). b. Distribuição de tamanhos, indicada pela função Log-Normal ( $\mathrm{f}_{\mathrm{LN}}$ - Figura 3.9) obtida a partir do ajuste, onde $\mathrm{d}_{V S M}$ corresponde à mediana e $\sigma_{V S M}$ ao desvio padrão. 

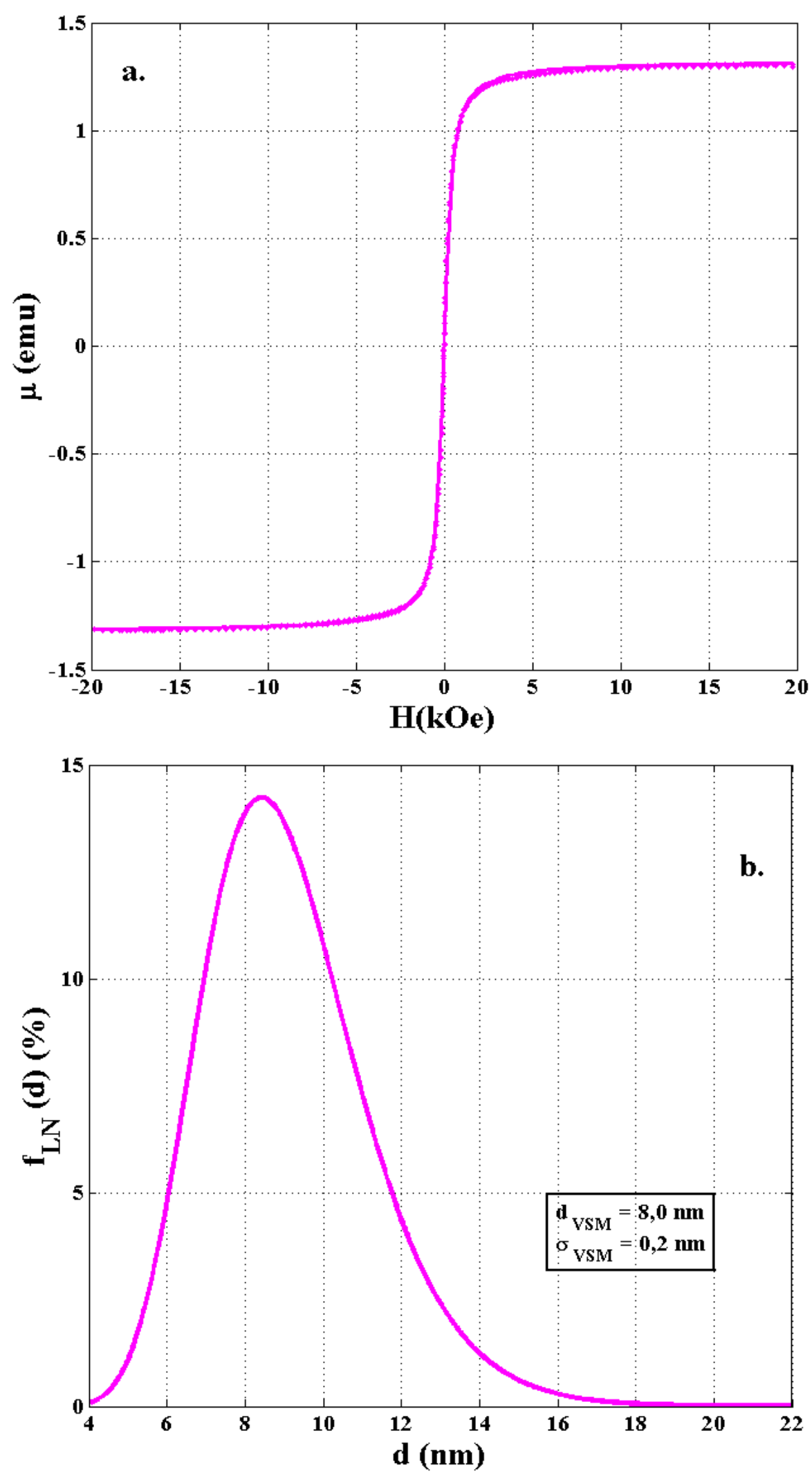

Figura 4.34: a. Ajuste do momento magnético (Equação 3.12 para as nanopartículas funcionalizadas com DMSA em razão de 1:40 (NPDMSA140). b. Distribuição de tamanhos, indicada pela função $\log$-Normal ( $\mathrm{f}_{\mathrm{LN}}$ - Figura 3.9) obtida a partir do ajuste, onde $\mathrm{d}_{V S M}$ corresponde à mediana e $\sigma_{V S M}$ ao desvio padrão. 

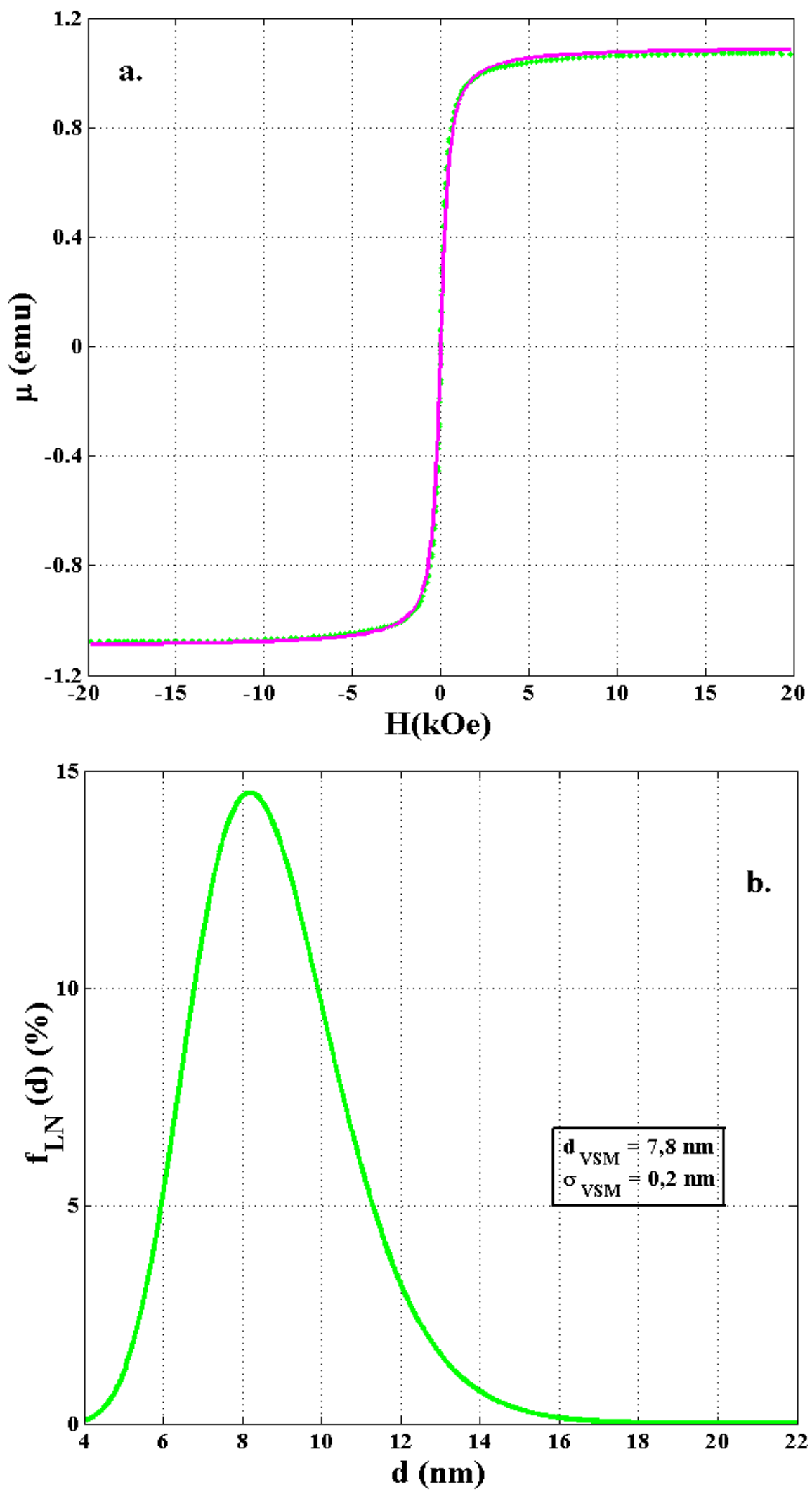

Figura 4.35: a. Ajuste do momento magnético (Equação 3.12 para as nanopartículas funcionalizadas com DMSA em razão de 1:80 (NPDMSA180). b. Distribuição de tamanhos, indicada pela função Log-Normal ( $\mathrm{f}_{\mathrm{LN}}$ - Figura 3.9) obtida a partir do ajuste, onde $\mathrm{d}_{V S M}$ corresponde à mediana e $\sigma_{V S M}$ ao desvio padrão. 
Tabela 4.13: Tamanho de grão cristalino $\left(\mathrm{D}_{D R X}\right)$, valor mediano $\left(\mathrm{d}_{0} T E M\right)$, desvio padrão $\left(\sigma_{T E M}\right)$ da distribuição de tamanhos obtidos da Microscopia Eletrônica, e valor mediano do diâmetro magnético $\left(\mathrm{d}_{V S M}\right)$, e seu desvio padrão $\left(\sigma_{V S M}\right)$ obtidos a partir da distribuição de tamanhos fornecida do ajuste da variação do momento magnético $(\mu)$ às curvas do momento magnético de cada amostra.

\begin{tabular}{|c|c|c|c|c|c|}
\hline NPMs & $\mathrm{D}_{R X}(\mathrm{~nm})$ & $\mathrm{d}_{0 T E M}(\mathrm{~nm})$ & $\sigma_{T E M}(\mathrm{~nm})$ & $\mathrm{d}_{V S M}(\mathrm{~nm})$ & $\sigma_{V S M}(\mathrm{~nm})$ \\
\hline $\mathrm{NP}$ & $10,7(2)$ & 8,4 & 0,3 & 8,9 & 0,2 \\
\hline NPAO & $11,8(2)$ & 10,1 & 0,2 & 8,2 & 0,2 \\
\hline NPMSA110 & $10,8(2)$ & 11,3 & 0,4 & 8,0 & 0,2 \\
\hline NPMSA140 & $10,5(8)$ & 13,5 & 0,1 & 8,0 & 0,2 \\
\hline NPMSA180 & $11,7(3)$ & 11,0 & 0,3 & 8,0 & 0,2 \\
\hline NPDMSA110 & $11,4(3)$ & 11,4 & 0,3 & 8,0 & 0,2 \\
\hline NPDMSA140 & $10,6(2)$ & 10,7 & 0,2 & 8,0 & 0,2 \\
\hline NPDMSA180 & $11,4(3)$ & 13,3 & 0,3 & 7,8 & 0,2 \\
\hline
\end{tabular}

Conforme podemos observar, a amostra sintetizada e não modificada superficialmente (NP) apresenta um valor mediano da distribuição $\mathrm{d}_{V S M}$ da ordem de $9 \mathrm{~nm}$, compatível com os valores de TEM e ligeiramente menor que o $\mathrm{D}_{R X}$.

Por outro lado, a modificação da superfície seja pela adsorção de AO quanto pela troca de ligantes com MSA ou DMSA aparentemente diminui o valor mediano da distribuição para $8 \mathrm{~nm}$, mas devemos ressaltar que a distribuição continua a apresentar uma certa largura $(\sim$ 2nm) compatível com os valores observados por TEM e de grão cristalino observados por R-X.

Portanto, os resultados conjuntos das técnicas utilizadas de caracterização dão suporte para concluir que as NPs sintetizadas (NP) correspondem a NPs de magnetita, com carácter superparamagnético a temperatura ambiente, apresentam morfologia uniforme e esférica, cujos tamanhos da ordem de 10nm (e polidispersão em tornde de $2 \mathrm{~nm}$ ) são apropriados para aplicações biomédicas. Os resultados de FTIR indicam que a funcionalização da superfície destas NPs com MSA ou DMSA foi feita de maneira eficiente, de tal maneira que as mesmas apresentam grupos funcionais tióis na superfície (Figura 4.12). 


\subsection{Liberação de NO}

\subsubsection{Primeira Etapa}

No primeiro estágio deste projeto de dissertação de Mestrado foi realizado o estudo da liberação de NO, a partir da amostra NPMSA140 nitrosada, como indicado na Seção 2.5.1.

A Figura 4.36 apresenta os dados representativos de quimioluminescência para injeções de (i) $100 \mu \mathrm{l}$ da suspensão de NPMSA140 não nitrosada e (ii) $100 \mu \mathrm{l}$ de solução aquosa de nitrito de sódio (amostras controle). Conforme observamos, a ausência de sinal garante que o Analisador mede apenas NO liberado de NPs contendo grupos nitrosotióis. Por outro lado, os picos em (iii) e (iv) correspondem às injeções de 100 e $10 \mu \mathrm{l}$ da solução aquosa das NP-SNO, respectivamente. Observa-se uma maior intensidade para a injeção de $100 \mu l$ (pico (iii)) comparada com a injeção de $10 \mu \mathrm{l}$ (pico (iv)). Estes resultados mostraram que o procedimento de nitrosação foi efetivo, de tal maneira que NO foi ligado às nanopartículas magnéticas funcionalizadas com MSA (razão 1:40) indicando, portanto, que estas NPs podem ser consideradas como veículos carreadores de NO.

Em relação ao perfil de liberação de NO com respeito ao tempo, a Figura 4.37 apresenta a liberação total de $\mathrm{NO}$ depois de $1 \mathrm{~h}, 2,3 \mathrm{~h}, 4,2 \mathrm{~h}$ e $6,7 \mathrm{~h}$ à temperatura de $25^{\circ} \mathrm{C}$ no escuro. Pode-se observar que este novo material tem a capacidade de liberar NO espontaneamente por muitas horas à temperatura ambiente. Como reportado anteriormente na literatura para moléculas de S-nitrosotióis (R-SNO) de baixo peso molecular, como a S-glutationa (GSNO), os grupos S-NO sofrem clivagem homolítica, liberando-se assim NO (Equações 4.1 e 4.2) [29]. Os produtos de decomposição depois da liberação de NO são dímeros de MSA ligados através de ponte disulfeto, de acordo com as reações [38]:

$$
\begin{gathered}
\mathrm{NP}-\mathrm{MSA}-\mathrm{SNO} \longrightarrow \mathrm{NP}-\mathrm{MSA}^{\circ} \mathrm{S}^{\bullet}+\mathrm{NO}^{\bullet} \\
\mathrm{NP}-\mathrm{MSA}^{\cdot} \mathrm{S}^{\cdot}+\mathrm{NP}-\mathrm{MSA}-\mathrm{S}^{\cdot} \longrightarrow \mathrm{NP}-\mathrm{MSA}-\mathrm{S}-\mathrm{S}-\mathrm{MSA}-\mathrm{NP}
\end{gathered}
$$


onde NP-MSA-SNO representa a molécula adsorvida de ácido mercaptosuccínico nitrosado sobre a superfície das NPs, enquanto NP-MSA-S ' representa o radical thiil formado após a ruptura homolítica da ligação S-N, e os dimeros resultantes NP-MSA-S-S-MSA-NP são esperados permanecer adsorvidos na superfície das NPs [38]. Embora desorção dos dímeros não possa ser desconsiderada, sua ocorrência deve ser pequena devido à adsorção estabelecida entre os grupos carboxila do MSA e a superfície do óxido de ferro.

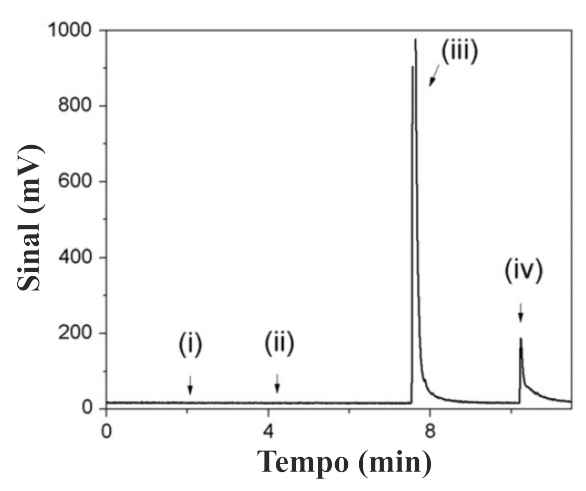

Figura 4.36: Dados representativos da quimioluminescência para a liberação de NO a partir dos grupos S-NO presentes nas superfície das NPs. As flechas indicam as seguintes injeções: (i): $100 \mu \mathrm{l}$ de NPs não nitrosadas (NPMSA140); (ii): $100 \mu \mathrm{l}$ de solução aquosa de $\mathrm{NaNO}_{2}$; (iii) e (iv): 100 e $10 \mu \mathrm{L}$ de da solução aquosa das NP-SNO, respectivamente. Figura extraída de [38].

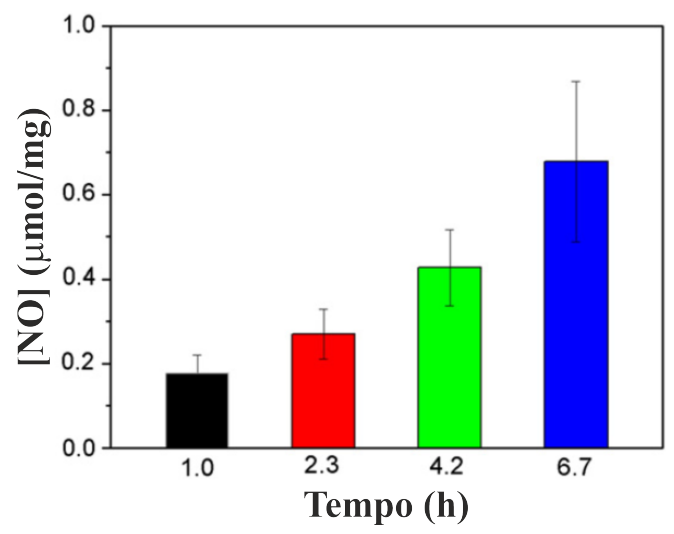

Figura 4.37: Perfil da Liberação de NO com respeito ao tempo. Figura extraída de [38]. 
Vale a pena ressaltar que a quantidade de NO liberado $(\mu \mathrm{mol} / \mathrm{mg})$ tem grande potencial para ser usado em diversas aplicações biomédicas. Particularmente, esta quantidade é adequada para promover cicatrização de feridas in vivo, como reportado na literatura [34]. Mais ainda, o perfil de liberação de NO (Figura 4.37) pode ser aplicado em situações que requerem um fluxo de NO liberado localmente por horas como, por exemplo, para acelerar cicatrização ou inibir adesão de plaquetas e formação de trombos em dispositivos médicos em contato com sangue [88].

Este é o primeiro trabalho referente à funcionalização de NPs magnéticas como carreadoras e liberadoras de NO e gerou uma patente (INPI 018120023545). O perfil de liberação de NO está de acordo com outros nanomateriais baseados em dendrímeros modificados, e nanopartículas de sílica liberadoras de NO [68]. Ressalta-se também, de maneira inovadora, o uso de MSA como agente de funcionalização de NPMs.

Tendo em vista explorar melhor a potencialidade destas NPs, resolvemos estender o trabalho investigando o papel da razão molar NP:MSA, assim como comparar os resultados obtidos com NPs funcionalizadas com DMSA, que apresentariam em princípio, dois grupos tióis expostos para reagir com NO.

\subsubsection{Segunda Etapa}

\subsubsection{Liberação de NO a partir das NPs funcionalizadas com MSA e DMSA}

Nesta parte experimental, injetamos $5 \mu \mathrm{l}$ de solução no analisador de NO (Figura 3.5) contendo NP-SNO que foram funcionalizadas com MSA e DMSA nas razões molares 1:10, 1:40 e 1:80. As Tabelas 4.14 e 4.15 apresentam os resultados de concentração de NO liberado em função da concentração de NPMSA e NPDMSA injetadas, respectivamente.

A Figura 4.38 apresenta as concentrações de NO liberado ([NO]) em função das concentrações finais das soluções de NP-SNO para as NPs funcionalizadas com MSA, enquanto a Figura 4.39 apresenta para as funcionalizadas com DMSA. 
Tabela 4.14: Concentrações das NP-SNO fornecidas pelo equipamento e corrigidas, obtidas a partir da funcionalização das NPs com MSA, e respectivas concentrações de NO [NO] liberado.

\begin{tabular}{ccccc}
\hline \multicolumn{4}{c}{ Solução das NP-SNO obtidas das NPs funcionalizadas com MSA } \\
\hline \multirow{2}{*}{ Amostra } & $\begin{array}{c}\text { Concentração } \\
\text { experimental }(\mu \mathrm{M})\end{array}$ & Fator de correção & $\begin{array}{c}\text { Concentração } \\
\text { final }(\mu \mathrm{M})\end{array}$ & $\begin{array}{c}{[\mathrm{NO}]} \\
(\mu \mathrm{M})\end{array}$ \\
\hline NPMSA110 & 17,58 & \multirow{2}{*}{0,94} & 16,53 & $271 \pm 40$ \\
NPMSA140 & 10,98 & & 10,32 & $131,5 \pm 14,4$ \\
NPMSA180 & 11,87 & & 11,16 & $150,4 \pm 1,5$ \\
\hline
\end{tabular}

Tabela 4.15: Concentrações das NP-SNO fornecidas pelo equipamento e corrigidas, obtidas a partir da funcionalização das NPs com DMSA, e respectivas concentrações de NO [NO] liberado.

\begin{tabular}{ccccc}
\hline \multicolumn{4}{c}{ Solução das NP-SNO obtidas das NPs funcionalizadas com DMSA } \\
\hline \multirow{2}{*}{ Amostra } & $\begin{array}{c}\text { Concentração } \\
\text { experimental }(\mu \mathrm{M})\end{array}$ & \multirow{2}{*}{ Fator de correção } & $\begin{array}{c}\text { Concentração } \\
\text { final }(\mu \mathrm{M})\end{array}$ & {$[\mathrm{NO}]$} \\
& 41,43 & & 36,46 & $1067,8 \pm 136,9$ \\
NPDMSA110 & 14,46 & 0,88 & 12,72 & $224,6 \pm 52,8$ \\
NPDMSA140 & 48,80 & & 42,94 & $997,2 \pm 58,7$ \\
NPDMSA180 & & & $4 \mathrm{M})$ \\
\hline
\end{tabular}




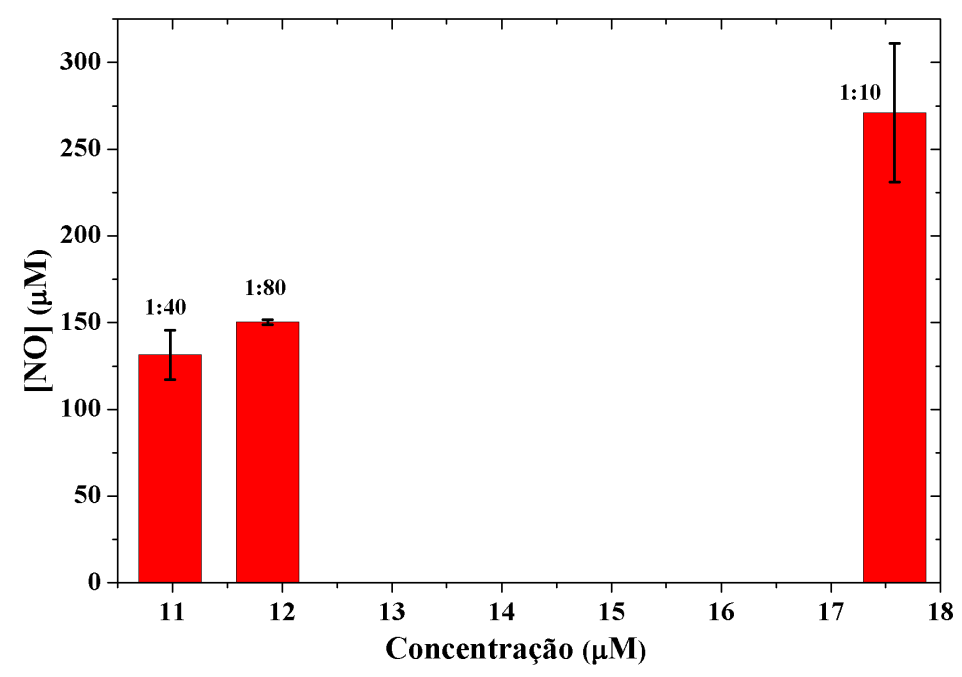

Figura 4.38: Concentração de NO liberado ([NO]) em função da concentração das NPs nitrosadas, obtidas a partir das NPs funcionalizadas com MSA em razões molares 1:10, 1:40 e 1:80 (Tabela 4.14).

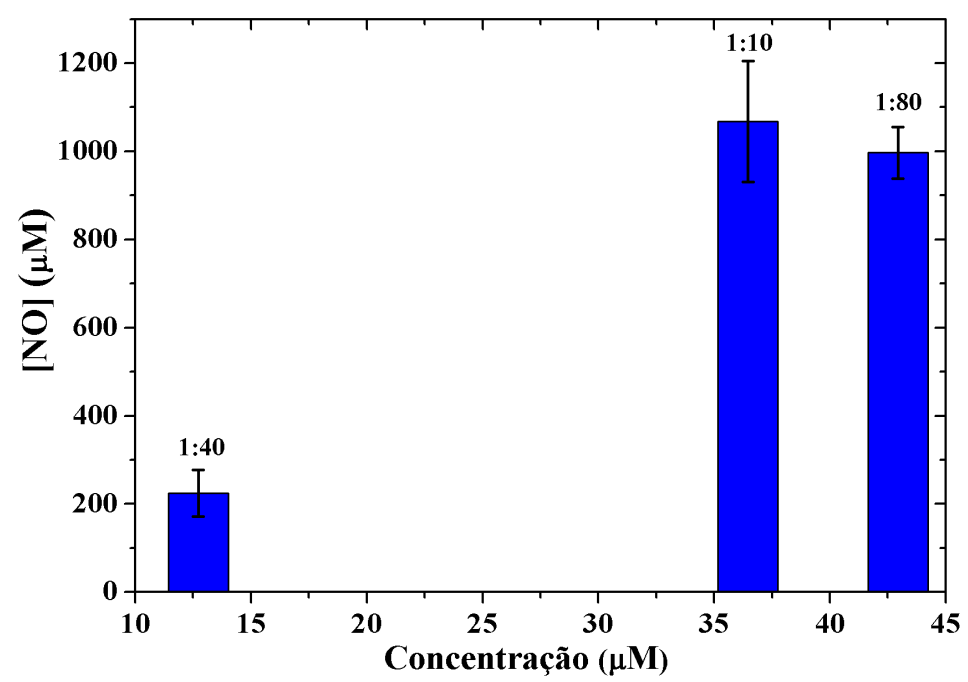

Figura 4.39: Concentração de NO liberado ([NO]) em função da concentração das nanopartículas nitrosadas, obtidas a partir das NPs funcionalizadas com DMSA em razões molares 1:10, 1:40 e 1:80 (Tabela 4.15). 
Conforme observamos das Figuras $4.38 \mathrm{e} 4.39 \mathrm{e}$ Tabelas $4.14 \mathrm{e} 4.15$, NPs funcionalizadas com DMSA nas razões molares de 1:10, 1:40 e 1:80 respondem à nitrosação de maneira mais efetiva que NPs funcionalizadas com MSA. Isto porque para um mesmo volume analisado de solução ( $5 \mu \mathrm{l}$ ), NPs recobertas com DMSA apresentam um maior grau de nitrosação (da ordem de 35 a $42 \mu \mathrm{M}$ ) em relação a MSA (da ordem de 12 a $18 \mu \mathrm{M}$ ). Ou seja, a nitrosação em NPs funcionalizadas com DMSA parece ser mais eficiente que com as NPs com MSA adsorvido. Mais ainda, a quantidade de [NO] liberado por NPs nitrosadas é também maior para NPs recobertas com DMSA: note que a produção de [NO] é da ordem de $1000 \mu \mathrm{M}$ para concentrações de NPDMSA nitrosadas de cerca de $40 \mu \mathrm{M}$ (Figura 4.39), resultando numa razão de 25, enquanto para MSA a produção de [NO] da ordem de $250 \mu \mathrm{M}$ para concentrações de $17 \mu \mathrm{M}$ de NPMSA nitrosadas resulta numa razão da ordem de 15 . Provavelmente, como DMSA possui dois grupos tióis disponiveis para reagir com NO, a eficiência da nitrosação é maior. Dentro deste contexto, poderíamos concluir que NPMs recobertas com DMSA seriam melhores candidatas a veículos de transporte e liberação de óxido nítrico.

Entretanto, os resultados de liberação de [NO] de NPs recobertas com MSA e DMSA na razão de 1:40 são similares e não compreendidos por nós. Além disso, o aumento na razão NP:MSA e DMSA, o que deveria influenciar o grau de modificação da superfície das NPs, não parece ter papel importante na taxa de nitrosação das mesmas.

Assim, concluimos de maneira preliminar, que a taxa de liberação de [NO] de grupos nitrosotióis adsorvidos na superfície das NPMs independe da razão molar NP:MSA ou NP:DMSA empregada. Novos experimentos são necessários para uma melhor interpretação destes resultados.

Para finalizar, gostaríamos de ressaltar aqui que avaliações toxicológicas destes nanomateriais já foram iniciadas. Resultados preliminares realizados pelas Dra. Paula Haddad e Dra. Amedea Seabra (ambas da UNIFESP) demonstraram que as NPs tioladas via MSA e DMSA apresentam baixa citotoxicidade e genotoxicidade em linfócitos humanos. Por outro lado, quando nitrosadas aumentam o nivel de apoptose e morte celular , mostrando potencial aplicação em células tumorais [39, 40, 89]. 


\section{Capítulo 5}

\section{Conclusões}

\subsection{Caracterizações Químicas e Físicas das NPs}

- A partir dos experimentos de FTIR concluimos que as NPs obtidas pelo método de síntese por coprecipitação correspondem a óxidos de ferro devido às bandas características de deformação $\delta_{\mathrm{Fe}-\mathrm{O}}$ e estiramento $\nu_{\mathrm{Fe}-\mathrm{O}}$ entre $400-650 \mathrm{~cm}^{-1}$ que aparecem nos espectros. Além disso, as moléculas de MSA e DMSA são adsorvidas na superfície das NPs via ligação do grupo carboxila com átomos de Fe.

- A partir dos resultados de difração de R-X podemos concluir que as NPs obtidas, recobertas com AO e funcionalizadas com MSA e DMSA apresentam difratogramas, parâmetros de rede e distâncias interplanares correspondentes à estrutura espinélio da magnetita, conforme comparação com a ficha catalográfica. O tamanho de grão cristalino pode ser avaliado como $(11,1 \pm 0,7) \mathrm{nm}$ sem nenhuma tendência ao aumento ou diminuição com recobrimento por AO ou troca de ligantes por MSA e DMSA. Tal tamanho é apropriado para aplicações biomédicas.

- Dos resultados de TEM podemos inferir que as NPs tem morfologia esférica, com tamanhos da ordem do tamanho de grão cristalino, mas apresentam uma certa polidispersão em torno de $20 \%$. A funcionalização da superfície seja com MSA ou DMSA não altera o tamanho médio das NPs. 
- Dos resultados de VSM podemos concluir que as NPs tem um comportamento superparamagnético à temperatura ambiente. Para as NPs tanto recobertas com AO quanto funcionalizadas com MSA, a magnetização de saturação é da ordem de (67 \pm $5) \mathrm{emu} / \mathrm{g}$. Entretanto, as NPs funcionalizadas com DMSA apresentam uma magnetização de saturação da ordem de $(32,9 \pm 3,5) \mathrm{emu} / \mathrm{g}$. Estes valores estão abaixo do valor da literatura $(\sim 92 \mathrm{emu} / \mathrm{g})$, indicando uma diminuição da $\sigma_{s}$ devido à modificação da superfície da NP. Em particular, para DMSA, tal recobrimento diminue significativamente o valor de $\sigma_{s}$, provavelmente devido à formação de uma camada diamagnética na superfície da NP.

A análise das curvas de histerese fornece distribuições de tamanho das NPMs compatíveis com a análise de TEM.

\subsection{Liberação de NO}

- NPMs funcionalizadas tanto com MSA quanto com DMSA podem ser potenciais candidatas a veículos de transporte e liberação de óxido nítrico.

- A quantidade de óxido nítrico liberado pelas NPMs tem potencial aplicação em biomedicina, associada à possibilidade de liberação controlada (cinética de liberação).

- A liberação de óxido nítrico (NO) é maior no caso das NPs funcionalizadas com DMSA, nas razões NP:DMSA 1:10 e 1:80. Tal resultado pode ser atribuido à presença de dois grupos tióis (-SH) neste ligante, o qual permite uma maior ligação e liberação de óxido nítrico pelas NPs nitrosadas.

\subsection{Conclusão Final}

- Embora NPs funcionalizadas com DMSA parecem ser mais adequadas como veículos de transporte e liberação de NO do que as recobertas com MSA; elas afetam de maneira mais significativa as propriedades magnéticas do material ( $\sigma_{s}$ decresce por um fator 3 ). Além disso, como mencionamos na Introdução deste trabalho, MSA é menos custoso financeiramente que DMSA, o que favorece economicamente um processo de produção de nanopartículas magnéticas como carreadoras de NO para aplicações biomédicas. 
No nosso trabalho, demonstramos que em ambos os casos (NPs nitrosadas a partir de NPs funcionalizadas com MSA e DMSA), ocorre nitrosação e liberação de óxido nítrico, embora em graus diferentes. Portanto, ambas podem ser utilizadas como veículos de transporte e liberação de NO. 



\section{Referências Bibliográficas}

[1] A. Kunzmann, B. Andersson, T. Thurnherr, H. Krug, A. Scheynius, and B. Fadeel, "Toxicology of engineered nanomaterials: Focus on biocompatibility, biodistribution and biodegradation," Biochimia et Biophysica Acta 1810 (2011) 361-373.

[2] X. Q. Zhang, X. Xu, N. Bertrand, E. Pridgen, A. Swami, and O. C. farokhzad, "Interactions of nanomaterials and biological systems: Implications to personalized medicine," Advanced Drug Delivery Reviews 64 (2012) 1363-1384.

[3] L. Y. Yang, X. Zhang, M. Ye, J. Jiang, R. Yang, T. Fu, Y. Chen, K. Wang, C. Liu, and W. Tan, "Aptamer-conjugated nanomaterials and their applications," Advanced Drug Delivery Reviews 63 (2011) 1361-1370.

[4] X. M. Liu and J. K. Kim, "Solvothermal synthesis and magnetic properties of magnetite nanoplatelet," Materials Letters 63 (2009) 428-430.

[5] Z. Zhang and A. Chai, "Core-shell magnetite-silica composite nanoparticles enhancing DNA damage induced by a photoactive platinum-diimine complex in red light," Journal of Inorganic Biochemistry 117 (2012) 71-76.

[6] Y. Zhang, N. Kohler, and M. Zhang, "Surface modification of superparamagnetic magnetite nanoparticles and their intracellular uptake," Biomaterials 23 (2002) $1553-1561$.

[7] A. K. Gupta and M. Gupta, "Cytotoxicity suppression and cellular uptake enhancement of surface modified magnetic nanoparticles," Biomaterials 26 (2005) $1565-1573$. 
[8] L. X. Tiefenauer, A. Tschirky, G. Khüne, and R. Y. Andres, "In vivo evaluation of magnetite nanoparticles for use as a tumor contrast agent in MRI," Magnetic Resonance Imaging 14 (1996), no. 4, 391-402.

[9] P. S. Haddad and A. B. Seabra, Biomedical Applications of Magnetic Nanoparticles. Nova Science Publishers, 1ra ed., 2012.

[10] A. Simchi, R. Ahmadi, S. M. Reihani, and A. Mahdavi, "Kinetics and mechanism of nanoparticle formation and growth in vapor phase condensation process," Materials and Design 28 (2007) 850-856.

[11] M. Shigeta and T. Watanabe, "Two-dimensional analysis of nanoparticle formation in induction thermal plasmas with counterflow cooling," Thin Solid Films 516 (2008) 4415-4422.

[12] S. H. Cho, S. Lee, D. Y. Ku, T. S. Lee, B. Cheong, W. M. Kim, and K. S. Lee, "Growth behavior and optical properties of metal-nanoparticle dispersed dielectric thin films formed by alternating sputtering," Thin Solid Films 447-448 (2004) 68-73.

[13] M. L. Paramês, J. Mariano, M. S. Rogalski, N. Popovici, and O. Conde, "UV pulsed laser deposition of magnetite thin films," Materials Science \& Engineering B 118 (2005) 246-249.

[14] M. Mukherjee and A. Mahapatra, "Catalytic effect of silver nanoparticle on electron transfer reaction: Reduction of $\left[\mathrm{Co}\left(\mathrm{NH}_{3}\right)_{5} \mathrm{Cl}\right]\left(\mathrm{NO}_{3}\right)_{2}$ by iron (II)," Colloids and Surfaces A: Physicochemical and Engineering Aspects 350 (2009) 1-7.

[15] N. J. Tang, W. Zhong, H. Y. Jiang, X. L. Wu, W. Liu, and Y. W. Du, "Nanostructured magnetite $\left(\mathrm{F}_{3} \mathrm{O}_{4}\right)$ thin films prepared by sol-gel method," Journal de Magnetism and Magnetic Materials 282 (2004) 92-95.

[16] Y. Mizukoshi, S. Seino, K. Okitsu, T. Kinoshita, Y. Otome, T. Nakagawa, and T. A. Yamamoto, "Sonochemical preparation of composite nanoparticles of $\mathrm{Au} / \gamma-\mathrm{Fe}_{2} \mathrm{O}_{3}$ and magnetic separation of glutathione," Ultrasonics Sonochemistry 12 (2005) 191-195.

[17] Y. H. Kim, D. K. Lee, B. G. Jo, J. H. Jeong, and Y. S. Kang, "Synthesis of oleate capped Cu nanoparticles by thermal decomposition," Colloids and Surfaces A: Physicochemic. Eng. Aspects 284-285 (2006) 364-368. 
[18] Y. Cha, M. Kim, Y. Choa, J. Kim, B. Nam, J. Lee, D. H. Kim, and K. H. Kim, "Synthesis and Characterization of Surface-Coated Superparamagnetic Magnetite Nanoparticle," IEEE Transactions on Magnetics 46 (2010), no. 2, 443-446.

[19] A. Figuerola, R. D. Corato, L. Manna, and T. Pellegrino, "From iron oxide nanoparticles towards advanced iron-based inorganic materials designed for biomedical applications," Pharmacological Research 62 (2010) 126-143.

[20] L. Zhang, R. He, and H. C. Gu, "Oleic acid coating on the monodisperse magnetite nanoparticles," Applied Surface Science 253 (2006) 2611-2617.

[21] M. T. L. López, J. D. G. Durán, A. V. Delgado, and F. G. Caballero, "Stability and magnetic characterization of oleate-covered magnetite ferrofluids in different nonpolar carriers," Journal of Colloid and Interface Science 291 (2005) 144-151.

[22] M. Rudolph, J. Erler, and U. A. Peuker, "A TGA-FTIR perspective of fatty acid adsorbed on magnetite nanoaprticles-decomposition steps and magnetite reduction," Colloids and Surfaces A: Physicochemical and Engineering Aspects 397 (2012) 16-23.

[23] F. Yazdani and M. Edrissi, "Effect of pressure on the size of magnetite nanoparticles in the coprecipitation synthesis," Materials Science and Engineering B 171 (2010) 86-89.

[24] C. R. Vestal and Z. J. Zhang, "Effects of surface coordination chemistry on the magnetic properties of $\mathrm{MnFe}_{2} \mathrm{O}_{4}$ spinel ferrite nanoparticles," Journal of the American Chemical Society 125 (2003) 9828-9833.

[25] L. H. Reddy, J. L. Arias, J. Nicolas, and P. Couvreur, "Magnetic nanoparticles design and characterization, toxicity and biocompatibility, pharmaceutical and biomedical applications," Chemical Reviews 112 (2012) 5818-5878.

[26] D. B. Shieh, F. Y. Cheng, C. H. Su, C. S. Yeh, M. T. Wu, Y. N. Wu, C. Y. Tsai, C. L. Wu, D. H. Chen, and C. H. Chou, "Aqueous dispersions of magnetite nanoparticles with $\mathrm{NH}_{3}^{+}$surfaces for magnetic manipulations of biomolecules and MRI contrast agents," Biomaterials 26 (2005) 7183-7191. 
[27] C. H. Liu, C. J. Yu, and W. L. Tseng, "Fluorescence assay of catecholamines based on inhibition of peroxidase-like activity of magnetite nanoparticles," Analytica Chimica Acta 745 (2012) 143-148.

[28] M. P. Garcia, R. M. Parca, S. B. Chaves, 1 P Silva, A. D. Santos, Z. G. M. Lacava, P. C. Morais, and R. B. Azevedo, "Morphological analysis of mouse lungs after treatment with magnetite-based magnetic fluid stabilized with dmsa," Journal of Magnetism anf Magnetic Materials 293 (2005) 277-282.

[29] R. Mejías, S. P. Yagüe, L. Gutiérrez, L. I. Cabrera, R. Spada, P. Acedo, C. J. Serna, F. J. Lázaro, A. Villanueva, M. P. Morales, and D. F. Barber, "dimercaptosuccinic acid-coated magnetite nanoparticles for magnetically guided in vivo delivery of interferon gamma for cancer immunotherapy," Biomaterials 32 (2011) 2938-2952.

[30] P. S. Haddad, T. M. Martins, L. D. Souza-Li, L. M. Li, K. Metze, R. L. Adam, M. Knobel, and D. Zanchet, "Structural and morphological investigation of magnetic nanoparticles based on iron oxides for biomedical applications," Materials Science and Engineering C 28 (2008) 489-494.

[31] B. M. Raafat, A. E. Barbary, E. Touson, and S. Aziz, "Di-Mercapto Succinic Acid (DMSA) and vitamin C chelating potency in lead intoxication, regarding oxidative stress and apoptotic related proteins in rabbits," Journal of Genetic Engineering and Biotechnology 9 (2011) 121-131.

[32] K. Jomova and M. Valko, "Advances in metal-induced oxidative stress and human disease," Toxicology 283 (2011) 65-87.

[33] P. Parvex, R. Rozen, A. Dziarmaga, and P. Goodyer, "Studies of urinary cystine precipitation in vitro: ontogeny of cystine nephrolithiasis and identification of meso-2,3-dimercaptosuccinic acid as a potential therapy for cystinuria," Molecular Genetics and Metabolism 80 (2003) 419-425.

[34] T. P. Amadeu, A. B. Seabra, M. G. de Oliveira, and A. M. A. Costa, "Nitric Oxide donor improves healing if applied on inflamatory and proliferative phase," Journal of Surgical Research 149 (2008) 84-93. 
[35] A. B. Seabra and N. Duran, "Nanotechnology allied to nitric oxide release materials for dermatological applications," Current Nanoscience 8 (2012) 520-525.

[36] J. Tamargo, R. caballero, R. Gómez, L. Núñez, M. Vaquero, and E. Delpón, "Efectos del óxido nítrico sobre la función cardíaca," Revista Española de Cardiología Suplementos 6 (2006) 3A-20A.

[37] V. Bansal, H. Toga, and U. Raj, "Tone dependent nitric oxide production in ovine vessels in vitro," Respiration Physiology 93 (1993) 249-260.

[38] M. M. Molina, A. B. Seabra, M. G. Oliveira, R. Itri, and P. S. Haddad, "Nitric oxide donor superparamagnetic iron oxide nanoparticles," Materials and Science and Engineering C 33 (2013) 746-751.

[39] R. Lima, A. Ludescher, M. M. Molina, R. Itri, A. B. Seabra, and P. S. Haddad, "Nitric oxide releasing iron oxide magnetic nanoparticles for biomedical application: cell viability, apoptosis and cell death evaluations," Journal of Physics: Conference Series 429 (2013).

[40] R. Lima, J. Oliveira, M. M. Molina, R. Itri, P. S. Haddad, and A. B. Seabra, "Iron oxide nanoparticles show no toxicity in the comet assay in lymphocytes: A promising vehicle as a nitric oxide releasing nanocarrier in biomedical applications," Journal of Physics: Conference Series 429 (2013).

[41] R. M. Cornell and U. Schwertmann, The Iron Oxides Structures, Properties, Reactions, Occurrences and Uses. Wiley-VCH Verlag GmbH and Co., Weinheim, 2da ed., 2003.

[42] U. Schwertmann and R. M. Cornell, Iron Oxides in the Laboratory Preparation and Characterization. Wiley-VCH Verlag, 2da ed., 2000.

[43] B. D. Cullity and S. R. Stock, Elements of X-Ray Diffraction. Prentice Hall, 3ra ed., 2001.

[44] B. D. Cullity and C. D. Graham, Introduction to Magnetic Materials. John Wiley and Sons Inc. Publication, 1ra ed., 2009.

[45] R. Skomski, Simples Models of Magnetism. Oxford Graduate Texts, 2008. 
[46] M. Getzlaff, Fundamentals of Magnetism. Springer-Verlag Berlin Heidelberg New York, 2008.

[47] A. P. Guimarães, Principles of Nanomagnetism. Springer-Verlag Berlin Heidelberg, 2009.

[48] J. L. Dormann, D. Fiorani, and E. Tronc, "Magnetic relaxation in fine-particle systems," Advanced in Chemical Physics 98 (2007) 283-494.

[49] E. L. Duarte, Síntese e Caracterização de Nanopartículas baseadas em Óxidos de Ferro. Tese de doutorado, Universidade de São Paulo - Instituto de Física, 2005.

[50] X. Zhang, Electrochemical Sensors, Biosensors and their biomedical applications. Academic Press, 2008.

[51] A. Dhir and S. K. Kulkarni, "Nitric oxide and major depression," Nitric Oxide $\mathbf{2 4}$ (2011) 125-131.

[52] F. B. Jensen, "The role of nitrite in nitric oxide homeostasis: A comparative perspective," Biochemica et Biophysica Acta 1787 (2009) 841-848.

[53] J. R. J. Lancaster, "The Physical Properties of Nitric Oxide," Academic Press (2000) 209-224.

[54] J. M. Fukuto, J. Y. Cho, and C. H. Switzer, Nitric Oxide. Academic Press, 2000.

[55] A. J. Friedman, G. Han, M. S. Navati, M. Chacko, L. Gunther, A. Alfieri, and J. M. Friedman, "Sustained release nitric oxide releasing nanoparticles: Characterization of a novel delivery platform based on nitrite containing hydrogel/glass composites," Nitric Oxide 19 (2008) 12-20.

[56] O. von Bohlen und Halbach, "Nitric oxide imaging in living neuronal tissues using flourescent probes," Nitric Oxide Biology and Chemistry 9 (2003) 217-228.

[57] B. Bonavida, ed., Nitric Oxide and Cancer. Springer Science + Business Media, 2010.

[58] A. Weigert and B. Brüne, "Nitric oxide, apoptosis and macrophage polarization during tumor progression," Nitric Oxide 19 (2008) 95-112. 
[59] M. A. Smith, M. Vasák, M. Knipp, R. J. Castellani, and G. Perry, "Dimethylargininase, a nitric oxide regulatory protein, in Alzheimer disease," Free Radical Biology \& Medicine 25 (1998) 898-902.

[60] N. Shahani and A. Sawa, "Protein S-nitrosylation: Role for nitric oxide signaling in neuronal death," Biochimia et Biophysica Acta 1820 (2012) 736-742.

[61] S. F. Kim, "The role of nitric oxide in prostaglandin biology: Update," Nitric Oxide 25 (2011) 255-264.

[62] M. Sarr, M. Chataigneau, N. Etienne-Selloum, A. M. Diallo, C. Schott, M. Geffard, J. C. Stoclet, V. B. Schini-Kerth, and B. Muller, "targeted and persitent effects of NO by S-nitrosation of tissue thiols in arteries with endothelial dysfunction," Nitric Oxide 17 (2007) 1-9.

[63] G. C. Brown, "Nitric oxide and neuronal death," Nitric Oxide 23 (2010) 153-165.

[64] H. Chakrapani, T. C. Wilde, M. L. Citro, M. M. Goodblatt, L. K. Keefer, and J. E. Saavedra, "Synthesis, nitric oxide release, and anti-leukemic activity of glutathione-activated nitric oxide pro-drugs," Bioorganic 8 Medicinal Chemistry 16 (2008) 2657-2664.

[65] S. J. Wimalawansa, M. T. Chapa, C. Yallampalli, R. Zhang, and D. J. Simmons, "Prevention of corticosteroid-induced bone loss with nitric oxide donor nitroglycerin in male rats," Bone 21 (1997), no. 3, 275-280.

[66] S. P. Nichols, W. L. Storm, A. Koh, and M. H. Schoenfisch, "of nitric oxide: Targeted delivery of therapeutics to bone and conective tissues," Advanced Drug Delivery Reviews 64 (2012) 1177-1188.

[67] S. L. Huang, "Liposomes in ultrasonic drug and gene delivery," Advanced Drug Delivery Reviews 60 (2008) 1167-1176.

[68] A. B. Seabra, G. F. P. de Souza, L. L, M. N. Eberlin, and M. G. Oliveira., "S-nitrosoglutathione incorpored in poly(ethylene glycol) matrix: potencial use for topical nitric oxide delivery," Nitric Oxide 11 (2004) 263-272. 
[69] M. Zhang, G. Pan, D. Zhao, and G. He, "Xafs study of starch-stabilized magnetite nanoparticle and surface speciation of arsenate," Environmental Pollution 159 (2011) 3509-3514.

[70] D. Li, D. Jiang, M. Chen, J. Xie, Y. Wu, S. Dang, and J. Zhang, "An easy fabrication of monodisperse oleic-acid coated $\mathrm{Fe}_{3} \mathrm{O}_{4}$ nanoparticles," Materials Letters 64 (2010) $2462-2464$.

[71] P. C. Papaphilippou, A. Pourgouris, O. Marinica, alina Taculescu, G. I. Athanasopoulos, L. Vekas, and T. Krasia-Christoforou, "Fabrication and characterization of superparamagnetic and thermoresponsive hydrogels based on oleic-acid-coated $\mathrm{fe}_{3} \mathrm{O}_{4}$ nanoparticles, hexa (ethylene glycol) methyl ether methacrylate and 2-(acetoacetoxy) ethyl methacrylate," Journal of Magnetism and Magnetic Materials 323 (2011) 557-563.

[72] N. Hogg, "Biological chemistry and clinical potential of S-nitrosothiols," Free Radical Biology $\&$ Medicine 28 (2000), no. 10, 1478-1486.

[73] M. K. Iwatsuki, M. Yamaguchi, and M. Inoue, "Role of ascorbic acid in the metabolism of S-nitroso-glutathione," Federation of European Biochemical Societies Letters 389 (1996) 149-152.

[74] N. B. Colthup, L. H. Daly, and S. E. Wiberley, Introduction to Infrared and Raman Spectroscopy. Academic Press, 3ra ed., 1990.

[75] R. T. Conley, Infrared Spectroscopy. Allyn and Bacon, 1990.

[76] Y. Ge, Y. Zhang, J. Xia, M. Ma, S. He, F. Nie, and N. Gu, "Effect of surface charge and agglomerate degree of magnetic iron oxide nanoparticles on KB cellular uptake in vitro," Colloids and Surfaces B: Biointerfaces 73 (2009) 294-301.

[77] L. Slavov, M. V. Abrashev, T. Merodiiska, C. Gelev, R. E. vanderberghe, I. M. Deneva, and I. Nedkov, "Raman spectroscopy investigation of magnetite nanoparticles in ferrofluids," Journal of Magnetism and Magnetic Materials 322 (2010) 1904-1911.

[78] J. Mürbe, A. Rechtenbach, and J. Töpfer, "Synthesis and physical characterization of magnetite nanoparticles for biomedical applications," Materials Chemistry and Physics 110 (2008) 426-433. 
[79] S. Chawla and S. K. Jayanthi, "Fabrication of ZnO: Mn nanoparticles with organic shell in a highly alkaline aqueous environment," Applied Surface Science 257 (2011) 2935-2939.

[80] K. Yang, H. Peng, Y. Wen, and N. Li, "Re-examination of characteristic FTIR spectrum of secondary layer in bilayer oleic acid-coated $\mathrm{Fe}_{3} \mathrm{Oe}_{4}$ nanoparticles," Applied Surface.

[81] A. I. Lesnikovich, T. M. Shunkevich, V. N. Naumenko, S. A. Vorobyova, and M. V. Baykov, "Dispersity of magnetite in magnetic liquids and the interaction with a surfactant," Journal of Magnetism and Magnetic Materials 85 (1990) 14-16.

[82] Y. Li and S. Li, "FTIR spectra of $\mathrm{HSCH}_{2} \mathrm{CH}_{2} \mathrm{SH}, \mathrm{CH}_{3} \mathrm{SCH}_{2} \mathrm{sh}$, and $\mathrm{CH}_{3} \mathrm{SSCH}_{3}$ in argon and nitrogen matrices," Spectrochimia Acta 50A (1994) 509-519.

[83] R. Rostamian, M. Najafi, and A. Rafati, "Synthesis and characterization of thiol-functionalized silica nano hollow sphere as a novel adsorbent for removal of poisonous heavy metal ions from water: Kinetics, isotherms and error analysis," Chemical Engineering Journal 171 (2011) 1004-1011.

[84] J. F. Hochepied, P. Bonville, and M. P. Pileni, "Nonstoichimetric zinc ferrite nanocrystal synthesis and unusual magnetic properties," The Journal of Physical Chemistry B 104 (2000) 905-912.

[85] A. Tamion, M. Hillenkamp, F. Tournus, E. Bonet, and V. Dupuis, "Accurate determination of the magnetic anisotropy in cluster-assembled nanostructures," Applied Physics Letters 95 (2009) 062503-1 - 062503-3.

[86] A. Fontijn, A. J. Sabadell, and R. J. Ronco, "Homogeneous chemiluminescent measurement of nitric oxide with ozone," Analytical Chemistry 42 (1970), no. 6, $576-579$.

[87] T. M. M. T. Alves, "Síntese e caracterização de nanopartículas de óxido de ferro para aplicações biomédicas," Master's thesis, Universidade Estadual de Campinas, 2007.

[88] A. B. Seabra, R. Silva, G. F. P. Souza, and M. G. Oliveira, "Antithrombogenic Polynitrosated Polyester/Poly(methyl methacrylate) Blend for the Coating of Blood-Contacting Surfaces," Artificial Organs 32(4) (2008) 262-267. 
[89] A. B. Seabra, P. S. Haddad, M. M. Molina, R. Itri, and M. G. de Oliveira, "Nitric oxide (NO) releasing-superparamagnetic iron oxide nanoparticles for biomedical applications," Nitric Oxide Biology and Chemistry 27 (2012) S38. 


\section{ANEXO I}

\section{TRABALHOS PUBLICADOS EM PERIÓDICO INTERNACIONAL}

Nitric oxide donor superparamagnetic iron oxide nanoparticles Miguel M. Molina, Amedea B. Seabra, Marcelo G. de Oliveira, Rosangela Itri, Paula S. Haddad. http://dx.doi.org/10.1016/j.msec.2012.10.027

Nitric oxide releasing iron oxide magnetic nanoparticles for biomedical applications: cell viability, apoptosis and cell death evaluations R. de Lima, J. L. de Oliveira, A Ludescher, M. M. Molina, R. Itri, A. B. Seabra and P. S. Haddad. http://iopscience.iop.org/1742-6596/429/1/012034

Iron oxide nanoparticles show no toxicity in the comet assay in lymphocytes: A promising vehicle as a nitric oxide releasing nanocarrier in biomedical applications

R. de Lima, J. L. Oliveira, P. S. K. Murakami, M. A. M. Molina, R. Itri, P. Haddad and A. B. Seabra.

http://iopscience.iop.org/1742-6596/429/1/012021 



\section{Apêndice A}

\section{Propriedades Magnéticas}

\section{A.1 Consideração Semiclássica}

Assumindo que o campo magnético externo é orientado na direção $z$, da forma: $\vec{B}=$ $\mathrm{B} \widehat{k}$. A energia magnética associada aos momentos magnéticos orientados em certo ângulo, entre $\theta$ e $\theta+\mathrm{d} \theta$, com respeito ao eixo $z$ é dada por:

$$
\mathrm{E}=-\vec{\mu} \cdot \vec{B}
$$

sendo $\mu$ o momento magnético. A componente do momento magnético ao longo do eixo $z$ é:

$$
\mu_{z}=\mu \operatorname{Cos} \theta
$$

Considerando que o ângulo sólido seja:

$$
d \Omega=\operatorname{Sen} \theta d \theta d \phi
$$

Se o momento magnético apresenta a mesma probabilidade de se dirigir em qualquer direção entre $\theta$ e $\theta+\mathrm{d} \theta$; esta probabilidade está definida pelo razão entre o ângulo sólido subtendido na direção $\theta$ respecto ao campo magnético e o ângulo sólido em todo o espaço. Matematicamente temos: 


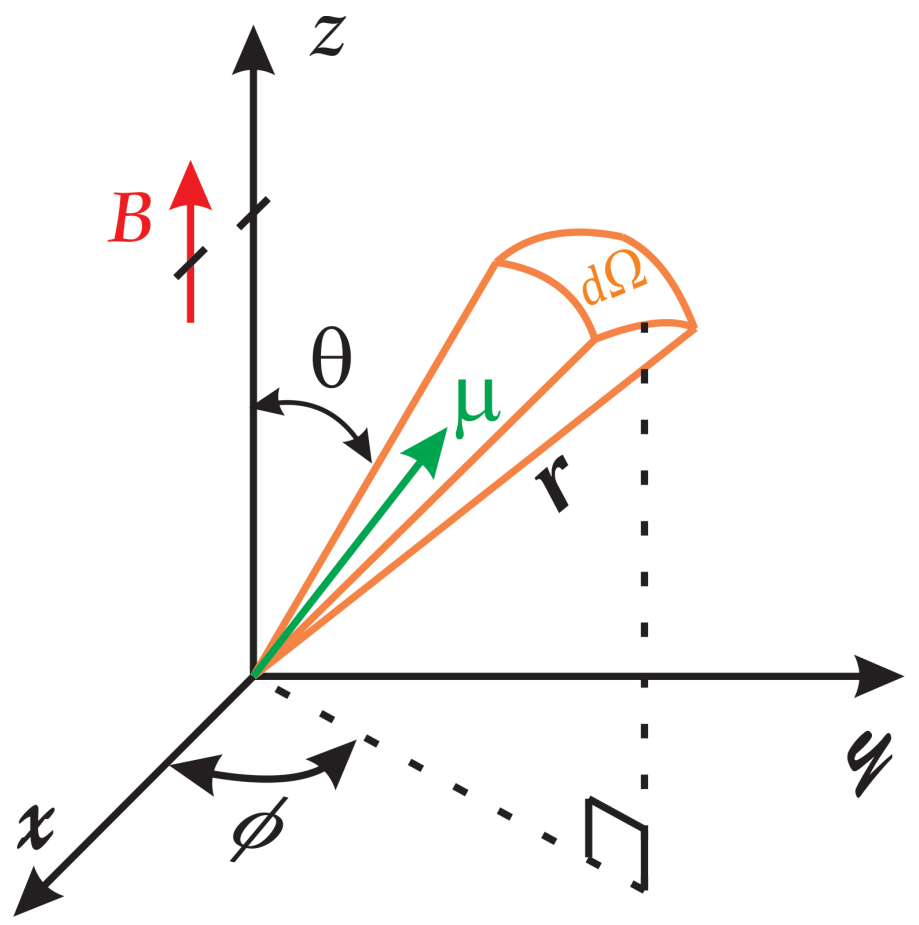

Figura A.1: Momento magnético $\mu$ na direção do ângulo sólido.

$$
p(\Omega)=\frac{\int_{0}^{2 \pi} d \Omega}{\int_{0}^{2 \pi} \int_{0}^{\pi} d \Omega}
$$

No numerador integramos a parte azimutal do ângulo sólido, pois devemos considerar todas as possíveis direções do ângulo $\theta$, entanto que no denominador o ângulo sólido é integrado em todo o espaço. Fazendo as contas, resulta:

$$
p(\Omega)=\frac{1}{2} \operatorname{Sen} \theta d \theta
$$

A probabiliadade que a uma temperatura $T$ apresente a energia $E=-\mu B \operatorname{Cos} \theta$, e dado pelo fator de Boltzmann:

$$
p(E)=e^{\left(-E / k_{B} T\right)}=e^{\left(\mu B \cos \theta / k_{B} T\right)}
$$


Então, a probabilidade do momento magnético apresentar uma energia magnética $E$ e estar em uma direção entre $\theta$ e d $\theta$ é o produto das probabilidades anteriores (Equações A.2 e.3., que resulta:

$$
\begin{gathered}
d \omega=p(\Omega) \times p(E) \\
d \omega=\frac{1}{2} \operatorname{Sen} \theta d \theta \times \exp \left(\frac{\mu B \operatorname{Cos} \theta}{k_{B} T}\right)
\end{gathered}
$$

O valor médio do momento magnético ao longo do campo é:

$$
\begin{gathered}
<\mu_{z}>=\frac{\int \mu_{z} d \omega}{\int d \omega} \\
\frac{\int_{0}^{\pi} \mu \operatorname{Cos} \theta e^{\mu \operatorname{Cos} \theta / k_{B} T} \frac{1}{2} \operatorname{Sen} \theta d \theta}{\int_{0}^{\pi} e^{\mu \operatorname{Cos} \theta / k_{B} T} \frac{1}{2} \operatorname{Sen} \theta d \theta}
\end{gathered}
$$

Fazemos uma mudança de variável:

$$
x=\frac{\mu B}{k_{B} T} \quad e \quad y=\operatorname{Cos} \theta
$$

Então:

$$
d y=-\operatorname{Sen} \theta d \theta
$$

e:

$$
\int_{0}^{\pi} \longrightarrow \int_{-1}^{1}
$$

com o qual resulta:

$$
<\mu_{z}>=\mu \frac{\int_{-1}^{1} y e^{x y} d y}{\int_{-1}^{1} e^{x y} d y}
$$

temos: 


$$
\begin{gathered}
\int e^{x y} d x=\frac{1}{x} e^{x y} \\
\int y e^{x y} d x=\frac{1}{x^{2}} e^{x y}(x y-1)
\end{gathered}
$$

Resultando:

$$
\begin{gathered}
\frac{<\mu_{z}>}{\mu}=\frac{e^{x}+e^{-x}}{e^{x}-e^{-x}}-\frac{1}{x} \\
\frac{<\mu_{z}>}{\mu}=\operatorname{coth} x-\frac{1}{x} \\
\frac{<\mu_{z}>}{\mu}=L(x)
\end{gathered}
$$

onde $L(x)$ é a função de Langevin, se consideramos um campo magnético externo pequeno ou altas temperaturas, i.e. $x \ll 1$, podemos aproximar:

$$
\operatorname{coth} x=\frac{1}{x}+\frac{x}{3}+\vartheta\left(x^{3}\right)
$$

com o qual a função de Langevin é:

$$
L(x) \approx \frac{x}{3}
$$

Finalmente, a expressão resultante do valor médio do momento magnético ao longo do campo:

$$
<\mu_{z}>_{T}=\mu L_{(x)}=\frac{\mu^{2} B}{3 k_{B} T}
$$

e consequentemente a magnetização (Equação 1.6) é :

$$
M=M_{s} L_{(x)}
$$

com a magnetização de saturação:

$$
M_{s}=n \mu
$$




\section{A.2 Consideração Quântica}

Considerando um sistema mecânico quântico e substituindo os momentos magnéticos por espins mecânicos quânticos com momento angular $J=1 / 2$. Sendo $\mathbf{J}$ (momento angular total) com valor esperado $J(J+1)$. e possui dois valores permitidos para as componentes do momento magnético no eixo $z, m_{J}= \pm 1 / 2$, é dizer, os espins estão alinhados paralelamente o antiparalelamente respectivamente na direção do campo B. A energia é dada por:

$$
E=g m_{J} \mu_{B} B
$$

onde a $g$ é razão giromagnética do elétron $(g=2)$ e $m_{J}= \pm 1 / 2$. O valor médio do momento magnético a uma temperatura dada é:

$$
<\mu_{z}>=\frac{\sum_{m_{J}=-1 / 2}^{1 / 2} \mu_{B} g m_{J} e^{-g m_{J} \mu_{B} B / k_{B} T}}{\sum_{m_{J}=-1 / 2}^{1 / 2} e^{-g m_{J} \mu_{B} B / k_{B} T}}
$$

Iterando a somatoria:

$$
\begin{gathered}
<\mu_{z}>=\frac{-\mu_{B} e^{\mu_{B} B / k_{B} T}+\mu_{B} e^{-\mu_{B} B / k_{B} T}}{e^{\mu_{B} B / k_{B} T}+e^{-\mu_{B} B / k_{B} T}} \\
<\mu_{z}>=\mu_{B} \tanh \left(\frac{\mu_{B} B}{k_{B} T}\right)
\end{gathered}
$$

Se consideramos um campo magnético externo pequeno ou altas temperaturas, i.e. $\frac{\mu_{B} B}{k_{B} T} \ll 1$, podemos aproximar:

$$
\tanh \left(\frac{\mu_{B} B}{k_{B} T}\right) \approx \frac{\mu_{B} B}{k_{B} T}
$$

Teriamos:

$$
<\mu_{z}>=\mu_{B} \frac{\mu_{B} B}{k_{B} T}
$$

Considerando o caso geral, quando $J$ é um valor enteiro ou semienteiro, utilizaremos a função de partição $Z$ : 


$$
Z=\sum_{m_{J}=-J}^{J} \exp \left(m_{J} g \mu_{B} B / k_{B} T\right)=\sum_{m_{J}=-J}^{J} e^{x m_{J}}
$$

com:

$$
x=\frac{g \mu_{B} B}{k_{B} T}
$$

valor médio para o número quântico do momento angular total:

$$
<m_{J}>=\frac{\sum m_{J} e^{x m_{J}}}{\sum e^{x m_{J}}}
$$

A derivada parcial da função de partição $Z$ (Equação A.24) é:

$$
\frac{\partial Z}{\partial x}=(-J) e^{x(-J)}+(-J+1) e^{x(-J+1)}+\ldots+(J-1) e^{x(J-1)}+(J) e^{x J}
$$

Então:

$$
\frac{\partial Z}{\partial x}=\sum m_{J} e^{x m_{J}}
$$

Da função de partição $Z$ (Equação A.24) e de sua derivada parcial (Equação A.28) no valor médio para o número quântico $m_{(J)}$ (Equação A.26), temos:

$$
<m_{J}>=\frac{1}{Z} \frac{\partial Z}{\partial x}
$$

A magnetização pode ser escrita como:

$$
M=n g \mu_{B}<m_{J}>
$$

da Equação A.29, temos:

$$
M=\frac{n g \mu_{B}}{Z} \frac{\partial Z}{\partial x}
$$




$$
M=\frac{n g \mu_{B}}{Z} \frac{\partial Z}{\partial B} \frac{\partial B}{\partial x}
$$

Mas:

$$
\frac{\partial \ln Z}{\partial B}=\frac{1}{Z} \frac{\partial Z}{\partial B}
$$

Da Equação A.25, temos:

$$
\frac{\partial B}{\partial x}=\frac{k_{B} T}{g \mu_{B}}
$$

Então a magnetização é:

$$
M=n k_{B} T \frac{\partial \ln Z}{\partial B}=n k_{B} T \frac{\partial \ln Z}{\partial x} \frac{\partial x}{\partial B}
$$

Desenvolvendo a Equação A.24, temos:

$$
Z=e^{x(-J)}+e^{x(-J+1)}+\ldots+e^{x(J-1)}+e^{x(J)}
$$

Do qual resulta:

$$
\begin{gathered}
Z=\frac{e^{-x J}-e^{x(J+1)}}{1-e^{x}} \\
Z=\frac{e^{-x J}-e^{x(J+1)}}{1-e^{x}} \times \frac{e^{-x / 2}}{e^{-x / 2}} \\
Z=\frac{e^{x\left(J+\frac{1}{2}\right)}-e^{x\left(J+\frac{1}{2}\right)}}{e^{-x / 2}-e^{x / 2}}
\end{gathered}
$$

A função de partição pode ser escrita como:

$$
Z=\frac{\operatorname{Senh}\left(J+\frac{1}{2}\right) x}{\operatorname{Senh}\left(\frac{x}{2}\right)}
$$


Aplicando o logaritmo à função de partição, temos:

$$
\ln Z=\ln \left[\operatorname{Senh}\left(J+\frac{1}{2}\right) x\right]-\ln \left[\operatorname{Senh}\left(\frac{x}{2}\right)\right]
$$

Derivando parcialmente com respeito a $x$ :

$$
\begin{aligned}
& \frac{\partial \ln Z}{\partial x}=\left(J+\frac{1}{2}\right) \frac{\cosh \left[\left(J+\frac{1}{2}\right) x\right]}{\operatorname{senh}\left[\left(J+\frac{1}{2}\right) x\right]}-\frac{1}{2} \frac{\cosh \left(\frac{x}{2}\right)}{\operatorname{senh}\left(\frac{x}{2}\right)} \\
& \frac{\partial \ln Z}{\partial x}=\left(J+\frac{1}{2}\right) \operatorname{coth}\left[\left(J+\frac{1}{2}\right) x\right]-\frac{1}{2} \operatorname{coth}\left(\frac{x}{2}\right)
\end{aligned}
$$

da Equação A.25, temos:

$$
\frac{\partial x}{\partial B}=\frac{g \mu_{B}}{k_{B} T}
$$

Das equações A.43 e A.44, a magnetização é:

$$
\begin{gathered}
M=n k_{B} T\left\{\left(J+\frac{1}{2}\right) \operatorname{coth}\left[\left(J+\frac{1}{2}\right) x\right]-\frac{1}{2} \operatorname{coth}\left(\frac{x}{2}\right)\right\} \times\left(\frac{g \mu_{B}}{k_{B} T}\right) \\
M=n \mu_{B} g J\left\{\left(\frac{2 J+1}{2 J}\right) \operatorname{coth}\left[\left(\frac{2 J+1}{2}\right) x\right]-\frac{1}{2 J} \operatorname{coth}\left(\frac{x}{2}\right)\right\}
\end{gathered}
$$

Fnalmente:

$$
M=M_{s} B_{J}(x)
$$

A magnetização de saturação $M_{s}$ :

$$
M_{s}=n \mu_{B} g J
$$


A função de Brillouin $B_{J}(x)$ :

$$
B_{J}(x)=\left(\frac{2 J+1}{2 J}\right) \operatorname{coth}\left[\left(\frac{2 J+1}{2}\right) x\right]-\frac{1}{2 J} \operatorname{coth}\left(\frac{x}{2}\right)
$$

